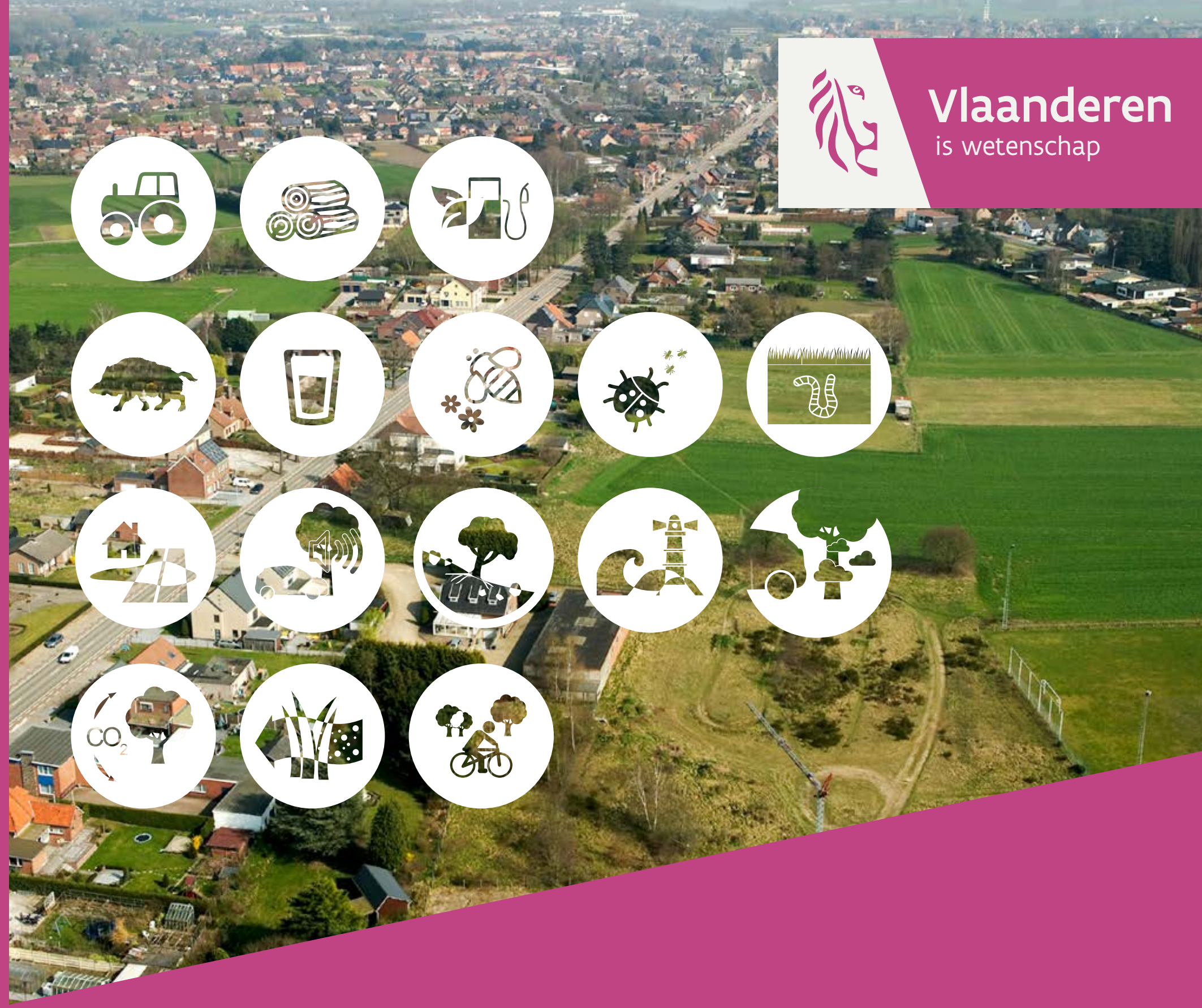

\title{
Nature Report 2016 \\ Working with nature
}

RESEARCH INSTITUTE FOR 


\section{CONTENTS}

1 Why ecosystem services?

1.1 Ecosystems and their services

1.2 The ecosystem service cycle

1.3 Towards a sustainable balance between supply and demand

1.4 An ecosystem assessment for Flanders: three phases

1.5 Flanders REA-P: the ecosystem service approach in practice

2 Building blocks

2.1 Green infrastructure

12

2.2 Valuing land use changes

2.3 A clear language

3 Practical examples

3.1 Afforestation and deforestation

3.2 On the farm

Stories of the pioneers

3.3 In the Regional Landscape Rivierenland

3.4 In the built environment

Stories of the pioneers

4 Recommendations

\footnotetext{
4.1 Building blocks for an

ecosystem service approach
}

4.2 Four recommendations 


\section{Nature Report 2016 \\ Working with nature}

mmm

\section{PREFACE}

It is an established fact that the loss of biodiversity has significant social and economic consequences. Our well-being and prosperity are closely linked to healthy ecosystems. Yet this contribution made by nature is usually invisible in the public debate. Ecosystem services improve the visibility of this invisible factor. The carefully considered and sustainable use of our natural capital both enhances our well-being and reduces costs, as well as being good for nature itself.

This message is increasingly finding its way through into national and international policy strategies. Thus ecosystem services form a key pillar of the European Biodiversity Strategy in addition to the Natura 2000 network. Moreover, as well as supporting nature policy, they are also being used to make Europe a sustainable and competitive region by 2020 .

The Research Institute for Nature and Forest (INBO) wishes to contribute actively to the achievement of these goals. This Nature Report, Flanders REA-P 2016, forms the second part of the ecosystem assessment for Flanders. With this assessment, we aim to lay the foundations for a policy that takes proper account of the conservation and restoration of biodiversity and ecosystem services. In the first part we performed a comprehensive analysis of the state and trends of ecosystem services in Flanders. In the second part, we aim to provide the tools for getting started with ecosystem services. Flanders REA-P is not just INBO's work. It is the product of close cooperation with different partners. These partners are very diverse: they are citizens, farmers, researchers and policymakers working in a wide range of policy and knowledge areas. We plan to continue making maximum use of this varied collaboration in the next phase of the assessment.

I therefore invite you to join us in writing the next chapter and in further integrating the concept of ecosystem services i n Flemish, supralocal and local policies.

I hope you enjoy reading the report.

\section{Dr. Maurice Hoffmann}

Acting Director, INBO

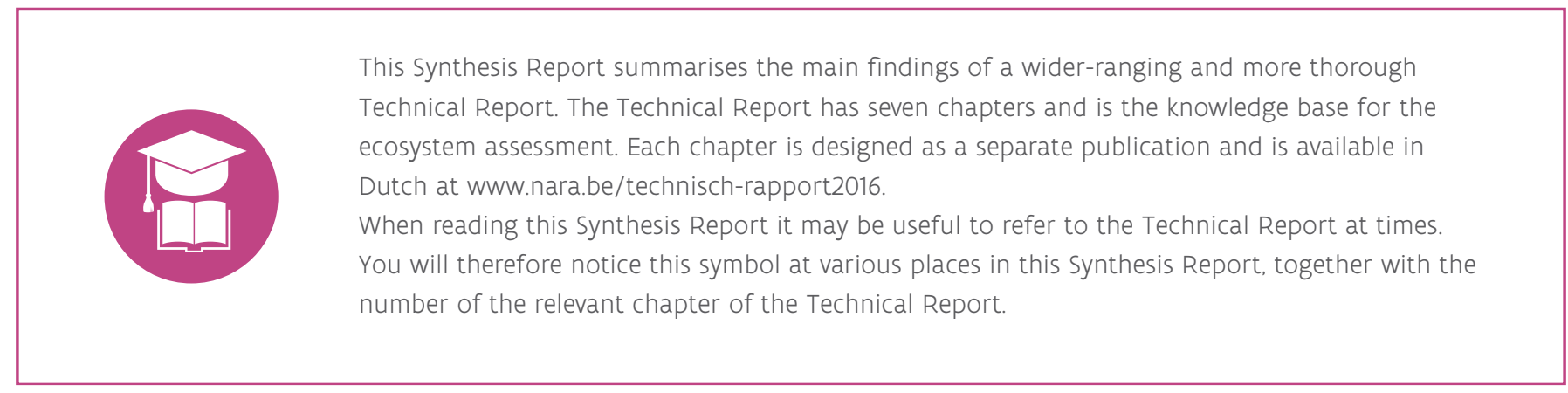




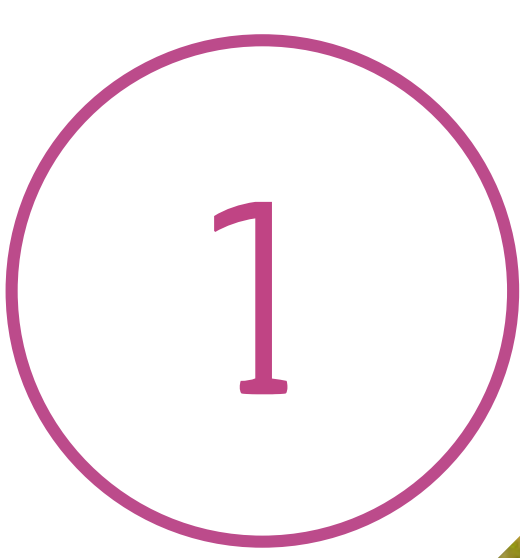

Q16

WHYY

Ecosystem services are invaluable to humans. It is therefore important for the interaction between nature and society to be taken into account in decisionmaking. This can be done by means of the ecosystem service approach.

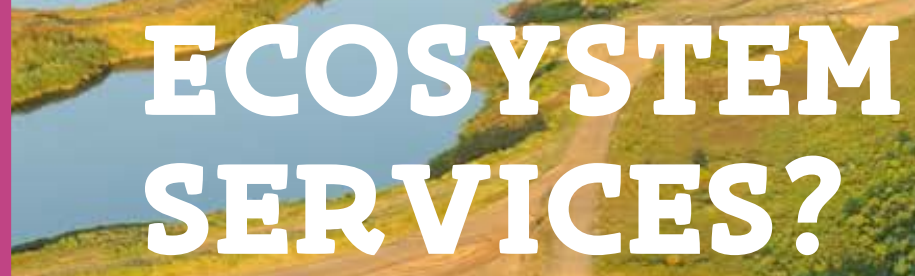

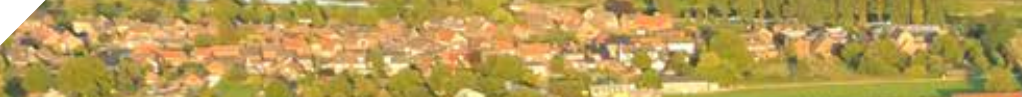


1.3 Towards a sustainable balance between supply and demand

We need to manage our ecosystems so that they meet society's various demands optimally, both now and in the future. At present, the demand for most ecosystem services in Flanders is greater than the supply, as is clear from Flanders REA-S\&T. Moreover, in the case of half of the studied ecosystem services, the supply is shrinking.

We make up for the shortfall in ecosystem services by importing them from other countries, or by replacing them with technological alternatives, such as a water treatment plant. Sometimes the shortfall leads to a loss of prosperity or well-being. This is something we experience, for example, when damage is caused by flooding or when the air is polluted in crowded cities.
Although we can increase the supply of a particular ecosystem service by changing the way land is managed and used, this often has an impact on the provision of other services and on biodiversity. For instance we can produce more food by using fertilisers, but as these penetrate deeper into the soil, they have an adverse effect on water quality. Another possibility is to restrain the demand for ecosystem services. Eating less meat, for example, means that we need less space to grow food. Starting to live more compactly saves space for other functions. And changes to our transport system or in the production and consumption of materials and energy have an impact on our use of space and our environment.

The ESS approach is central to Flanders REA. It is one way of contributing to the sustainable management of ecosystems and their services.

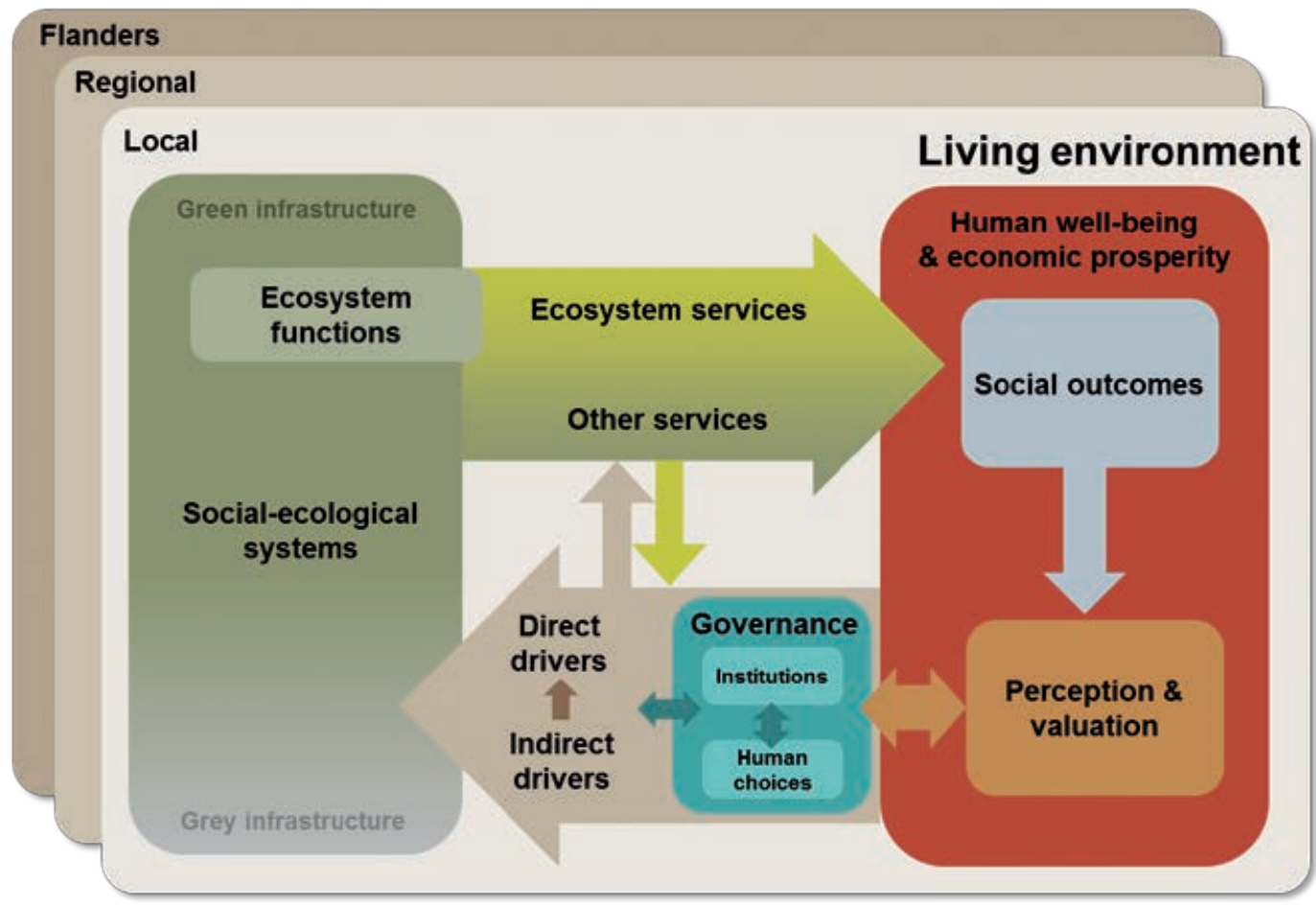

FIGURE 1. THE ECOSYSTEM SERVICE CYCLE

People are an inseparable part of the ecosystems in which they live. Our well-being and prosperity are only possible thanks to all the benefits with which nature provides us, including clean air, water, food and building materials. Conversely, we ourselves affect the ecosystems in which we live, by using or building on land, for example. And this in turn has an impact on the services provided by nature, and on society. 


\subsection{An ecosystem assessment for Flanders: three phases}

To be able to base their policies on an ESS approach, policymakers need to be accurately informed about the situation with regard to biodiversity, ecosystems and the services they provide to society. The scientific knowledge for this is provided by an ecosystem assessment. In 2005 the United Nations published the Millennium Ecosystem Assessment (MEA). This study, in which more than 1,000 experts worldwide were involved, describes the state of ecosystems and their services around the world.

In order to apply the ESS approach in Flemish policy. Flanders needs its own ecosystem assessment. Such an assessment gives our policy-makers the knowledge they need to base their policies on an ESS approach. Flanders REA represents a first assessment of ecosystems and their services for Flanders. The Flanders ecosystem assessment consists of three phases:

- In the first phase (Flanders REA-S\&T 2014), we produced a synthesis of the state of the ecosystems in Flanders and the services they provide.

- In the second phase (Flanders REA-P 2016), we consider how the ESS approach can be used when making policy decisions.

- In the third phase (Flanders REA-S 2018), we explore the impact of possible future scenarios on ecosystems and their services.

The Research Institute for Nature and Forest (INBO) is conducting the assessment, in close collaboration with other scientific institutions, governments and civil society.

\subsection{Flanders REA-P: the ecosystem service approach in practice}

Flanders REA-S\&T describes the state of ecosystem services in Flanders. Flanders REA-P examines how the conceptual and evaluative framework for ecosystem services - at various policy levels - can contribute to more sustainable land use and the improvement of biodiversity.

\section{The European Biodiversity Strategy}

The loss of biodiversity has important implications for our society and economy. This is recognised by the European Commission, which has therefore devised the European 2020 Biodiversity Strategy. With this strategy, the European Commission aims to halt biodiversity loss and the degradation of ecosystem services by 2020 and, where possible, commence a process of restoration in these areas.

The strategy includes six targets and a series of actions to address the main causes of biodiversity loss. Flanders REA-P focuses on Target 2 of the strategy. This target states that the European Union should maintain and enhance its ecosystems and ecosystem services between now and 2020 by 1) establishing green infrastructure and 2) restoring at least $15 \%$ of degraded ecosystems. To this end, each Member State should assess the state of ecosystems and ecosystem services in its territory. Each Member State must also develop a strategy to restore ecosystems through green infrastructure. This should safeguard biodiversity and ecosystem services.

The motto of Flanders REA-P is 'Working with landscapes'. This is intended to draw attention to the fact that:

- the report is the product of close collaboration with ambassadors, partners, pioneers and readers. The ambassadors are our primary partners in the various institutions of the Flemish government. The partners were actively involved in a project and contributed data, knowledge and expertise. The pioneers shared their knowledge and experience of alternative forms of management and ensuring the sustainability of land use. The reviewers read the various scientific background reports and gave constructive recommendations to improve them. 


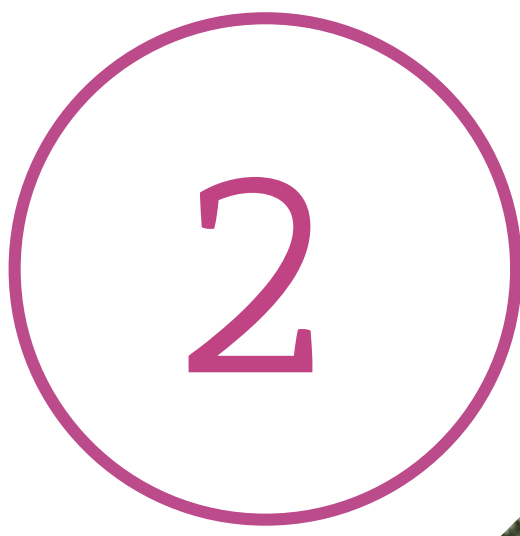

Bu DING BLOCKS
FOR IMPLEMENTING
ECOSYSTEM SERVICES 11 POHCY

MPe

clear language for communicating
about ecosystem services.

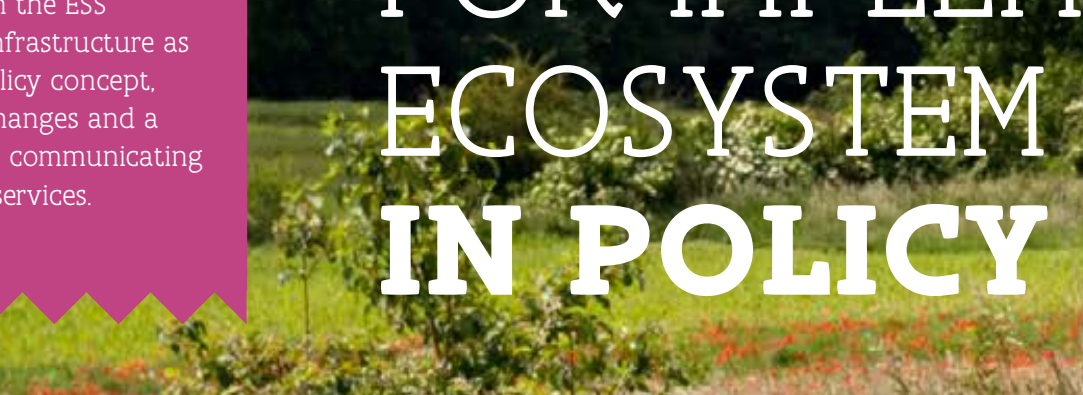

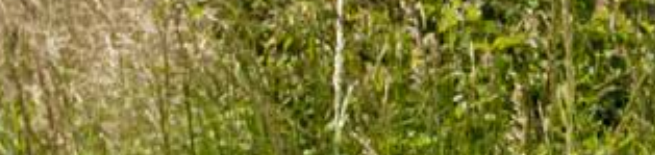
1. whentw

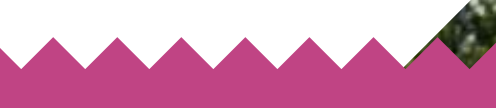

needed to help those tasked

sart we

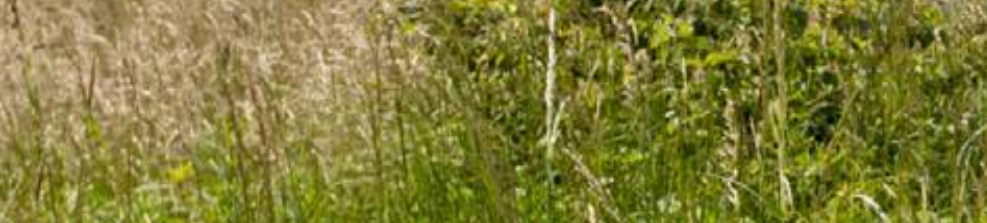

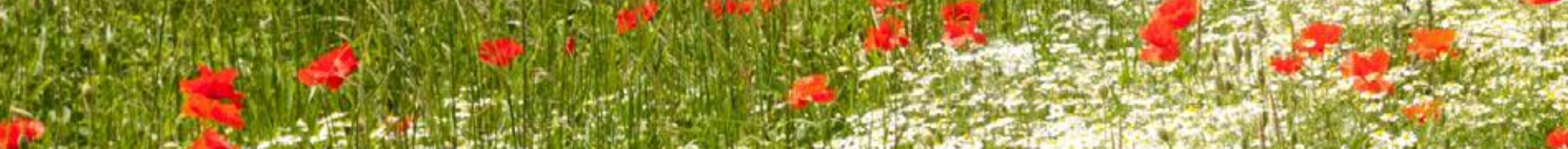

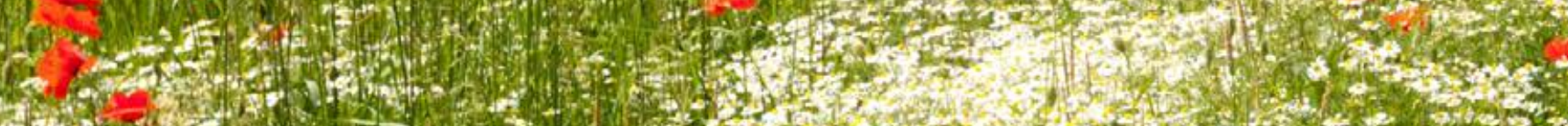

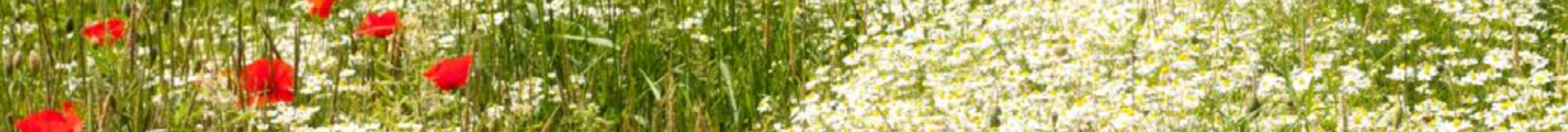

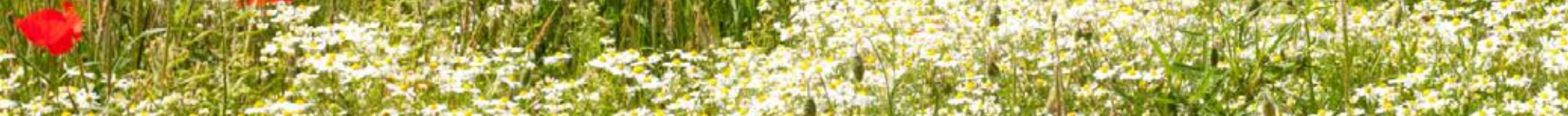

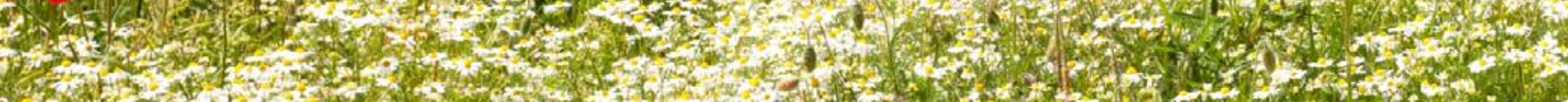

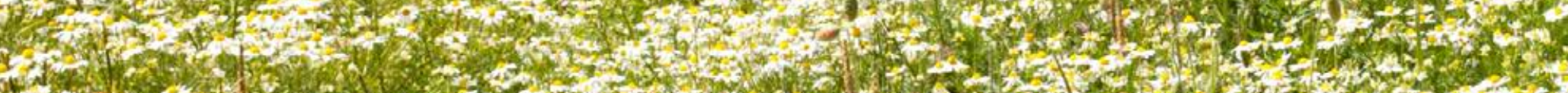

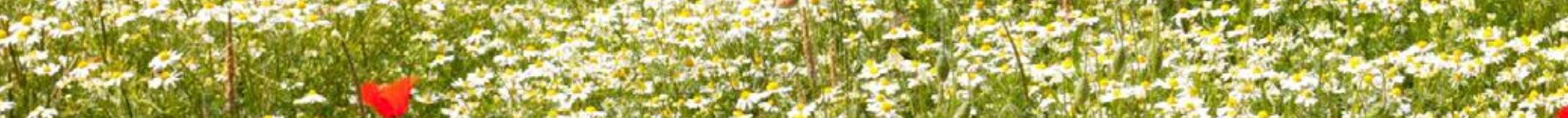
Lob.

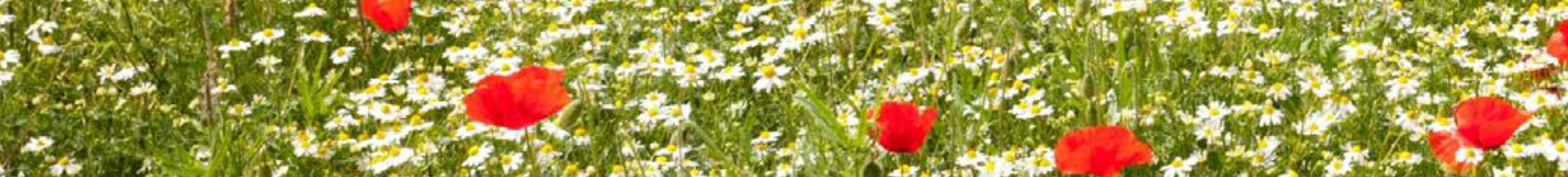

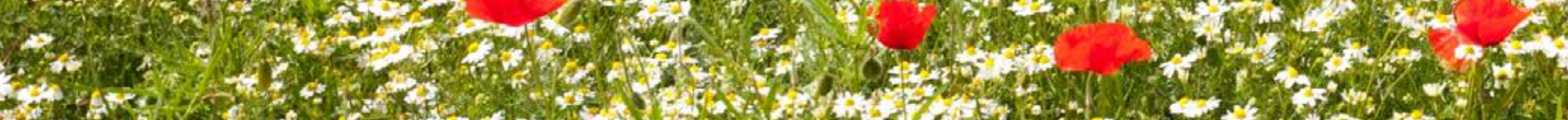

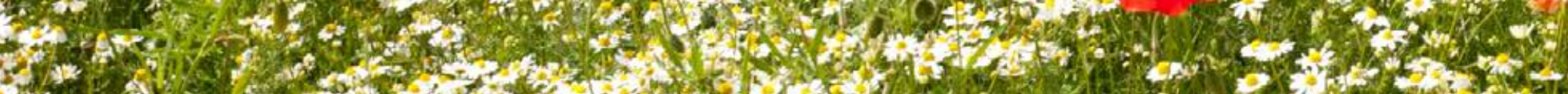




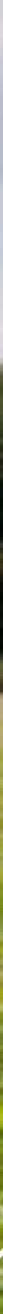

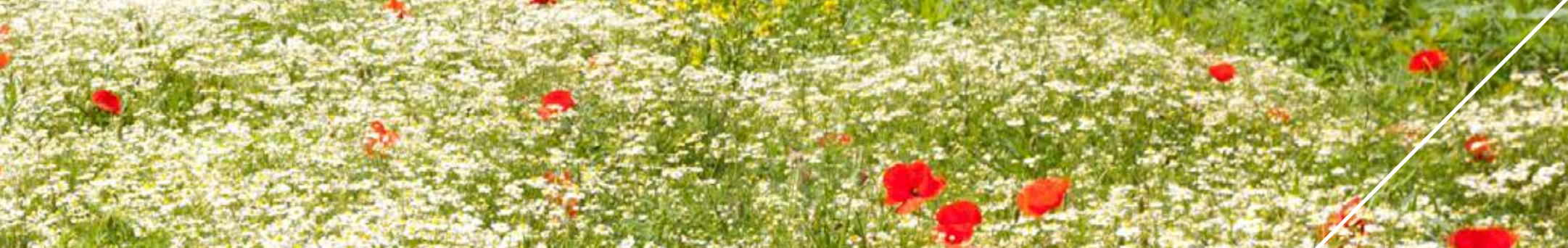

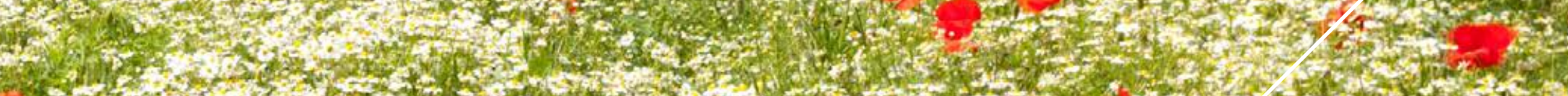

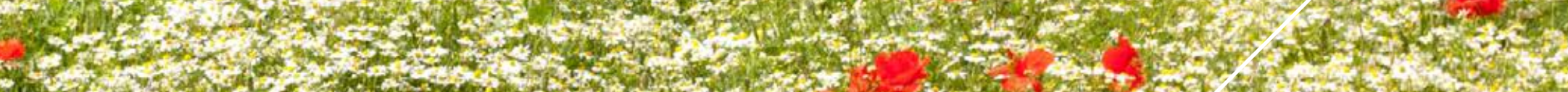

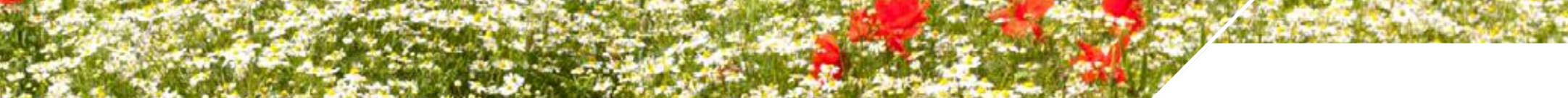

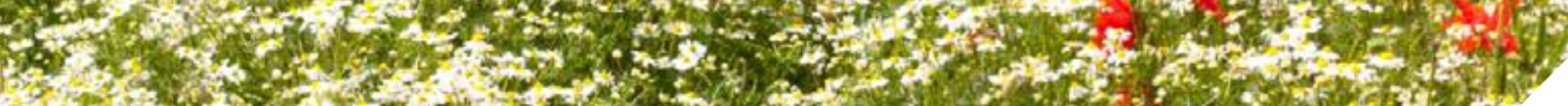

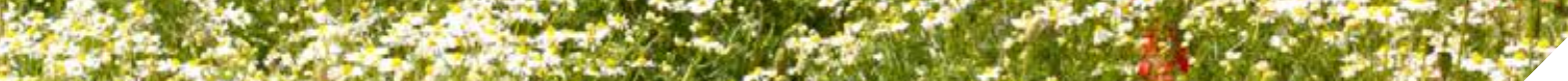

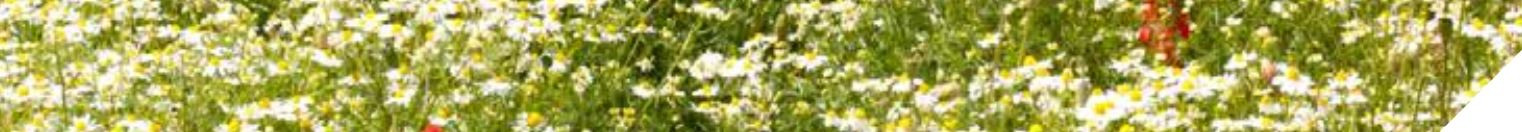

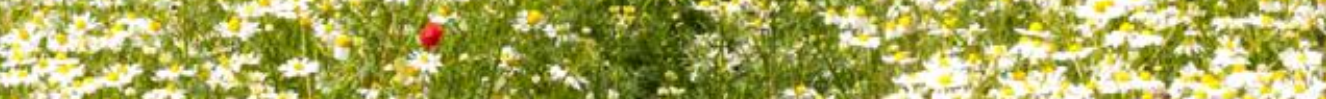

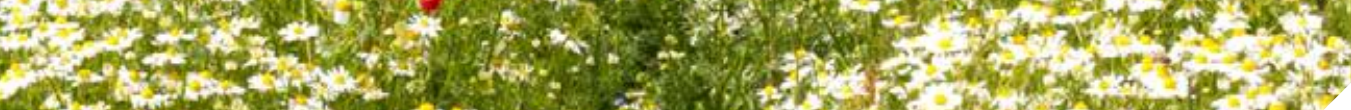

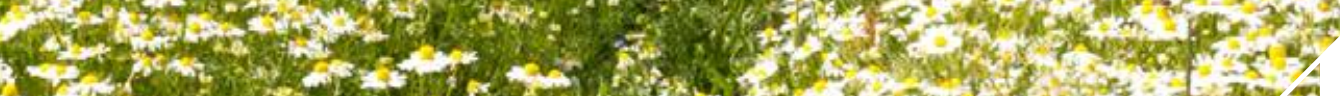

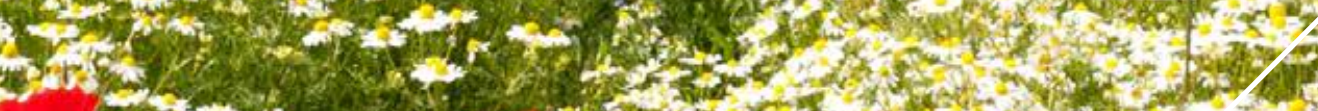

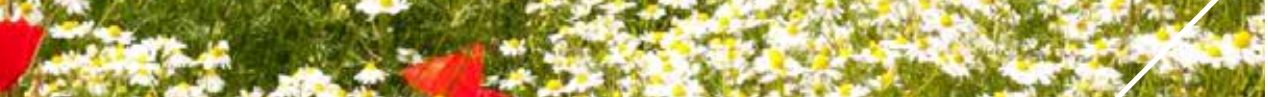

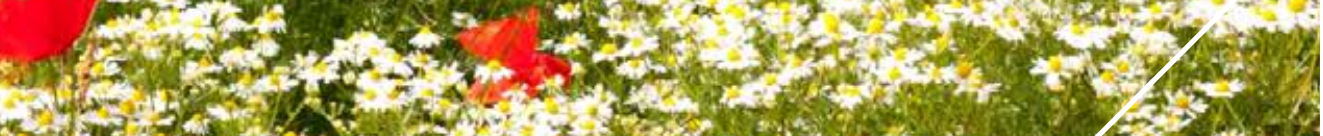

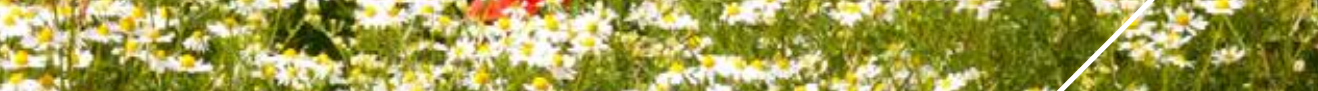

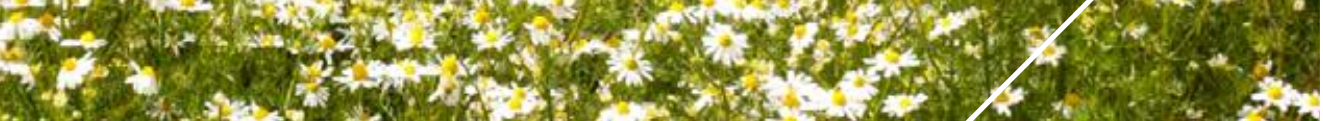

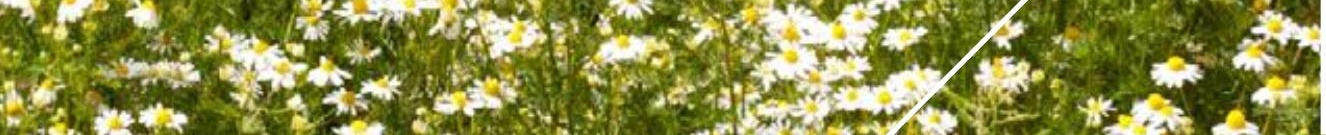




\subsubsection{Green infrastructure in Flanders}

Each EU Member State is supposed to develop a strategic framework to restore ecosystems and their services through green infrastructure. At present we lack such a strategy in Flanders. It is true that green infrastructure is already a tried and tested concept, as is clear from examples such as Natura 2000, the Flemish Ecological Network, the nature conservation policy, elements of spatial and rural policy, the green policy of cities and municipalities, the provincial nature policy, forest policy, water policy and environmental policy; and green infrastructure is also put forward as a tool in the Nature Decree, the MINA plan, the Spatial Policy Plan for Flanders, the Flemish coalition agreement, and the 2050 Vision. But because an overarching strategy is missing, the policy approach to green infrastructure is still highly fragmented. Users of space are not currently jointly responsible for a common green infrastructure. Flanders REA-P gives an initial impulse to the development of a fully fledged green infrastructure strategy for Flanders.

\subsubsection{Fifty shades of green}

\section{The gradient from green to grey landscapes}

Over the centuries we have significantly altered the ecosystems with our activities and interventions in the landscape. Forests, for instance, have been cleared to create farmland or residential areas. Since the industrial revolution, the human impact on ecosystems has increased still further.
Our numbers have grown, we consume fossil fuels, and we build on more land than ever. Our impact on ecosystems is particularly determined by changes in land use, urbanisation, pollution, over-exploitation and climate change. We see a gradual transition from 'green' to 'grey' landscapes. The historical shifts in land use are shown schematically in Figure 2. From left to right, we distinguish four types of landscapes:

1. Large, continuous, natural landscapes have almost completely disappeared in Flanders. Especially in pioneer ecosystems such as dunes, mudflats and salt marshes, natural processes are still dominant.

2. In addition, there are many semi-natural landscapes such as heathlands, wetlands, polder grasslands and certain types of forest. Natural processes can still dominate in these semi-natural landscapes, where human influence varies greatly.

3. As we move further to the right we find more grey infrastructure and the landscape becomes increasingly

fragmented. Continuous forests and heathlands evolve into a patchwork of grassland, hedges, scraps of forest, fields and built-up areas. Urbanisation and intensive farming increase. Land use becomes more intensive.

\section{On the extreme right are intensively used landscapes} with a marked presence of grey infrastructure and intensive land use. Only small remnants of nature are left here.

\section{FIGURE 2}

Schematic representation of the gradient from green to grey landscapes (adapted after Watz, 2011)

(Semi-)natural systems

Patchwork landscape

Natural element

Production landscape

- Green landscape elements

- Grey infrastructure

Urbanisation
(Semi-)natural systems

Extensive agriculture and forestry \& small-scale landscape structure
Increasing upscaling Increasing grey infrastructure
Large-scale production landscapes Strong growth in grey infrastructure Residual nature

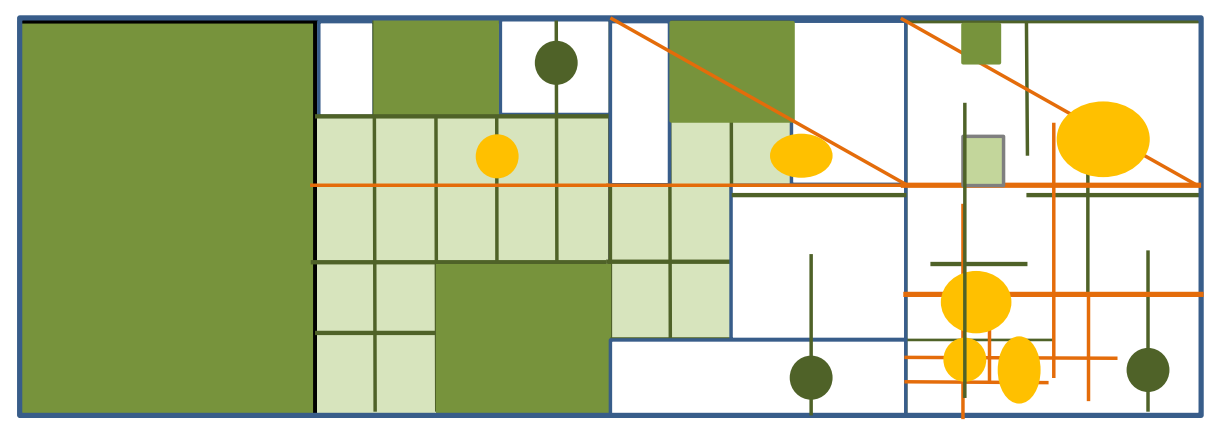




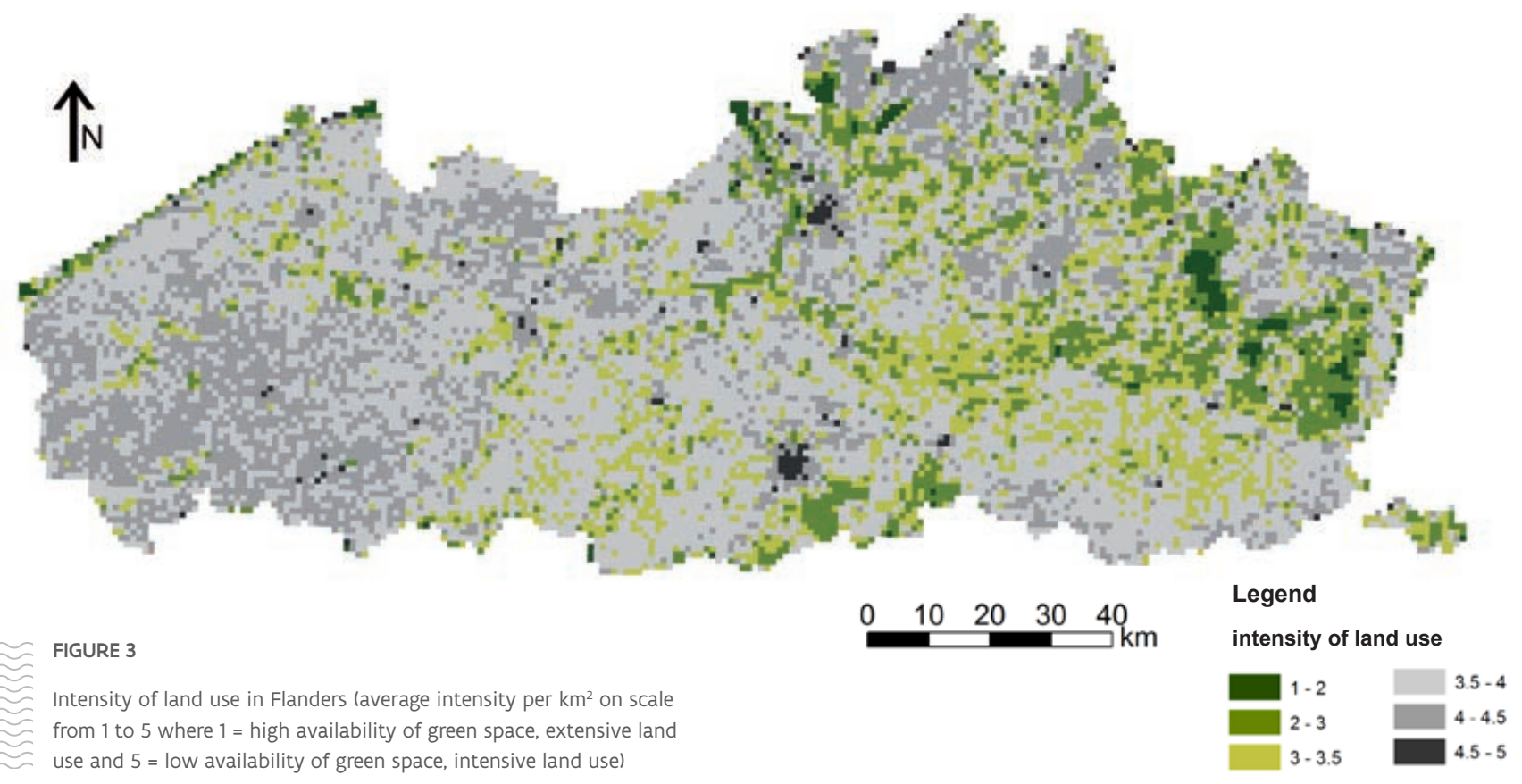

With more than 500 inhabitants per square kilometre, Flanders is among the most densely populated areas in the world. As a result, very little green space remains. For example, 90 percent of the surface is subject to intensive land use (see Figure 3 ). This results in pressure on biodiversity and the provision of fewer ecosystem services than required.

\section{Ecosystem services on the gradient from green to grey landscapes}

How does the supply of ecosystem services progress along the gradient from green to grey landscapes (see Figure 4)? At the green end, we see the ecosystem service in its purest form, in which exclusively natural processes take place. The further we move in the grey direction, the more technical and technological solutions and infrastructure are needed. For example, the 'greenest' form of food production is obtaining food such as berries, mushrooms and meat from nature. Further along, the impact of humans grows, and one finds. for example, farmers on the margins of natural areas who are combining nature management with meat production. Further along still, we find agro-ecological farming, followed by high-tech farming.
A similar gradient is found with water purification. Natural valley areas, salt marshes, mudflats and meandering rivers with a great self-cleaning capacity offer the greenest solution for water purification. Our modified and constructed wet berms and marshlands mimic these natural habitats. Going a step further, we arrive at small scale waste water purification stations using helophytes. At the greyest end are the conventional treatment plants, based on biotechnological processes requiring a large input of technology and energy.

As a landscape evolves from green to grey, it turns into a landscape where a single ecosystem service becomes dominant and the share of other services diminishes. A natural valley area combines various services (water purification, water storage, carbon storage, recreation), whereas a conventional treatment plant is completely focused on just one service. To restore ecosystem services, we must strive for the optimal delivery of combinations of ecosystem services tailored to the landscape. This also creates more opportunities for the biodiversity which is necessary to provide ecosystem services. In short, the restoration of ecosystem services mainly depends on the restoration of natural processes in the landscape. 


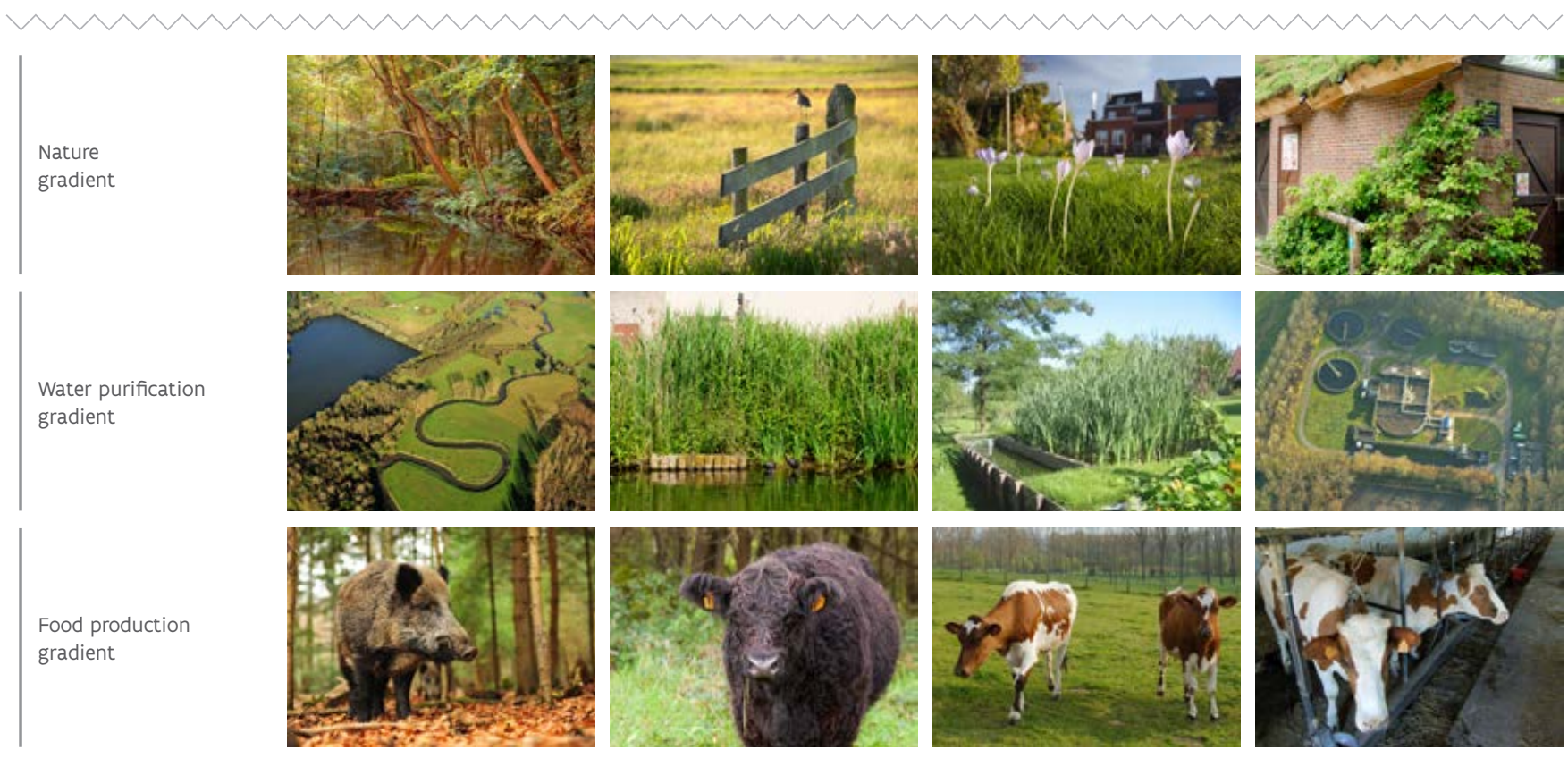

FIGURE 4

Ecosystem services on the gradient from green to grey landscapes

\section{Biodiversity on the gradient from green to grey landscapes}

Flanders is a densely populated and highly urbanised region with a lot of intensive farming and fragmented remnants of nature. In this type of landscapes, what kind of biodiversity can we expect? And what is the connection between biodiversity and intensity of land use?

In an attempt to describe biodiversity on a Flemish scale, we mapped the presence and absence of some 700 species for the whole region. Based on the outcome, we calculated two biodiversity scores. First, we calculated where the most Red List species (endangered animal and plant species in Flanders) occurred. Endangered species quickly disappear as land use becomes more intense.

Second, we looked at the total number of species you can expect. Here, each species counts equally, whether it is the blackbird or the nightjar. The overall species richness shows a different pattern. The highest richness is found with moderately intensive land use, but rapidly decreases to a minimum as the intensity grows. Mixed landscapes with a wide variety of land use can therefore potentially harbour a great wealth of species. Very intensive land use will always lead to a sharp decline in biodiversity. The analysis clearly shows the positive relationship between biodiversity and the delivery of combinations of ecosystem services. It therefore makes sense to use green infrastructure to restore biodiversity and ecosystem services together.

The meaning of the concept of green infrastructure To gain a better picture of practical experiences of green infrastructure in Flanders, we interviewed twenty policy experts, all of whom are responsible for the planning, installation or management of green infrastructure. We wanted to find out what characteristics a green space must have in order to qualify as green infrastructure. The experts' opinions contribute to the definition of green infrastructure. 
The majority of policy experts believe that green infrastructure has a dual role to play. The space must be useful for society, but must also provide a habitat for plants and animals. A win-win situation for humans and nature, in other words. The experts regard green infrastructure as referring to a spatial entity or to a collection of green elements such as city parks, nature reserves, green roofs and scraps of vegetation. Water bodies such as rivers, lakes, marshes, estuaries and the tidal zone are also covered by the concept of green infrastructure. Green infrastructure does not relate purely to large natural areas, but also to smaller green elements scattered across the landscape. The experts agree on this. Slightly more than half of them make a connection between green infrastructure and a green network. Some see green infrastructure as the counterpart of grey infrastructure such as the transport network. Like grey infrastructure, green infrastructure must be planned, managed and maintained. Society must invest in all sorts of infrastructure, so that everyone can benefit from it.

During an in-depth interview, we showed the experts a set of photos of green landscapes, fields and elements (see Figure 5). The question was: do the images correspond to your concept of green infrastructure or not? In order to decide the answer to this, policy experts take account of what they regard as feasible or necessary, among other considerations. In addition, they refer to the location of the landscape, piece of land or element. A green element in a nature reserve will be judged differently from a green element in a city. As land use intensity increases, their judgement becomes less strict. A field in an urban environment, for example, is valued more highly than a field in the countryside. When the experts express the view when looking at a photo that opportunities have been missed to create green infrastructure, they will not count that photo as an example of green infrastructure. By contrast, when an extra effort has been made to provide some greenery, for example with a green roof, even built-up space can be referred to as green infrastructure.

The interviews show that the concept of green infrastructure provides arguments to undertake and justify policy actions: starting up projects, coming up with good and creative ideas, landscaping an area, developing a plan...

\subsubsection{Three complementary strategies}

Green infrastructure is a valuable concept for policy-making. When it is developed as a powerful and overarching strategy. it can contribute to a widely supported policy for ecosystems and their services. One element of such a strategy is the formulation of goals and quality standards for all sectors.

To restore ecosystems and their services, it is helpful to create green infrastructure along the entire gradient from green to grey landscapes. Green infrastructure can be seen as a quality label for a green space, contributing effectively to the restoration of ecosystems and their services.

Taking into account the relationship between biodiversity and land use intensity, we propose to use three mutually reinforcing strategies for green infrastructure along the gradient from green to grey landscapes (see Figure 6).

1. In the first zone, on the left of the gradient, most endangered species are found. Natural processes such as germination, growth and flowering are hardly disturbed. Red List species quickly disappear as land use intensifies.

Strategy: Target 1 of the Biodiversity Strategy 2020 focuses on such areas. To protect fragile biodiversity against harmful human influences, we follow the strategy of enlarging and protecting. Human interventions in this area mainly focus on achieving biodiversity targets through nature management. Shared use by people (for recreational purposes) should be in balance with these goals. The protection of such areas must be established by law and management must be adapted to reach the biodiversity targets. A policy of acquisition and management of reserves contributes to the implementation of this strategy. 


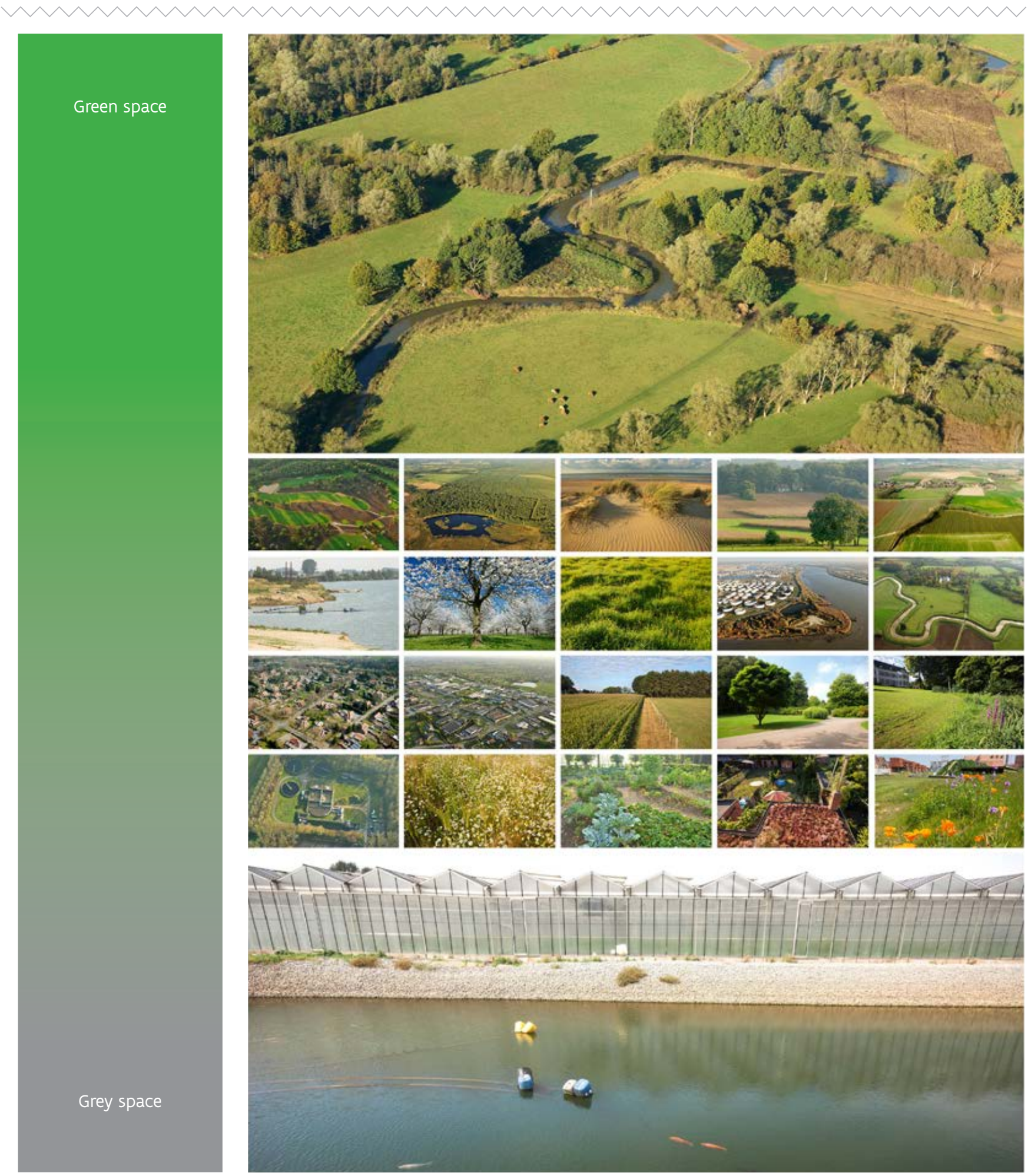

$\cong$ The transition from green to grey space illustrated with photos. These photos were shown to the experts.

$\approx$ source: Vildaphoto - Yves Adams - Jeroen Mentens - Lars Soerink 
2. Potentially, large numbers of species can occur in the second zone of moderate land use intensity. There are fewer Red List species present. Either there is a diverse landscape in which built-up areas, forest and grasslands alternate, or there is a single multifunctional land use type, such as a multifunctional forest where timber production, recreation and species protection are combined. This intermediate zone is currently under great pressure.

Strategy: Nature is usually not the main objective in this area. A strategy of land sharing and

connectivity is needed. Humans have a great impact on the areas in this zone, but the provisioning services do not stand in the way of the delivery of regulating and cultural ecosystem services. Multifunctional use is the main objective, but it must be balanced with the requirements of the species that live here and that can provide important ecosystem services. The management and organisation of shared land zones and connecting areas falls largely outside the nature reserves. These areas require a different type of policy (mechanisms and instruments).

3. The third zone, covering the largest part of Flanders (90 percent), is used intensively. This zone is characterised by fragmented remnants of nature. Either there is maximum focus on a single ecosystem service, such as food production, or land is built over. In both cases, the impact of humans is high. That impact is also felt in the other two zones, which means that additional management and buffering is needed in order to achieve the biodiversity targets there. The demand for ecosystem services - recreation, food, flood protection and so on - is very great in zone three. Such services are needed to ensure human wellbeing and prosperity.

\section{Strategy: A strategy of changing and mitigating is} called for here. Much of the solution lies in changing or adjusting the intensively used systems so that their environmental footprint shrinks and demand for ecosystem services is more in line with supply. Non-sustainable systems need to be redesigned and the human impact must be reduced.
The feasibility of this approach is illustrated with the pioneers' stories later in the report. Technical interventions (such as green roofs, wadis, ecoducts. roadside vegetations, reduced tillage or the replacement of maize with grass-clover) and green space help to mitigate the impact of land use.

\section{Everyone can contribute}

The three zones complement and reinforce each other The continuous green areas in the first zone deliver many regulating and cultural services for Zones 2 and 3, as well as provisioning services such as water production. The green infrastructure of Zone 2 can serve as a buffer for Zone 1 and link together the isolated green areas in that zone. Many endangered species from the first zone are partly dependent for their life cycle on Zone 2. Thus, common vipers need damp undergrowth away from the heathland, and badgers like a varied landscape of forest with an adjoining patchwork of fields, meadows and small landscape elements. Zone 2 can also help meet the demand for footpaths and walking trails from Zone 3 . The latter zone benefits in turn from the services from Zones 1 and 2 .

If we make intensive land use more sustainable, our ecological footprint shrinks and the opportunities for biodiversity restoration grow in all three zones. Solutions such as green roofs, street greenery, vertical gardens, parks, wild or ecologically managed gardens and soil-preserving farming techniques provide opportunities for local biodiversity in Zone 3 .

Green infrastructure is a network: if the different green spaces are well connected, the effectiveness of green infrastructure increases and it provides greater benefits. Streams and rivers form an integral part of it. A network of linked flood areas can reduce the risk of flooding, provide migration routes for species and reinforce the network for 'soft' (non-motorised) recreation.

Each of us is active in at least one of the three zones and can thus contribute to green infrastructure, biodiversity and ecosystem services. Implementing the three strategies outlined above is essentially a social duty. 
Anyone can make a contribution, within our powers or our activity, to restoring ecosystems and their services. Collaboration and co-creation are important in each zone. The intertwining and connecting areas of Zone 2, for instance, are very diverse, so that a customised approach is required. Different policy domains, target groups and landowners need to devise connecting and intertwining strategies together for these intermediate areas.

\section{Eco-effectiveness or extensification?}

Wherever you are on the green-grey spectrum, restoration is always a combination of increasing eco-effectiveness and extensification (see Figure 6). Increasing eco-effectiveness means working more effectively and sustainably within an activity or business. By doing so, you not only reduce the local impact, but make certain ecological goals attainable elsewhere in the landscape. To give an example, by changing the feeding system of dairy cows - namely by replacing corn with grass and clover - dairy farmers can mitigate the environmental impact of their activity without any effect on milk output. The soil quality is enhanced, the health of the animals improves, no more fertilisers are used and soya stops being imported.

Extensification includes a whole range of measures that lead to more extensive land use, such as creating hedges or grass buffer strips, introducing environmental management, changing land use, rewetting the landscape. The yield for provisioning services such as agriculture and forestry can be reduced as a result. For many regulating and cultural ecosystem services, extensification adds value.
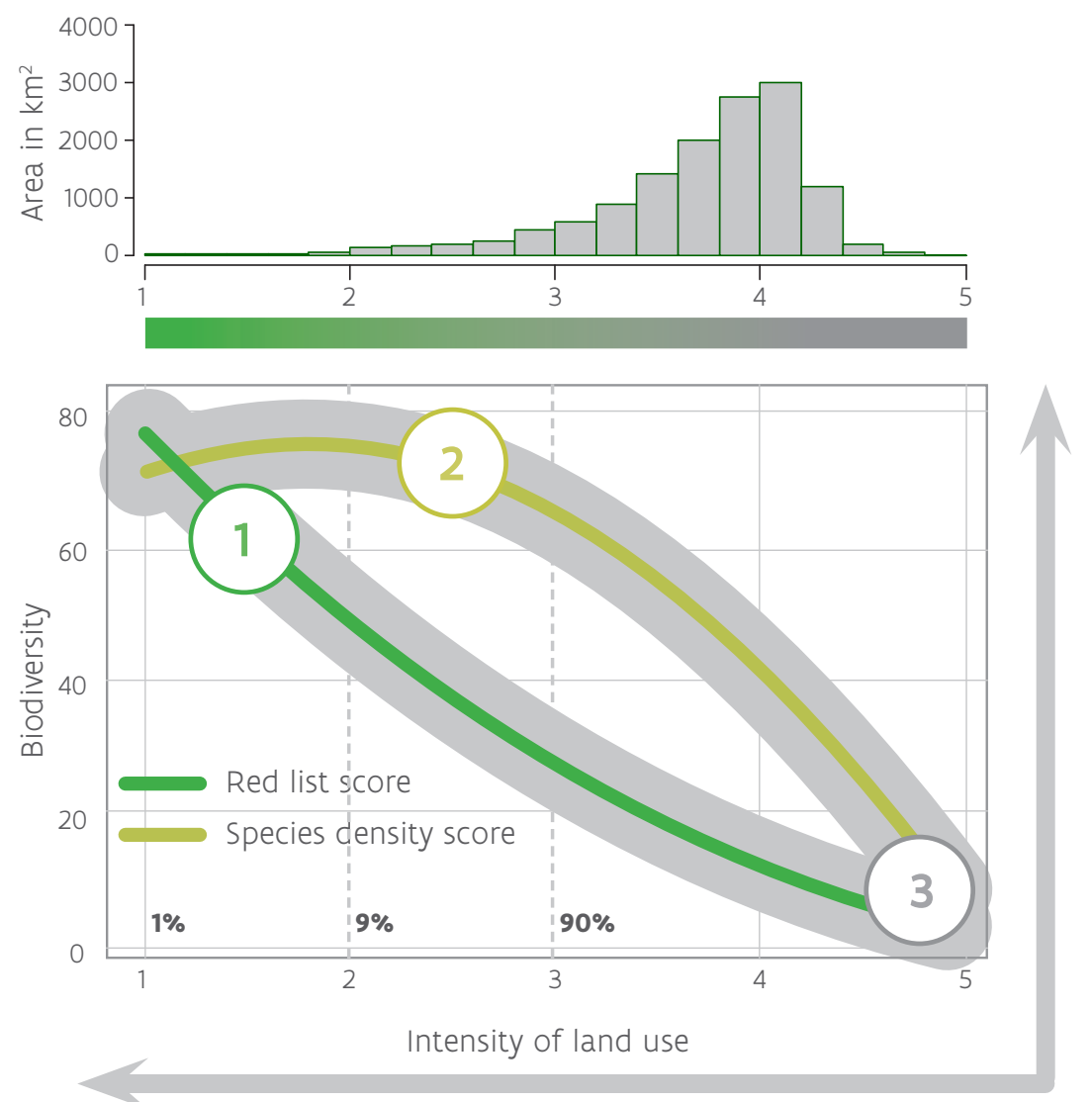

Method 1: extensification
Zone 1: focus on specialists of nature, endangered and rare species and habitats

Zone 2: moderately demanding species, but great species richness, patchwork landscapes with diversity of habitats

Zone 3: more flexible species, including specific species, e.g. those adapted to urban environment, which are also under pressure.

\section{FIGURE 6. Strategic choices on the spectrum} from green to grey

(1) strategy of enlarging and protecting because of the high and specific environmental requirements of certain species; (2) strategy of intertwining and connecting in which moderately intensive land use is associated with high species richness; (3) strategy of changing. mitigating and transition because the intensity of land use has a negative impact on human well-being and prosperity. 


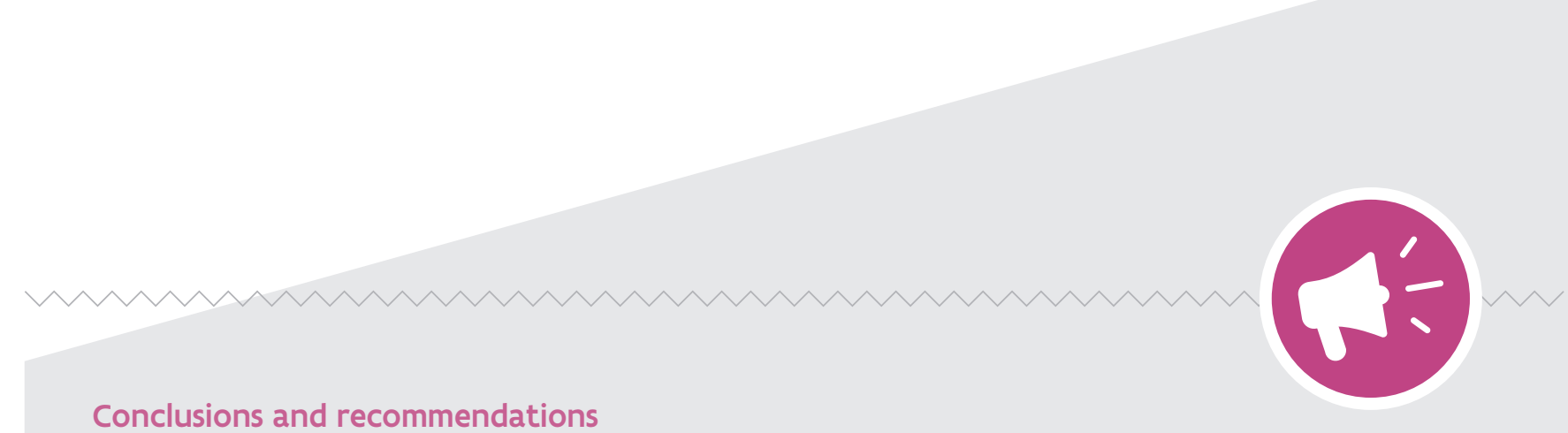

\section{Conclusions and recommendations}

\section{Green infrastructure as an integrating strategy} generating a win-win for biodiversity and society. We recommend that green infrastructure should be treated as an overarching and integrating policy strategy to improve and expand green space. Such a strategy should target benefits for society and nature. In this way, the green infrastructure strategy can become a melting-pot for innovative developments in both open and built-up space, and at different levels. We propose to define 'green infrastructure' as follows: Green infrastructure is the network of healthy and robust ecosystems used for the simultaneous achievement of social objectives and nature conservation targets.

\section{Key objectives per zone on the gradient from green} to grey landscapes. A green infrastructure policy involves formulating key objectives and core qualities for each area across policy domains and sectors. In Zone 1, the conservation of biodiversity is the main goal, in Zone 2 the main point is to strike a balance between social goals and nature-related goals, while in Zone 3 the aim is to reduce humans' ecological impact. There is a need for policy ambitions right across the gradient from green to grey landscapes.
3. A question of tailor-made solutions. All types of land use can be covered: natural and semi-natural ecosystems, waterways, private and public green spaces such as gardens and parks and so on. Green infrastructure is a search for tailor-made solutions, adapted to local needs. The landscape and its features are the starting-point for designing green infrastructure.

\section{Through co-creation, all participants have an} impact. Green infrastructure is therefore best developed in partnership with various agencies and stakeholders and is based on input from different disciplines, such as socio-economic expertise, landscape ecology, urban and regional planning. landscape architecture and so on. Consideration is given to how visions and goals from different sectors support and reinforce one another. The development of green infrastructure is the shared responsibility of anyone taking initiatives in the area: garden owners, architects, developers, intermunicipal bodies, cities and municipalities, non-profit organisations... It would be good to build a network of experts around the three green infrastructure zones and designate both initiators and implementers.

\subsubsection{Working to make land use more sustainable}

Many people - both members of the public and entrepreneurs - are aware of the importance of their contribution to sustainable land use, a healthier community and the restoration of biodiversity. Across the green-grey spectrum, they organise activities that help ecosystems and their services.

\section{Location determines activity}

The measures you can take to use land more sustainably obviously depend on the location. A farmer on the outskirts of a town will tend to opt for a local supply chain and a pick-your-own farm where customers can harvest fruits and vegetables for themselves. A farmer located close to a Natura 2000 site, on the other hand, will give more thought to the cultivation of specific varieties adapted to the terrain and to grazing management in compliance with the nature targets. A farm in the countryside will focus more on water storage, while one in the city will be more interested in recreational benefits for local residents.

Like to know more about this subject? You can read all about it in Chapter 2 of the Technical Report. 
The impact of such activities can be felt at various levels. For instance, you can manage a country garden so that it is attractive to butterflies or birds and forms a kind of miniature nature reserve. At a higher level, such a garden can form part of a garden complex linking together larger nature units, promoting the migration of species and functioning as an entity to provide ecosystem services to society. Through more sustainable land use, a farmer can improve soil quality locally, reduce the negative impact of fertilisers in the wider environment and mitigate the impact of food production on the rest of the world, for example by not importing soya beans.

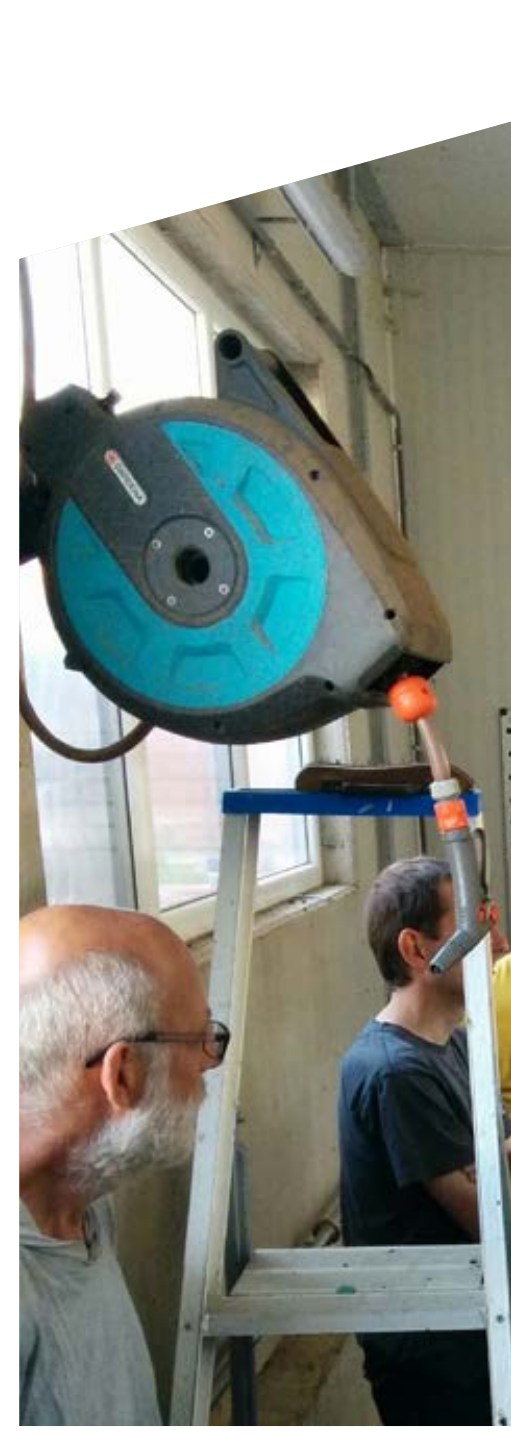

\section{Pioneers' stories}

Work can be done on green infrastructure everywhere. It is an amalgam of solutions, each arising from the local situation, that has the potential to bring about multifunctional use of space and make society more sustainable. In order to demonstrate the range of solutions, we interviewed two series of pioneers. Their stories may inspire others to get started on more sustainable land use.

The first series of stories is about food production. Along the gradient from green to grey landscapes, four farmers talk about their contribution to a more sustainable agricultural system and the restoration of biodiversity. The second series brings together testimonies about gardens as an ecosystem. Our network of gardens can become an important green infrastructure spreading all the way across Flanders. A garden's location is one of the factors determining its contribution to the restoration of biodiversity and ecosystem services. That contribution may be an individual one, or it may take the form of a social project such as 'Gardening Together'.

You can read a compilation from the two sets of accounts on pages 46 and 64 . 


\subsection{VALUING LAND USE CHANGES}

Increasing urbanisation and the intensification of agriculture have an impact on ecosystems and their services. If our society wishes to benefit fully from ecosystems and their services, it must protect and maintain them. Flanders REA-P proposes a method for valuing changes in land use so to be able to take more sustainable decisions about land use. Ecological, social and economic interests are all taken into account.

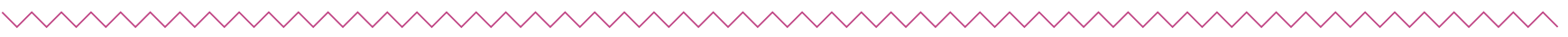

2.2.1 Changes in land use

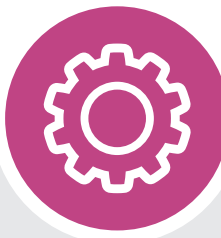

How did we proceed?

- To help policy-makers take decisions that take the importance of a wide range of ecosystem services into account, we created a value typology for the integrated valuation of land use changes.

- We applied this integrated valuation approach to two current policy issues: forest expansion and erosion control. In this synthesis report, we discuss the issue of forest expansion only. We compare three alternative scenarios. Each one relates to the same area of forest expansion, but the location and the main function of the forest enlargement differ. This results in different patterns of land use changes. We value these land use changes and compare them with one another on the basis of 20 indicators that reflect a mix of ecological, social and economic values.
The supply of ecosystem services in Flanders is insufficient to meet the society's needs. Changes in land use are among the main causes (or drivers) of this imbalance. In Flanders those changes largely relate to increasing urbanisation - around six hectares of open space disappears every day - and changes in crop choice and management in agriculture.

When we make decisions about land use changes, ecosystem services are often not a decisive argument. We are often insufficiently aware of the importance or value of ecosystem services, regard them as replaceable or base our decisions solely on values that can be converted into financial terms in market transactions. Yet ecological, social and economic impacts should be taken into account in order to make sustainable decisions about land use changes. Only then will we be able to manage the growing imbalance between supply and demand in ecosystem services more effectively.

\subsubsection{What is valuation?}

Valuation involves going through a decision-making process in which we measure the characteristics of something against certain norms or standards. Often, this process is done very intuitively and instinctively, or is partly affected by a social context. Often too, we combine very different criteria. The result of this decision-making process is the value or importance that we attach to something. We can formalise or mimic the process using a particular evaluation method, but even then it always involves a selection process based on normative criteria or assumptions. 
Objectifying values is an almost impossible task; it is more a matter of making subjective, normative viewpoints visible and open to discussion.

In the ESS cycle we value (changes in) ecosystem services largely as a function of the effect they have on our wellbeing and prosperity, to the extent that we are aware of that effect. This kind of valuation thus lies at the heart of our individual choices and collective decision-making (governance) about how we deal with ecosystems and land use changes. Valuation is thus based on personal preferences and ethical choices. These in turn are affected by the sociocultural and institutional context in which we find ourselves. When we value, we are influenced by the knowledge system within which we are thinking, the technology that surrounds us, the social structures to which we belong and our physical environment. For a dairy farmer, the meaning of a 'good pasture' is different from its meaning for a botanist. The professional forester has different criteria for defining a 'good forest' from the conservationist.
In conducting the valuation study, Flanders REA-P starts with the following questions, which are closely related to the different links in the ESS cycle (Figure 7):

1. To what individual or collective choices does the valuation relate?

2. What changes in the social-ecological system are we valuing?

3. What (ecosystem) services are we valuing? Are we valuing supply, or also demand and use?

4. With reference to which social outcomes (jobs, health, food, income, flood damage, climate, proximity to greenery) are we conducting our valuation?

5. Whose and which perspectives (stakeholders, spatial, time scale) affect the valuation?

6. What value types and ethics are the basis of the valuation?

7. From which institutional perspective (market, government, local community, etc.) are we conducting the valuation?

8. Towards which institutions and target groups is the valuation oriented? With what purpose?

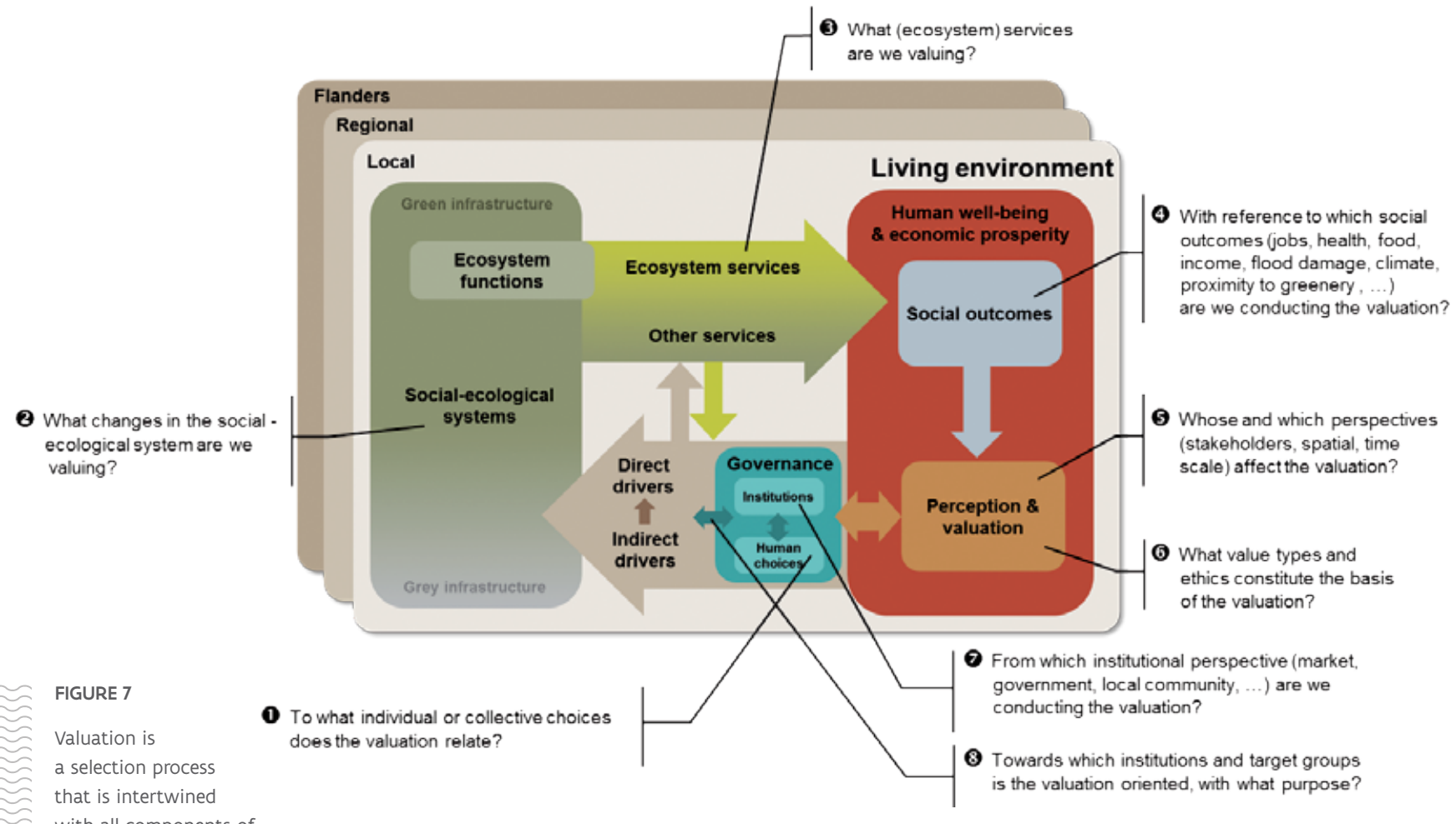

with all components of

the ecosystem service cycle 
There is no single superior valuation method or tool that policy-makers and stakeholders should use to determine a choice of land use. A valuation study is by definition selective and subjective. Precisely because valuation forces us to make choices, the values and interests of a particular group are given more weight in valuation studies than those of others. The point is to be open about this selectiveness and to engage in discussion about it.

\subsubsection{Methods for valuing nature and land use}

Value: more than just a matter of economic prosperity In the current discourse about ecosystem services, value is often expressed in financial and economic terms. In past decades various environmental economic methods have been developed and refined in order to estimate the environmental impact of economic development and to express the positive value of ecosystems and their services in monetary terms. Although researchers and policy-makers have shown interest in these economic valuation studies and such studies yield policy-relevant insights, they have also attracted considerable criticism from a scientific perspective and from civil society too.

The critics have warned against an excessively narrow economic focus on what can be quantified and converted into monetary value. Such a way of thinking largely ignores the complexity of social-ecological systems and the rich variety of social-cultural values that determine our well-being and prosperity. This can lead to a commodification of nature and to an over-exclusive focus on financial and marketbased policy instruments. In recent years much work has been done to embed economic valuation in a broader, more interdisciplinary approach to valuation in which value types other than economic value are taken into account.

\section{Which comes first: humans or nature?}

In the valuation of ecosystem services, the emphasis is on the importance of ecosystems for human beings and society. The ESS approach considers ecosystems as a form of natural capital which constitutes the basis of our wellbeing and prosperity - and in fact of society itself. The risk of this approach is that ecosystems are seen as redundant or replaceable whenever there are technical alternatives to take over their function. Questions have also been raised about the anthropocentric value system itself. Thus it is generally accepted that non-human living beings and systems have a value that is separate from, and independent of, their usefulness to humans. This principle is also enshrined in the Convention on Biological Diversity and the European Biodiversity Strategy.

Inherent moral or intrinsic values are difficult to convert into unambiguous indicators or hard decision-making criteria. That makes it difficult to use them as a basis for policy decisions on the conservation or restoration of biodiversity. Moreover, indicators and criteria with respect to intrinsic value are often mixed with anthropocentric motives. Many of our protected habitats and species, to which we assign a high 'biological value', are connected to and witnesses of a cultural and historical heritage that is becoming increasingly rare. Thus we often regard a population of skylarks or a moorland as more valuable than a flock of jackdaws or a monotonous conifer plantation. On the other hand, a pine forest may also be a typical regional feature of value.

In interdisciplinary research into the value of nature and ecosystem services, the following four value types are distinguished: intrinsic moral values (because something is valuable, regardless of its usefulness to humans), fundamental values (because something is so essential that it constitutes a basic requirement for human existence), relational, social and cultural values (because something is a prerequisite for a good and decent life) and instrumental values (because something is a means to an end).

\section{Valuation for more sustainability}

The central question in Flanders REA-P is: How can we valuate land use changes on the scale of Flanders with a view to sustainable decision-making? This means that we link 'valuation' with 'sustainability'. Sustainability means that the carrying capacity of the earth is not exceeded (ecological criterion - planet), that resources and means are fairly distributed (sociocultural criterion - people) and that we thus attain the highest possible level of prosperity for everyone (economic criterion - profit) 
In Flanders REA-P we opt for integrated valuation that addresses ecological, , social and economic values. We apply this evaluation to two contemporary policy issues in which land use changes are key: forest expansion and erosion control. As value judgements come into these valuations, we indicate clearly in each scenario which values and criteria form the basis of the examined land use changes (see below).

\subsubsection{Value typology: three dimensions of values}

Flanders REA-P classifies values from three angles.

- Range of values: What part of the reality do the values cover? Do the values lie within the ecosystem (ecological values), the social system (social values) or the economic system (economic values)?
- Focus of values: For which aspect of the ESS cycle is a value defined (for example, ecosystem characteristics such as area or species diversity, ecosystem services or social outcomes for certain stakeholders)?

- Motive of values: Out of what motives are the values expressed? What do we want to achieve with the values? The motives are associated with the intrinsic, fundamental, social-cultural and instrumental values mentioned above.

Based on these three angles, we propose a value typology (Figure 8). This can be used to clarify what values our valuation of land use changes is based on. It also reveals the valuation study's selectivity and normative assumptions. S1, S2 and S3 indicate the value types which have been used as the basis for the development of three alternative forest expansion scenarios. Later in this study, we compare these scenarios with reference to a number of ecological, social and economic values.

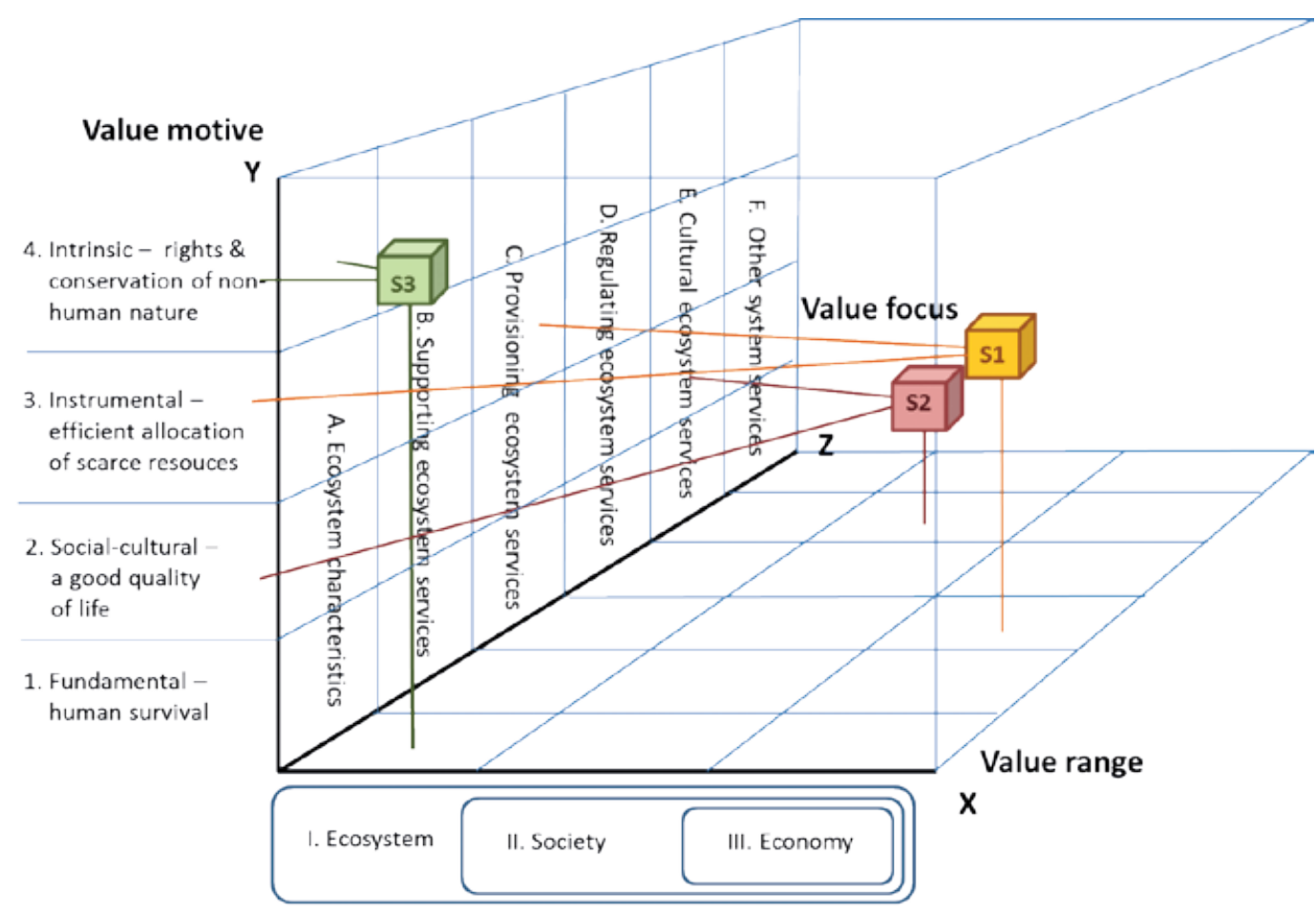

FIGURE 8

Value typology for integrated valuation of land use changes

Like to know more about this subject? You can read all about it in Chapter 4 of the Technical Report. 


\subsubsection{Valuing forest expansion}

\section{Flanders: a poorly forested region}

There are few forests in Flanders. Approximately 11.5 percent of the Flemish Region is forested. Together with Ireland, the United Kingdom, the Netherlands and Denmark, Flanders is one of the least forested regions of Europe. The low woodland cover in Flanders is both a historical and a recent phenomenon. Half of the woodlands in our region had already been cleared by the time of the Roman Empire. Forests today are not typically located in places that generate a high yield in wood production, but rather where they present the least obstruction to urbanisation and modern agriculture.

\section{Objectives for forest expansion}

To increase the amount of forest in Flanders, the Flemish government drew up the Long-Term Plan for Forestry in the nineties. The plan aimed for a woodland cover rate of 12 percent (162,264 hectares) by 2010, with an increase of 1 percent every five years thereafter, up to 30 percent (405,660 hectares) by 2100 . The Spatial Structure Plan for Flanders (RSV) formulated a more modest ambition in 1994. The binding section of the plan imposed an increaseby 10,000 hectares of the spatial designation category forest or forest expansion area for better protection of existing forest or for new forest. This was initially planned to take place by 2007, but was later postponed to 2012. The non-binding section of the RSV also provided for an effective forest expansion of 10,000 hectares, through nature development or linkage measures, or in the vicinity of urban areas with little woodland cover.

However, both forest expansion and forest compensation (the obligation to compensate for any authorised deforestation in another location) have progressed much more slowly than anticipated. There is often a lack of political or public support for converting existing land use into forest. For landowners and users, both residential and agricultural land use is more profitable than a forest almost anywhere. Many of the ecosystem services that forests provide, especially regulating and cultural services, may also be difficult or impossible to monetise. There are therefore few economic incentives for landowners and users to maintain or expand their woodlands.
The policy objectives with regard to afforestation today mainly relate to the conservation objectives for forest habitats of European interest (listed in the European Habitats Directive) and to the creation or expansion of urban forests. These urban forests are partly financed from the forestry compensation fund (see 3.1). For conservationrelated afforestation, the Flemish Region has set a target area ranging between 5,875 hectares and 9,210 hectares. The targets for urban forests are determined less specifically at the regional level, because the initiative for them partly comes from the provincial and local level of administration.

Flanders REA-P examines three forest expansion scenarios. This valuation study is not intended as a recommendation; we do not specify what area of forest expansion is desirable or necessary. We also do not consider what kind of forest expansion is best for Flanders. What we want to show, however, is that alternative choices regarding the type or location of forest expansion have very different ecological social and economic impacts, and that we can make these more apparent to policy-makers and stakeholders through integrated valuation.

\section{Scenarios}

We compare three alternative forest expansion scenarios. To facilitate comparability, the three scenarios are based on the same area of forest expansion. The location (where?) and type (conservation-related or urban forest?) of forest expansion vary per scenario, depending on the dominant objectives or priorities for that scenario. We have developed these alternative targets per scenario in the form of a general 'guiding principle' for the choice of location, which we have elaborated in further detail in a number of 'operational constraints' (see Table 1).

In the comparative analysis we examined how the three scenarios score on the alternative objectives and on an number of side effects. This analysis was conducted with reference to 20 indicators that reflect a mix of ecological, social and economic norms and values. We discuss five of these in this synthesis report. For each scenario, they show what land use changes the forest expansion causes; the impact of forest expansion on forest fragmentation and forest morphology; the effect of the proximity of urban greenery and urban forests on residents of urban areas; 
land use changes; and the economic value of changes in food production, timber production, regulation of air quality. regulation of erosion risk, regulation of global climate and recreation. Table 1 summarises the main principles of the three scenarios.

\section{TABLE 1}

Main principles and assumptions of the three forest expansion scenarios

\section{Results}

The three afforestation scenarios are based on the same area, but a different spatial distribution. The latter was determined on the basis of alternative ecological, social and economic values and priorities and criteria derived from them (see Figure 8). We will now look at how these spatial differences translate into environmental, social and economic effects.

\author{
Scenario 2 - recreation for Scenario 3 - opportunities \\ urban area \\ for ancient forest
}

\section{Scenario 1 - forest \\ expansion with limitation \\ of agricultural losses}

\begin{tabular}{|c|c|c|c|}
\hline Forest expansion area & $\begin{array}{l}9,800 \text { ha: } 5,900 \text { ha } \\
\text { conservation-related and } \\
3,900 \text { ha urban forest }\end{array}$ & $\begin{array}{l}9,800 \text { ha: } 5,900 \text { ha } \\
\text { conservation-related and } \\
3,900 \text { ha urban forest }\end{array}$ & $\begin{array}{l}9,800 \text { ha: } 9,200 \text { ha } \\
\text { conservation-related and } \\
600 \text { ha urban forest }\end{array}$ \\
\hline $\begin{array}{l}\text { Guiding principle in choice } \\
\text { of location }\end{array}$ & $\begin{array}{l}\text { Limit impact on income of } \\
\text { professional farmers }\end{array}$ & $\begin{array}{l}\text { Focus on recreational } \\
\text { opportunities for residents of } \\
\text { urban areas with little urban } \\
\text { forest }\end{array}$ & $\begin{array}{l}\text { Focus on increasing or } \\
\text { creating links between forests } \\
\text { with core of ancient forest }\end{array}$ \\
\hline Operational constraints & $\begin{array}{l}\text { Conservation-related forest: } \\
\text { - } 5,600 \text { ha within, } 300 \text { ha } \\
\text { outside special protection } \\
\text { area (SPA) } \\
\text { - preferably on land } \\
\text { belonging to Agency for } \\
\text { Nature and Forest or nature } \\
\text { conservation ngo, or with } \\
\text { hobby farming } \\
\text { Urban forest preferably: } \\
\text { - on land under hobby } \\
\text { farming > 0.5 ha } \\
\text { Both forest types: } \\
\text { - if on professional farmland, } \\
\text { preferably on land with } \\
\text { lowest economic benefits } \\
\text { for food production }\end{array}$ & $\begin{array}{l}\text { Conservation-related forest: } \\
\text { - } 5.600 \text { ha within, } 300 \text { ha } \\
\text { outside SPA } \\
\text { - adjoining forests with core } \\
\text { of ancient forest, regardless } \\
\text { of any farming revenue } \\
\text { Urban forest preferably: } \\
\text { - near centres with the } \\
\text { greatest population density } \\
\text { - strive for clusters of forest } \\
\text { + open green space } \\
>60 \text { ha (less than } 3.2 \mathrm{~km} \\
\text { away) or > } 200 \text { ha (less than } \\
5 \mathrm{~km} \text { away) }\end{array}$ & $\begin{array}{l}\text { Conservation-related forest: } \\
\text { - } 5,600 \text { ha within, } 3,600 \text { ha } \\
\text { outside SPA } \\
\text { - adjoining forests with core } \\
\text { of ancient forest, regardless } \\
\text { of any farming revenue } \\
\text { Urban forest preferably: } \\
\text { - near centres with the } \\
\text { greatest population density } \\
\text { - strive for clusters of forest } \\
+ \text { open green space } \\
>60 \text { ha (less than } 3.2 \text { km } \\
\text { away) or > } 200 \text { ha (less than } \\
5 \mathrm{~km} \text { away) }\end{array}$ \\
\hline
\end{tabular}

Urban forest preferably near population centres whose inhabitants do not have 60 hectares of open green space less than $3.2 \mathrm{~km}$ from their home.

No conservation-related or urban forest expansion in reconfirmed agricultural areas. No forest expansion on unforested land of very high or high biological value. 


\section{Ecological values}

In order to achieve forests of high ecological value through forest expansion, it is important to have new forests bordering on ancient forests. This allows the specific biodiversity of ancient forests to spread into the new forests. In addition, links should ideally be made between existing forests, and new forests should protect ancient forests against external environmental pressures. We compare the ecological values of the three scenarios based on two indicators: forest connectivity and forest morphology.

- Forest connectivity: Of the three scenarios that were tested, Scenario 3 is succeeds best in increasing the area of continuous forest complexes containing ancient forest (see Figure 9).

- Forest morphology: The forest core is the part located more than 50 metres from the outer edge. The higher the proportion of (ancient) core forest to non-core forest, the more likely it is that the forest will provide a suitable habitat for species associated with ancient core forest and the more resilient the forest will be to environmental pressure. Here too, Scenario 3 results in the greatest increase in forest cores with ancient forest. Scenario 2 leads to a greater overall increase in forest cores, as a choice was made in that scenario for clusters of green space of 60 to 200 ha near densely populated areas with little woodland. This provides more opportunities for recreation (see below), but offers fewer opportunities for biodiversity associated with ancient forests.

The two ecological indicators show how goal-oriented spatial control of ecological forest expansion leads to forest complexes with a higher ecological value. When the goal is to preserve the biodiversity of ancient forest, it is advisable to focus on enlarging or linking ancient forests and clustering forest expansion in sufficiently large units.

\section{Social values}

We compare the social values with reference to two indicators: land use changes and the percentage of the population with urban greenery or urban forest in the immediate vicinity.

- Land use changes: Changing the management approach to or expanding green space can have profound effects locally. Those effects are different for each local community. When we compare the impact of forest expansion on different land uses and their stakeholders, we find that the different priorities in the three scenarios also cause differences in land use changes. Figure 10 shows how the different priorities in the three

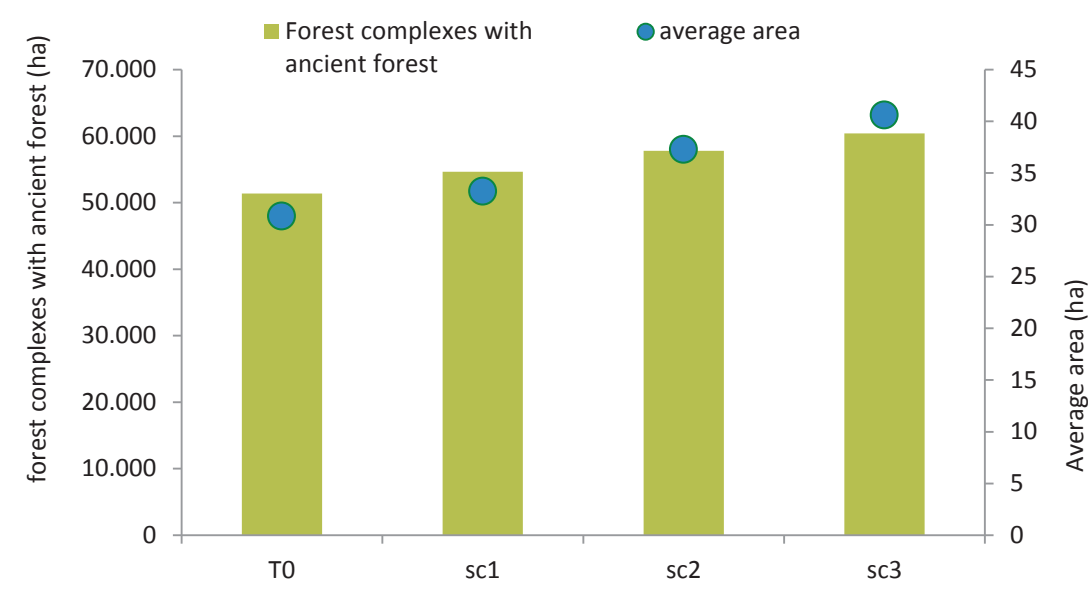

FIGURE 9

The third scenario leads to the greatest increase in forest complexes containing ancient forest (left-hand $Y$ axis). It also results in forest complexes with a larger average area (right-hand $\mathrm{Y}$ axis), so that these forests are more resilient to external pressure. 
afforestation scenarios lead to a variety of land use changes. Locally these differences may be even more pronounced.

\section{- Percentage of population near urban greenery or} urban forest: There are no laws or policy norms that determine how close people in Flanders should live to green space. What is clear is that having green space nearby is necessary for a happy and healthy lifestyle. Today, almost 20 percent of the population have no access to urban greenery (i.e. 60 ha less than $3.2 \mathrm{~km}$ away), and 30 percent have no access to urban forest (i.e. 200 ha less than $5 \mathrm{~km}$ away). Of the three cases of forest expansion studied, Scenario 2 brings about the greatest increase in urban greenery and urban forest near densely populated, poorly forested areas. The fragmentation of forest expansion in Scenario 1 ensures that in this scenario, the smallest number of Flemish people have urban greenery or urban forest near their home.

\section{Economic values}

We investigated the impact of forest expansion on the supply of seven ecosystem services: food production, timber production, air purification, erosion prevention, flood risk reduction, carbon storage and green space for recreation. For six of those services, it was possible to estimate the economic value of the increased or decreased service supply. We confine ourselves here to an analysis of the economic benefits for Flanders as a whole. Some notable findings:

- In all three scenarios, forest expansion results in an increase in the supply of five of the six ecosystem services. Only food production decreases, because the forest expansion always takes place in part on farmland (See Figure 11).

- The total net benefit that the six services yield together is positive in the three scenarios. In other words, the economic value of the increase in timber production, air purification, erosion prevention, carbon storage, and recreation is greater than the economic cost of the lost agricultural revenue. Figure 11 shows the economic value of the change in six ecosystem services for the three forest expansion scenarios.

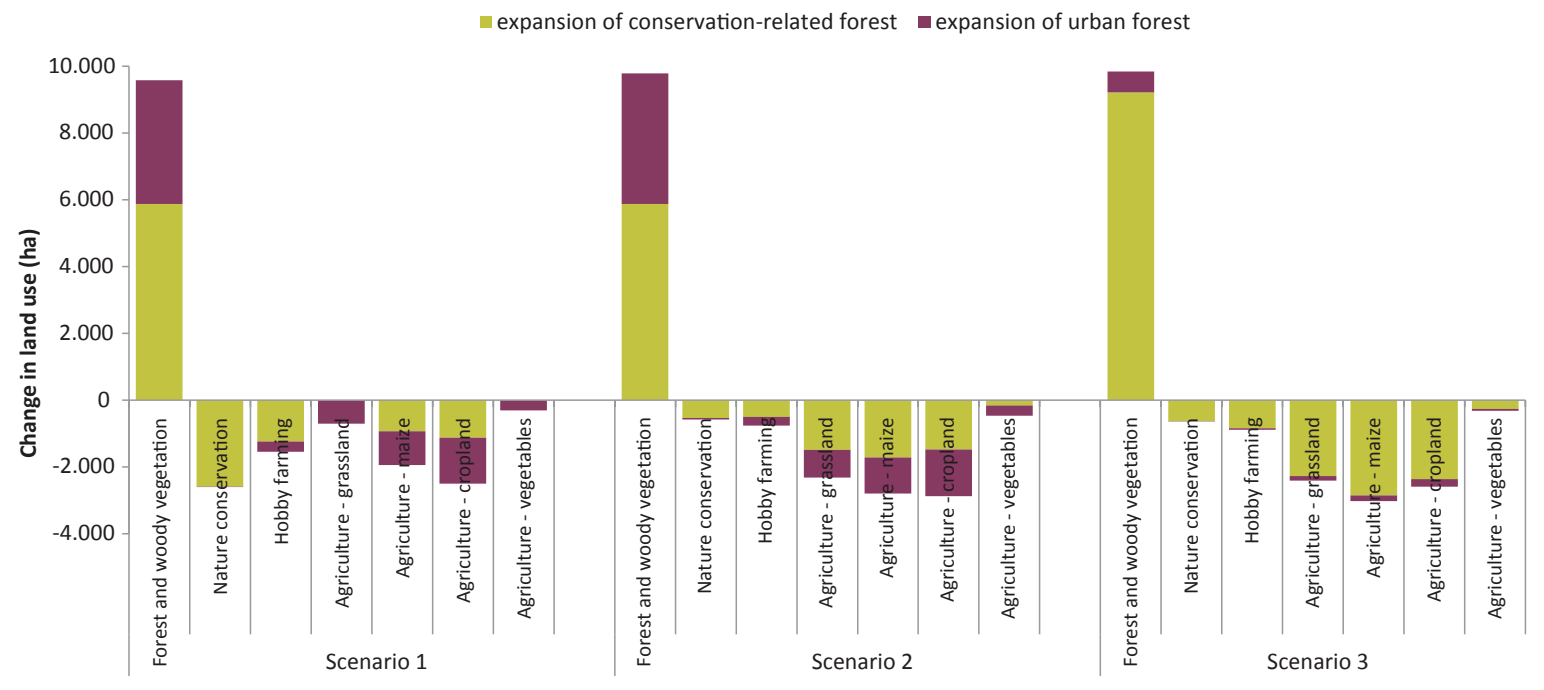

\section{FIGURE 10}

Depending on the values on the basis of which a forest expansion scenario is developed (see Figure 8 and Table 1), the same area of forest expansion can result in very different land use changes. This figure shows which land uses in the three scenarios undergo a diminution of area for the benefit of conservation-related forest or urban greenery and urban forest. 


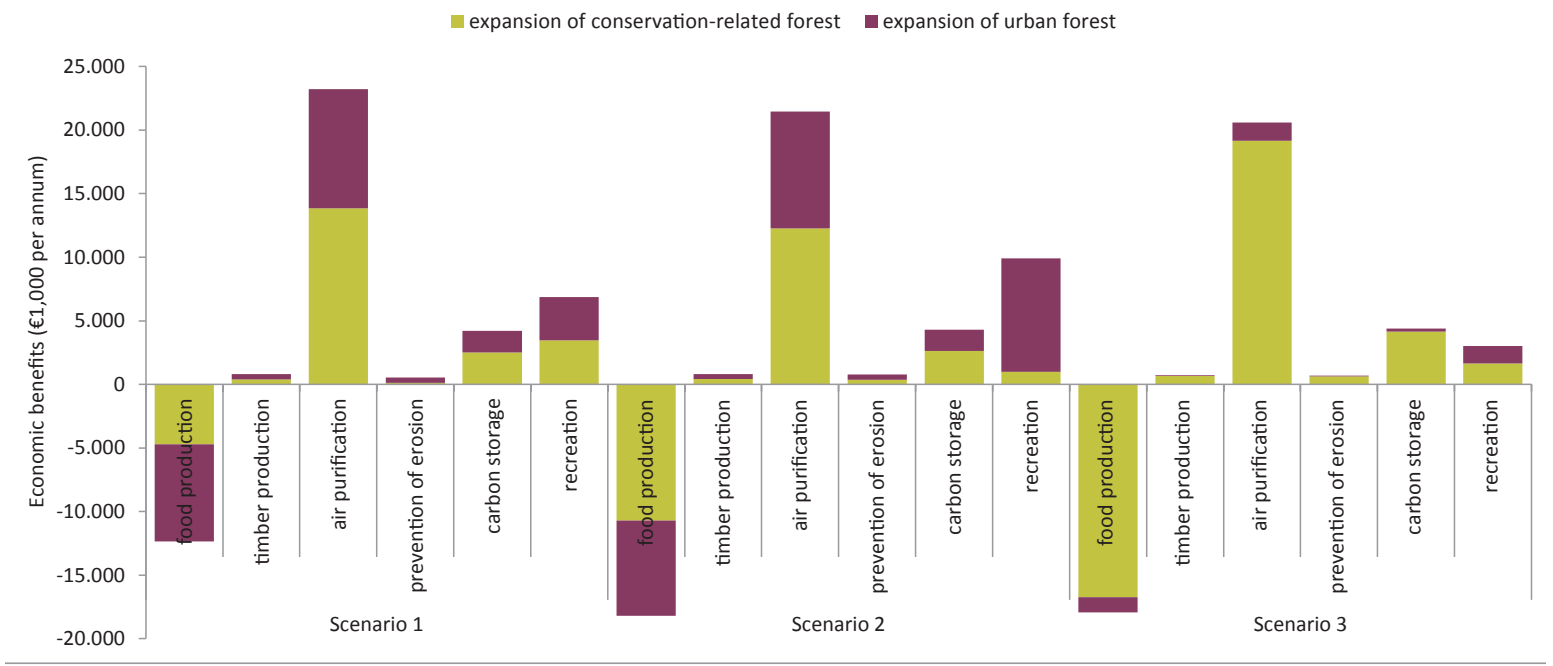

FIGURE 11

In the three forest expansion scenarios, the economic benefits of five increased ecosystem services turn out to be greater than the economic cost of the decrease in food production. On the basis of the existing policy instruments and market mechanisms, however, these benefits would not serve farmers, who would see their income decline as a result of forest expansion.

An important caveat here is that there are currently few if any policy instruments or other institutional mechanisms to convert the decrease or increase in ecosystem services into compensatory financial flows. Only changes in the supply of commercialised ecosystem services such as food and timber production directly generate impacts on revenue.
An owner or user of farmland who exchanges his crop for an urban forest, for example, would generate insufficient financial income to make the conversion economically viable.

In Muizen Forest in Ranst, new forest adjoins a core of ancient forest. This enables characteristic ancient forest plants such as wood anemone to spread in the new forest.

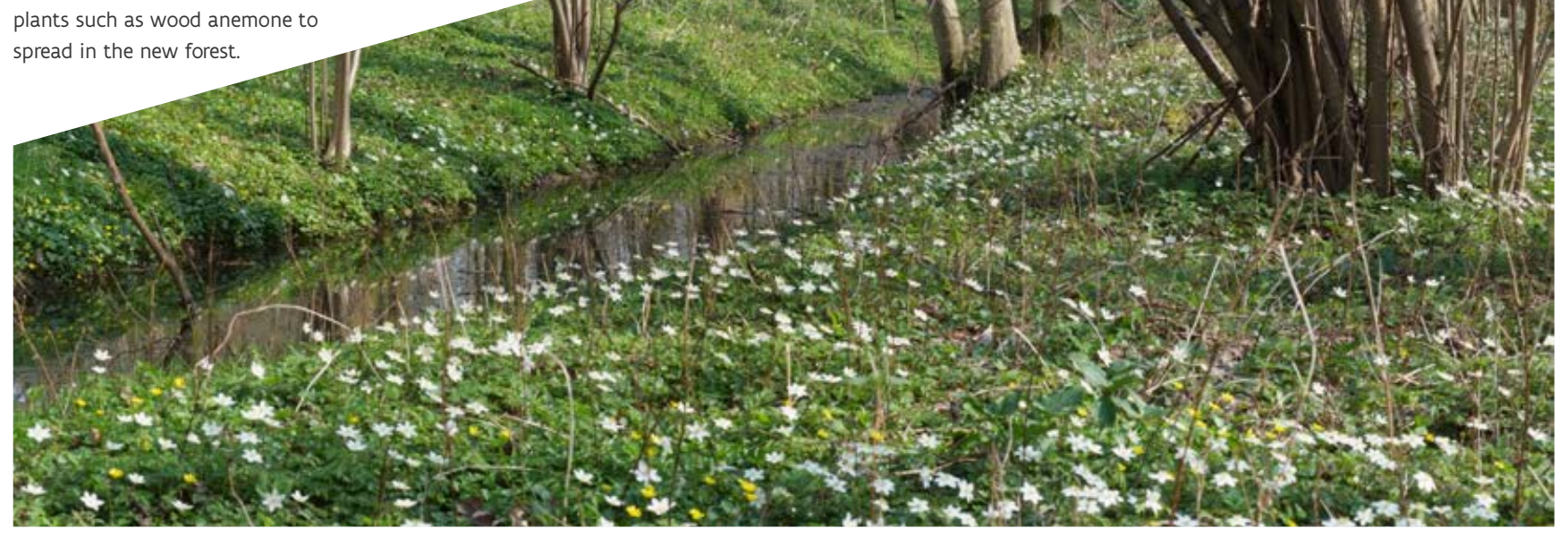




\section{Conclusions and recommendations}

- Where integrated valuation is used, alternative scenarios or policy options are compared with one another and assessed on the basis of a number of ecological, social and economic values. A variety of value types are placed side by side.

- Relational, sociocultural values refer to what we consider to be a good and decent life, including on the basis of our relationship with our environment and the landscape. Optimising these values is relevant only insofar as fundamental values, which relate to human survival, are satisfied.

- Economic valuation calculates monetary exchange values. This assumes that what is valued can be replaced by something else of equal or greater monetary value. Economic exchange values offer no information on how best to deal with irreversible ecological processes, with the loss of unique or irreplaceable sociocultural values, or with the moral, intrinsic value of living organisms.

- Integrated valuation can provide information that helps with weighing up decisions about the characteristics of ecosystems (such as areas and populations), of ecosystem services (such as air purification or food production), or of other services delivered by anthropogenically altered socialecological systems (such as transport, employment and housing).

- All of the three scenarios studied for 10,000 hectares of forest expansion in Flanders were found to realise a number of ecological, social and economic values. In each case, this was at the expense of other land uses and their associated values, including professional farming, hobby farming and grassland with nature management.

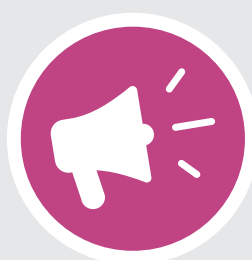

- For the conservation of EU-protected forest biodiversity, the scenario that focuses on enlarging and connecting complexes with ancient forests offers the best prospects.

- Around 20 percent of the population currently have no access to urban greenery in their local area, and around 30 percent have no access to urban forest in their local area. On the basis of the three scenarios studied, 10,000 hectares of forest expansion can reduce these figures to 9 percent for urban greenery and 23 percent for urban forest. These projections do not take population growth or increasing urbanisation into account.

- As a result of the increased timber production. air purification (capture of particulate matter), prevention of erosion, climate regulation (carbon storage) and recreation, the economic benefits from 10,000 hectares of forest expansion to Flanders as a whole were found to be greater than the loss of income through foregone food production. These values may differ significantly at the local level.

- The social and economic effects of forest expansion are distributed very unevenly among different social groups. The compensation of disadvantaged groups is only possible to the extent that the studied values (e.g. land use, professional activities or income) are regarded as replacable or exchangeable. Whether this is actually the case is an ethical question.

Like to know more about this subject? You can read all about it in Chapter 4 of the Technical Report. 
Suppose everyone realised all the things that nature does for us... Without a doubt, we would look at nature differently, and this would have an effect on how we treated it. At present, nature is still all too often seen as a threat to our prosperity. To reverse that perception, we must learn to talk more eloquently about what nature does for us. This is why, together with the Agency for Nature and Forest, the Department for the Environment, Nature and Energy and a whole series of other partners, we have developed a clear ecosystem services language.

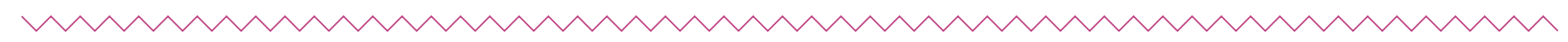

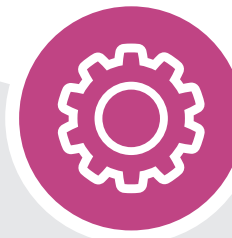

\section{How did we proceed?}

- We interviewed various stakeholders and prospective users of the ESS language. In these interviews, we asked about the terminology they used, their experience of communicating with and about ecosystem services and points to consider for the development of a clear ESS language.

- A first version of the language was presented at a large stakeholder event. During several interactive sessions, the participants at the event gave feedback and suggestions. Based on this, we wrote a basic narrative and four variants on it.

- Anyone who wishes can now start using this language. Naturally, the language will evolve further through use Various communication tools are still being developed to assist people in using the language.

\subsubsection{Ecosystem services: a compelling narrative}

Most of what is said about nature and biodiversity today can be more or less boiled down to one of these four messages:

1) Nature is losing its richness and is under threat.

2) Nature deserves our respect and admiration.

3) Nature has an economic value. We depend on biodiversity

for our prosperity.

4) Everyone can do something to help nature and biodiversity

Reporting on nature often focuses on what a poor state it is in. That message, which is also often conveyed in specialised contexts, rarely prompts people to take action. Moreover, if it is repeated too often, there is a risk of people becoming indifferent to the message. The consequences of biodiversity loss for our prosperity are not particularly tangible at present. If we want to arouse people's enthusiasm for taking action on behalf of nature and biodiversity, we need to paint a clearer picture of the benefits it provides them.

Coverage is already being given of the benefits of nature for humans. For example, the Agency for Nature and Forest spotlights the multiple benefits of nature in the city in its publication Investeer in groen, winst verzekerd (Invest in nature, profit guaranteed), and the Forest NGO BOS+ draws attention to the value of a forest in its 'Dokter Bos' (Doctor Forest) campaign. Yet this kind of communication is mostly ad hoc. And although the ecosystem services conceptual 
framework originally had a markedly educational character, many regard it today as a technical and scientific framework. It has evolved into an analytical framework with numerous applications and its own terminology which is often abstract in character. In order to communicate effectively about what nature does for us, some translation work is needed. We need a clear ESS language - one which is not off-putting, but which encourages people to talk about how it pays to invest in nature and how nature can often provide a solution to our problems.

\subsubsection{One common narrative, four variants}

We have developed a clear language to make it easier to communicate about the benefits of nature. This language needs to be easy so that everyone can understand it. This is important, because we want people to start using the language to communicate with a broad public: colleagues, government agencies, partners, stakeholders in area-specific projects and so on. For quite a number of ecosystem services and several related terms, we have devised an alternative terminology that is more intuitive and thus clearer. We have written five narratives in the new language: a basic narrative and four variants, each in a short and a long version.

\section{TESTIMONIAL OF JORIS GANSEMANS, HEAD OF THE COMMUNICATION SERVICE AT NATUURPUNT (THE LARGEST FLEMISH NATURE NGO)}

$\checkmark 6$ Imagine if it became absolutely commonplace for the impact on nature to be taken into account whenever a political decision was made. For the authorities, farmers and entrepreneurs to be constantly on the look-out for possibilities to use nature to solve problems. Wouldn't this give both humans and nature an incredible boost? I'm convinced that it would. But to ensure that policymakers and businesses see nature as a solution rather than a problem, they must have a language available with which to engage in dialogue about nature. Up to now, that language has not existed.

$6 \mathbf{6}$ In the academic world, research into nature's services to the economy and society is already at an advanced stage. Yet the insights still remain behind closed doors to an excessive degree. Ecosystem services? Intrinsic value? Monetisation? The jargon, the complexity of the message and the examples from remote countries make the debate inaccessible. $\mathbf{6}$ It's common knowledge that you have to adapt your message to your target audience. You talk differently to your children or grandchildren from the way you do to your colleagues. Yet we forget this when we are talking about our discipline. We need to talk to decision makers about the benefits of nature in a language they can understand, otherwise we saddle ourselves with an enormous handicap. However, there is a potential pitfall: we must avoid talking exclusively about the utility of nature. The big challenge is to talk about economic and social benefits while continuing to defend the value of nature in itself.

$\checkmark 6$ The trick will be to connect the economic story with emotional messages for a wide audience. You gain support for conservation by communicating about wonder, awe and joy - in short, about emotions. If we can transform the idea of ecosystem services into a language that is compatible with this, this will represent a major step forwards. INBO is taking the first step in this initiative. And as you know, the first step is always the most important" 
The basic narrative talks about what nature does for us: it supports our prosperity and well-being. It also conveys the message that investing in nature is often cheaper than the technical solutions that we devise. The four variants convey exactly the same message as the basic narrative, but focusing on a specific environment: the city, an agricultural area, a business park and a river valley. Each narrative - the basic text and the variants - has a fixed structure. First, a description is given of nature and its richness. This is followed by an overview of the various benefits that nature gives us. Finally, each text includes a call to action.

\section{More accessible language}

The language and the narratives we create must be recognisable and clear. The general public must understand the terms intuitively. We have therefore opted for simple terms using common words. A few examples:

- Ecosystem services: benefits of nature

- Air quality regulation: natural air purification

- Local climate regulation: cooling

\section{Zooming in on the narratives}

Each narrative about ecosystem services that we have developed exists in a short and a long version. Below, we give the example of the short variant about benefits of nature in business parks.

\subsubsection{Ambassadors of an ecosystem services language}

This project has been a collaborative venture from start to finish. The culmination of this collaboration so far was a stakeholder event in October 2016 at which the project and a first version of the new language were presented. With input from the stakeholders, we revised the vocabulary and developed the narratives. These stakeholders will continue to play an important role in the future: they will become the ambassadors of the new language. The idea is that they will assimilate the language, use it as much as possible and encourage others to do the same. What is most important is not the new vocabulary, but the message of the narrative and the way we deliver that message: clearly.
More and more businesses are opting to design their environment in a more natural way. This is valuable for all kinds of plants and anals, which are better able to survive there but also has many benefits for humans.
Employees prefer working in a natural environment They become ill less often and are therefore more productive.
A natural environment makes businesses more attractive to employees, customers and the local area.

Property on business parks with a nature-

The more nature there is in a business park, cases, introducits of nature there are. In many is actually less expensive maintaining nature and maintaining manicured introducing clipped box hedges. Thus, nature not neatly more makes business parks moture not only secure, but is often cheaper too. pleasant and oriented design is more valuable and the vacancy rate is lower. By looking after their environment, businesses acquire a more sustainable image.

sustainable image.
Trees and shrubs purify the air and reduce and noise. They also make sure to dust water is retained and can sure that rain or evaporate. In this way penetrate the soil rainwater from causing wature prevents some business owners even use plants to purify water. The animals use plants to are useful too. For instance that plants attract pests such as rats and mice. A naturally designed business park is mor secure, because people walk or cycle there outside office hours too. Investing in nature also offers numerous opportunities for working with the neighbourhood and the local government. 
We have taken an important first step, but we are very much at the beginning of this process. In 2017 we will support anyone who wants to work with this language. To make the language more powerful, we are looking for good, personal stories and vivid images that allow us to recount the general narratives that have been defined in a compelling way. On a website, we want to share all available material, including practical applications and experiences of the partners who use the language. In this way, we hope to inspire people at all levels and encourage them to communicate comprehensibly about what biodiversity does for us. We would like to work with you on all these things.

The project will only be successful when people start using the language and learn to talk about what nature does for us in a clear way. The ultimate goal, however, is to raise awareness that investing in nature is neither expensive nor an obstacle to our prosperity and well-being. The message gradually needs to get through to everyone that what is good for nature has other benefits too: it is good for our health, it brings people together, it stimulates the local economy and so on. This realisation will lead to better projects and better policies.

During the stakeholder event participants got down to work with great enthusiasm. Their input was very important for the development of a clear language.

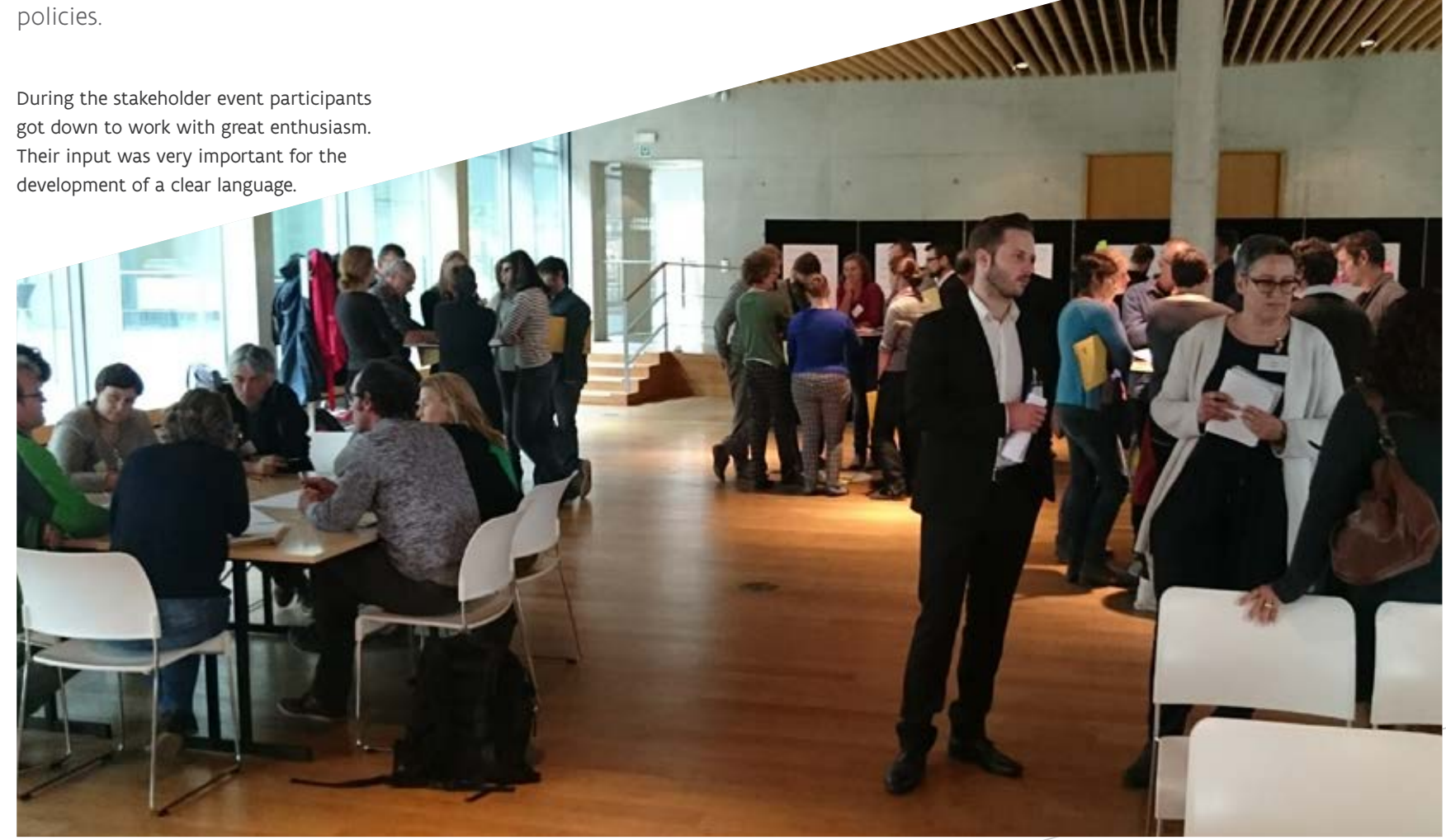

In the development of this language we have benefited from the cooperation of many organisations: the Agency for Nature and Forest, the Department for the Environment, Nature and Energy, the Flemish Spatial Planning Department, the Flemish Land Agency, the Flemish Environment Agency, the Flemish Public Waste Agency, the Department of Agriculture and Fisheries, the Heritage Agency, the Innovation and Entrepreneurship Agency, Waterwegen en Zeekanaal NV (the Flemish government agency for inland waterways), Inverde, the Regional Landscapes, the Bosgroepen (associations of forest owners and lovers), the five Flemish provinces and several of their nature education centres, the municipalities of Ghent, Antwerp, Leuven, Geel and Meerhout, the Association of Flemish Cities and Municipalities,

Natuurpunt (a nature NGO), the Bond Beter Leefmilieu (an environment association), Kempens Landschap, the Farmers' Union, Bioforum, the Research Institute for Agriculture, Fisheries and Food Research, the Flemish Institute for Technological Research, IGO and Sibelco.

Like to know more about this subject? You can read all about it in Chapter 6 of the Technical Report. 

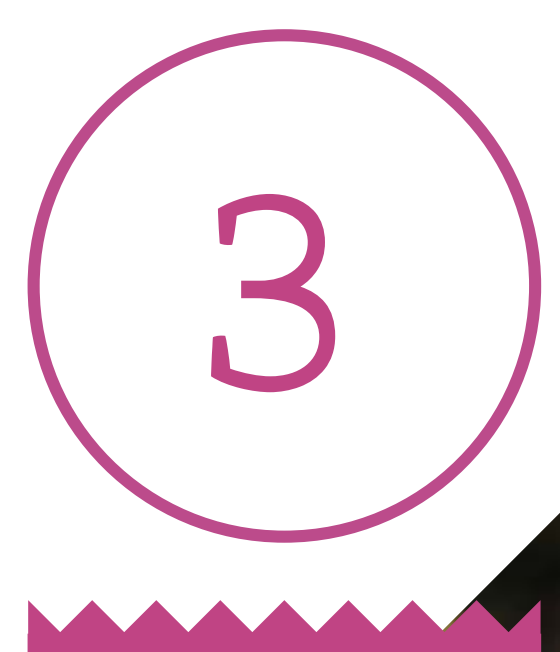

\section{PRACHICAI}

In four practical examples we apply the ESS approach and its building blocks, taking a close look at afforestation and deforestation, the farm, the Regional Landscape Rivierenland and the built environment.

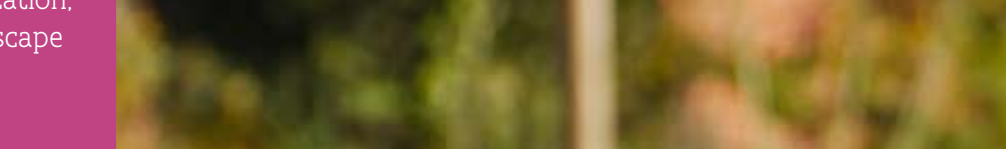

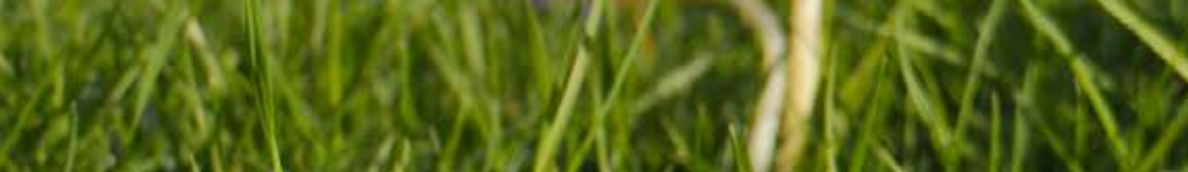

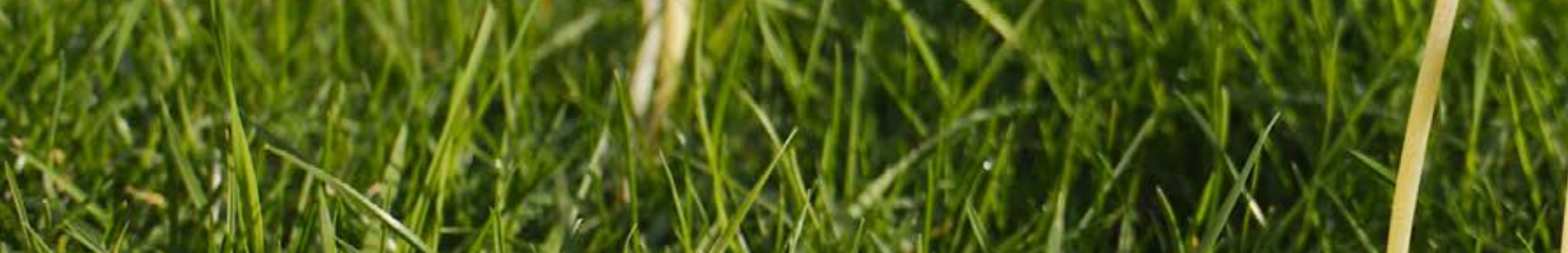
$2=20$ -

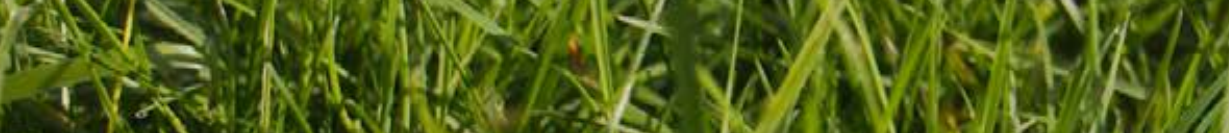
S.

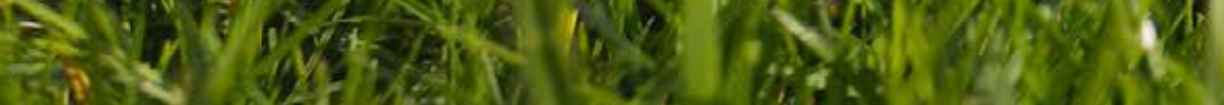

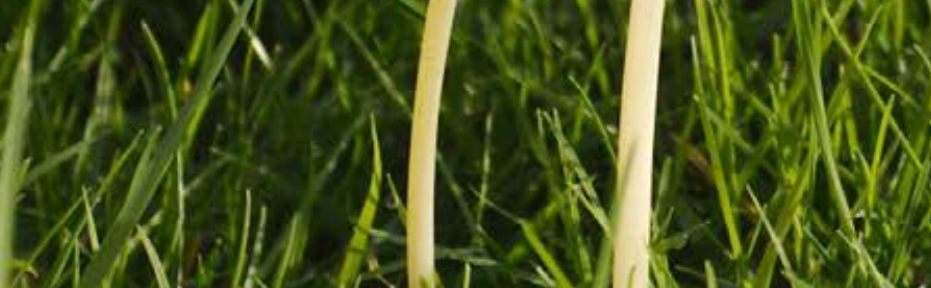
(1/2) 5. 


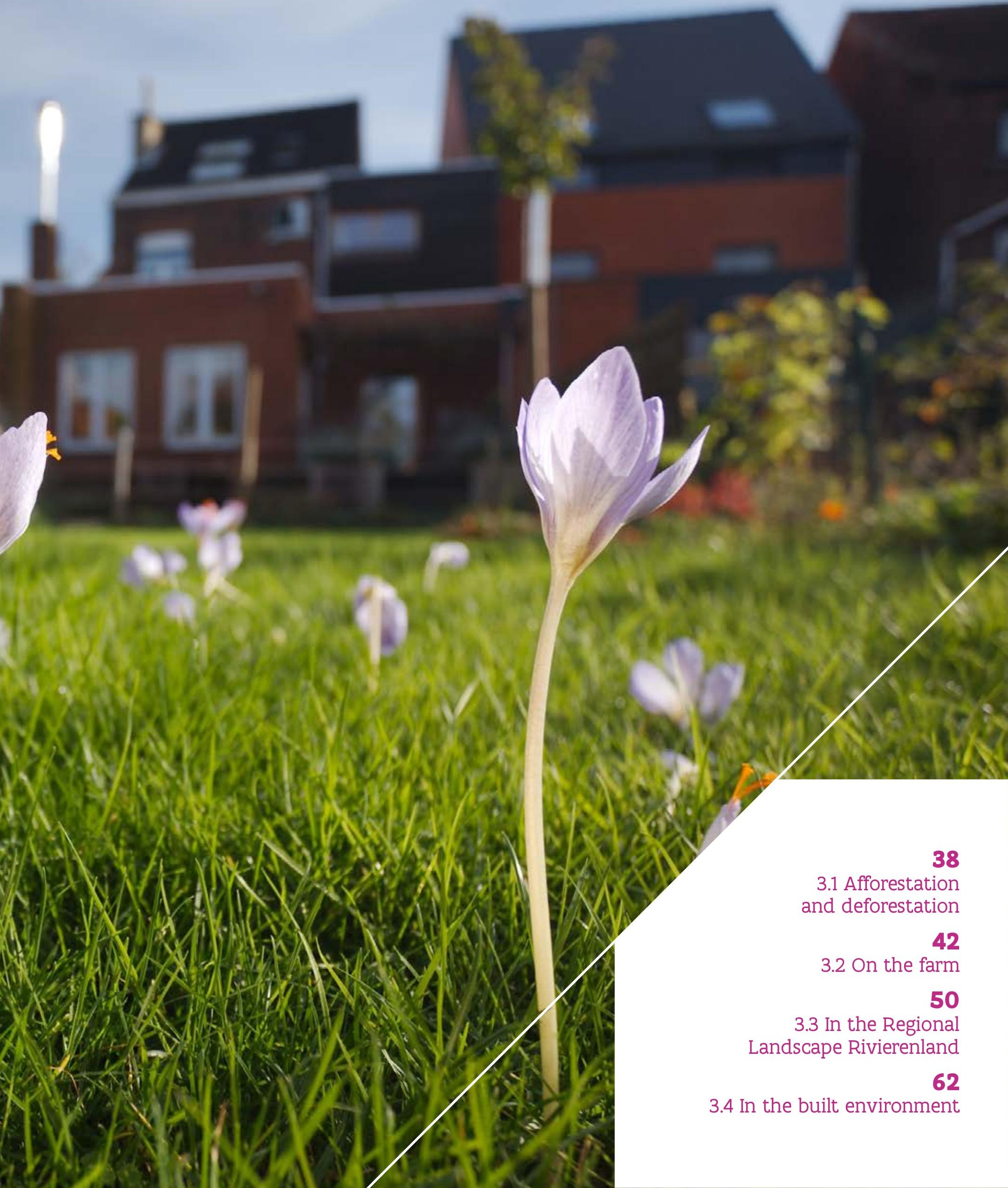




\section{Forest ecosystem services mapped}

We take as our basis maps showing the various ecosystem services of the forest ecosystem. From this we work out what the geographical differences are in the provision of ecosystem services. Whether forest ecosystem services are provided in a particular place may depend on differences in soil characteristics, population density or terrain. The provision of ecosystem services also depends on the forest type. For example, a coniferous forest may provide different services from a deciduous forest.

In the assessment framework for deforestation we use ecosystem service maps that show the current land use and (if available) the existing policy measures. Based on these maps, we can estimate what ecosystem services are provided by the existing forest. In order to assess afforestation, we use maps that reflect the (physical) potential of a particular location for the different services. These provide the best indication of how suitable a given piece of land would be to provide the ecosystem service(s) if it were forested.

\section{Selection of ecosystem services}

For six services that are relevant to the forest ecosystem we can use maps to establish the assessment framework for deforestation and afforestation. These services are 1) water production, 2) regulation of air quality, 3) regulation of erosion risk, 4) timber production, 5) the production of energy crops and 6) green space for outdoor activities. For the assessment framework for afforestation we can also use a map for the conservation of soil fertility. And for the framework for deforestation, we use a map for the regulation of global climate. For six other ecosystem services that are relevant to forest, full and detailed maps are not (yet) available for Flanders. These are 1) regulation of noise nuisance, 2 ) regulation of water quality, 3) regulation of flood risk, 4) pollination, 5), pest control, and 6) production of wild game.

\subsubsection{New assessment frameworks}

The use of the new assessment frameworks results in a so-called ecosystem service factor or score (ranging from class 0 to class 5). In terms of orders of magnitude, this is roughly comparable with the current forest compensation factor.

\section{Three types of framework}

The basic framework for forest compensation and afforestation gives each ecosystem service equal weight. We have also created seven specific assessment frameworks, in each of which we give one ecosystem service four times more weight. On the maps you can see the locations that can provide a particular service to a high (or low) degree. This allows policy-makers to place emphases. For example if they mainly want forest in a place where many people live. they can use the assessment framework that highlights 'green space for outdoor activity'.

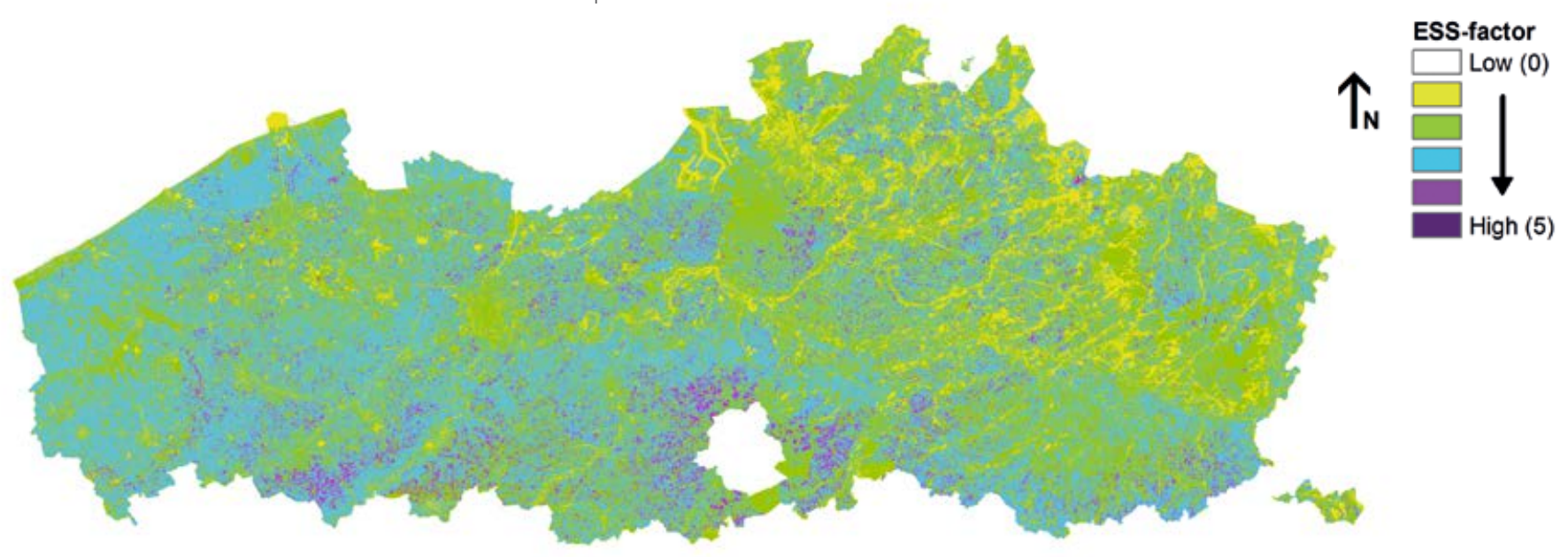

FIGURE 12

ESS factor for assessing afforestation in which the ESSs concerned are given the same weight

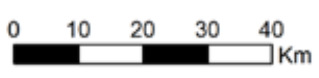




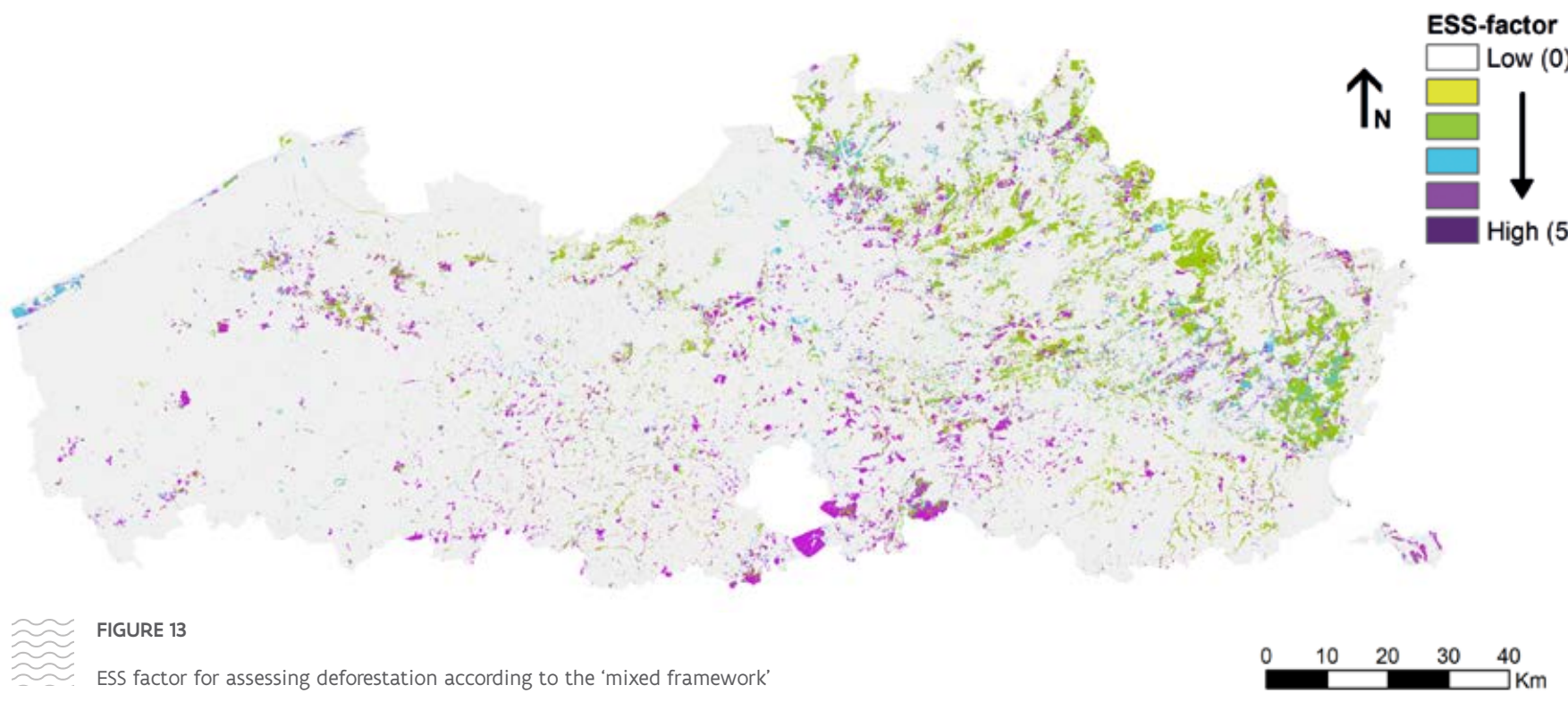

To assess deforestation, we also put together a mixed

framework. Half of this framework relates to the forest type (via the forest compensation factor), while the other half relates to the seven ecosystem services, each of which is given equal weight.

\section{A few trends}

The two extreme ESS factors, 0 and 5, rarely occur. Whether an area is assigned a factor of 1, 2, 3 or 4 depends on the assessment framework. The choice of framework thus allows certain emphases to be promoted. In this way, regional characteristics and differences are clearly revealed. A few examples:

- From the map that gives more weight to the ecosystem service 'timber production', it is clear that there are areas that are more or less suitable for supplying timber. If you plant a forest in a sandy area, the timber yield will be lower than in an area with moist, heavy soils. The map focusing on 'water production' shows the reverse. In sandy areas, a forest can 'produce' more water than a field. The presence of forest ensures more infiltration into the soil. However, a forest also causes evaporation, which is why grassland is a better choice if you are mainly interested in water infiltration.
- In densely populated regions, there is more demand for greenery for a range of outdoor activities. Forests can meet this demand. If you want to fell forest in these regions, the new assessment frameworks indicate that the highest rate of compensation should be due for such forest.

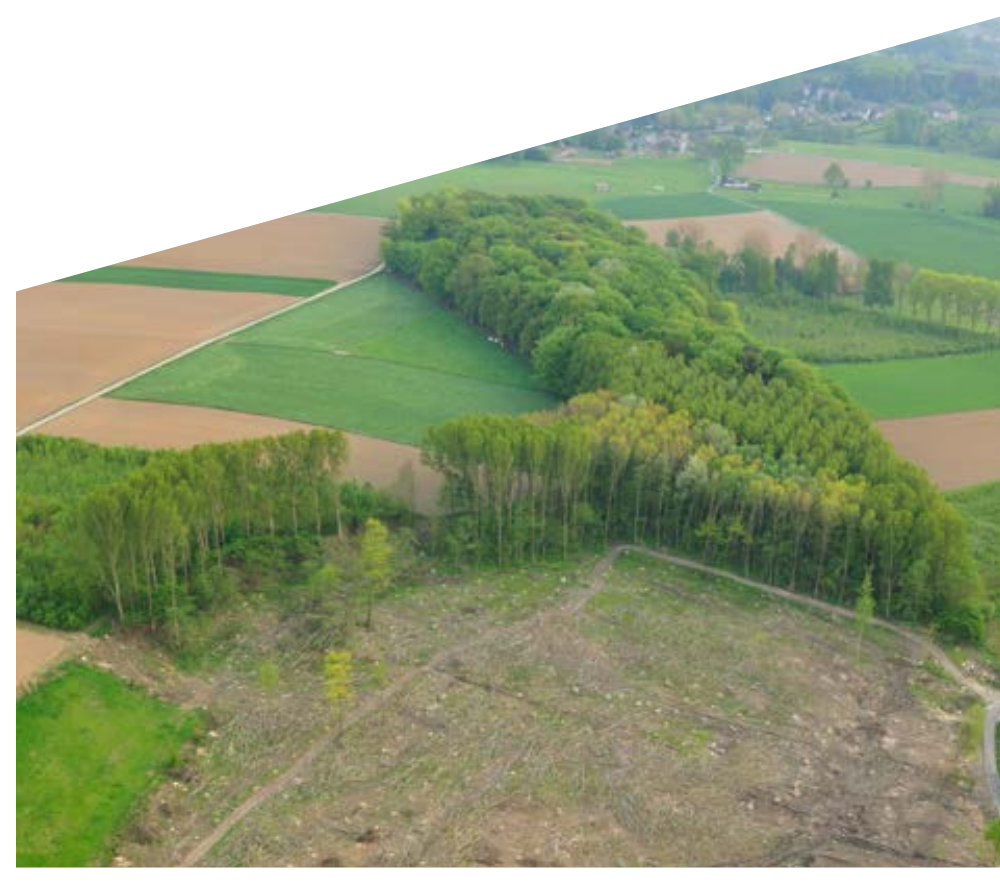




\section{Conclusions}

We have compared the results we obtained with the new assessment frameworks with the results of the current policy frameworks. The main conclusions are as follows:

- While the seven individual ecosystem services clearly differentiate according to the location (e.g. sandy soil versus heavier soils, densely populated areas versus sparsely populated regions), the differentiating capacity of the ESS frameworks is very limited. When the seven ESS maps are combined, the differences are blurred and we end up with fairly similar values throughout Flanders. More than half of Flanders falls within one or two (depending on the framework) of the six ESS factors. The differentiation is slightly greater in most ESS frameworks in which specific ecosystem services are given more weight. The deforestation frameworks also provide little variation.

\section{- In two of the specific assessment frameworks}

there is no connection between the ESS score and forest type. In the other frameworks, there is a slight or a clear link between the ESS factor and the forest type. This link is most evident in the mixed framework. From the results of the mixed assessment framework we can deduce that forests with a high forest compensation factor are also more likely to have a high ESS factor. This pattern is not found in the basic assessment framework. When the mixed framework is applied, it thus takes account of a forest's natural values as well as the ecosystem services it provides, with higher compensation charges for more ecologically valuable forest.

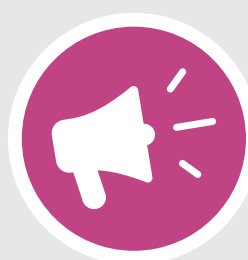

- If we apply the new frameworks to some forests that have recently been cleared, we see fairly large differences between the results of the different frameworks and between the frameworks and the forest compensation factor which is actually applied. The patterns are similar, however: a forest receives either a high, low or average score across all frameworks.

- From the various assessment frameworks for afforestation, we can deduce that a relatively small area of Flanders is important for the ecosystem service 'regulation of erosion risk'. On the other hand, we can see that this seems to be the service most provided by the existing forests in Flanders. A relatively large area of Flanders can provide the ecosystem services 'regulation of air quality' (limited to particulate matter), 'timber production' and 'production of energy crops' if afforested.
Like to know more about this subject? You can read all about it in Chapter 5 of the Technical Report. 


\subsection{ON THE FARM}

The main function of agricultural land in Flanders is the production of food or materials (energy crops and ornamental plants). However the soil can also deliver a whole range of other ecosystem services. If farmers adapt their management methods, they can increase this potential. The area of farmland in Flanders is large, which means that the impact on the overall supply of ecosystem services can be considerable. The Flanders REA-P takes a close look at a number of promising measures on the farm.

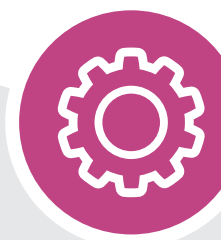

How did we proceed?

- We asked the Research Institute for Agriculture, Fisheries and Food Research for a summary of the results of their study of ecosystem services in agricultural areas.

- We supplemented these results with other relevant output from Flemish research or research relevant to the Flemish situation (e.g. research carried out in a region with comparable climatic conditions).

- Based on data and expertise from the Land and Soil Protection, Subsoil and Natural Resources Service (ALBON) of the Flemish government, we were able to take account of the effects on the ecosystem service 'regulation of erosion risk'.
3.2.1 Towards adapted farm management

Grassland, cropland and maize, fruit and vegetable plots are essential to our food supply. To increase the yield per hectare, the modern farmer uses technical aids such as fertilisation, drainage and the use of plant protection products and pesticides. The use of these techniques also affects other ecosystem services, often negatively. Greenhouse gases are implicated in climate change, drained soils jeopardise water production, the water quality is adversely affected by nutrients that find their way into it and the soil becomes less fertile due to a decreasing carbon stock.

By managing their lands to take these effects into account, farmers can increase the supply of ecosystem services. Even individual measures can yield large gains; a combination of measures reinforces that effect still further. Much of Flanders is taken up with farmland, so changes in farm management have a great effect on the overall supply of ecosystem services in Flanders.

In Flanders REA-P, we examine two types of measure. The first type relates to the shift towards agro-ecological farming or organic farming. In the literature, these measures are typically emphasised as the solution to the shortage of ecosystem services. However, these farming methods are associated with a decrease in food output. In this report we therefore also consider a second type of measure. 
Measures of this second type increase eco-efficiency without decreasing food output. All the measures examined are promoted by the Flemish Government and used in the Flemish agricultural sector.

\subsubsection{Agro-ecological cultivation systems and organic farming}

More and more farmers are making space for nature once more and wholly or partly converting to agro-ecological or organic farming. Extensification is integral to these farming methods. Because this form of agriculture is less intensive, it has a lower impact on the environment and nature. Various measures can be taken to extensify farming. We highlight a few of them: 1) grass strips, 2) the establishment of field margins with hedges or rows of trees and 3) agroforestry.
Grass strips that serve as a buffer zone are an efficient way of preventing eroded soil, which includes plant protection products and/or nutrients, from entering neighbouring plots or surface water. They also reduce the amount of sediment in surface water. A grass strip is therefore good for water quality. Grass also has a positive effect on global climate, as more carbon is stored in grass than in arable land. On the other hand, a grass strip occupies space that could be used for crop-growing, which means a reduction in food output.

The effect of this measure depends on the width of the grass strip. A grass strip 5 metres wide reduces nitrogen and phosphorus run-off by 50 percent on average. With a strip 10 metres wide, nitrogen run-off decreases by 82 percent and phosphorus run-off by 73 percent.

Grass strips are strips sown with grass or herbs on the edge of a field. They may occur spontaneously or be purposefully created. Roughly speaking, we can distinguish between two types: grass strips with a natural function which encourage biodiversity and grass strips with a buffer function.

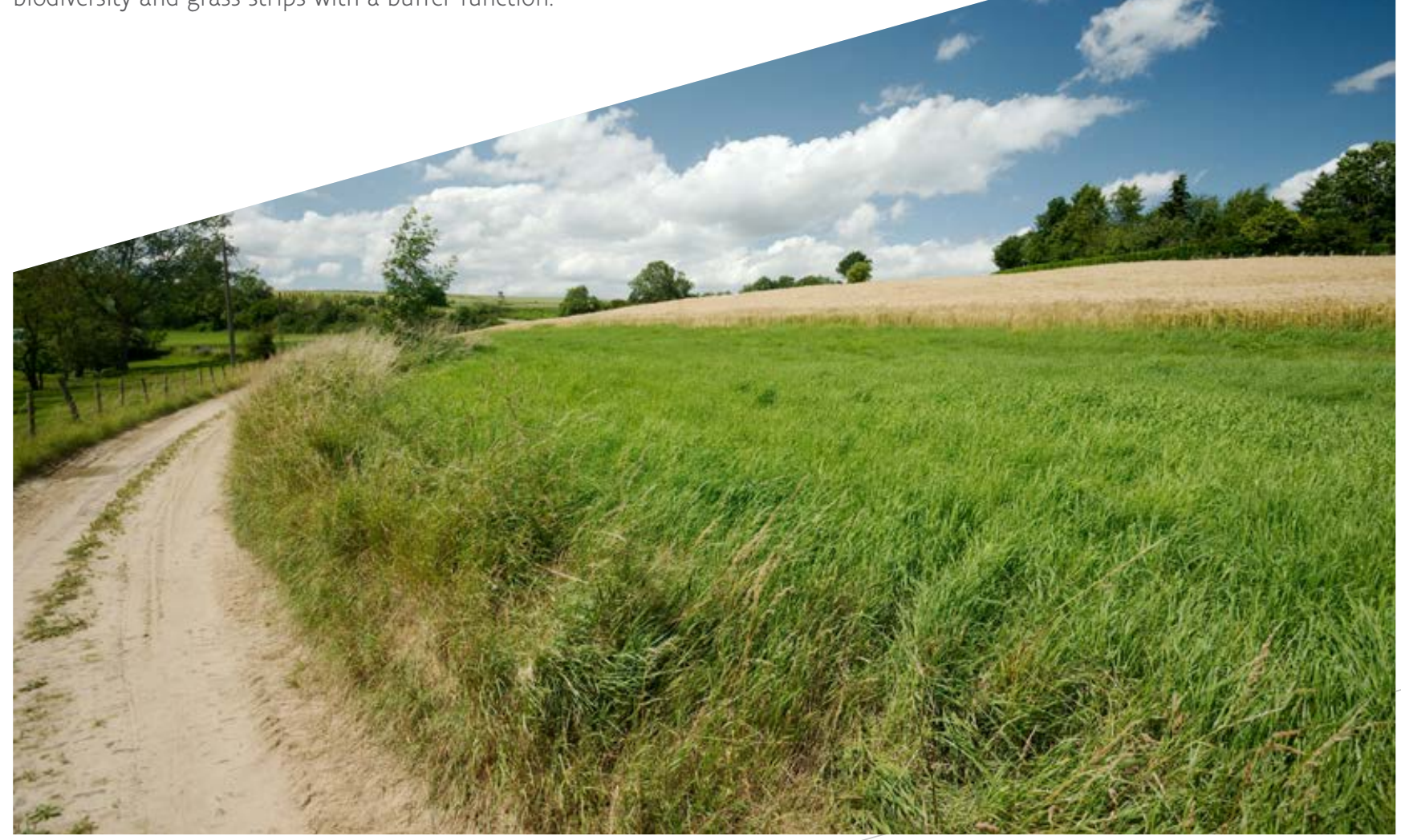


We see similar results with the establishment of field margins with hedges or rows of trees and agroforestry - the two other measures that we examined. Both measures have a positive effect on soil fertility, water quality and global climate. However, they also occupy space that the farmer then cannot use to produce food, although in agroforestry total output (of food, wood and energy crops) does increase.

\subsubsection{Measures to improve eco-efficiency}

Farmers can use certain measures to increase the ecoefficiency of their land. Per unit area, the supply of ecosystem services increases without food production being adversely affected. We scrutinised the following measures: 1) reduced tillage, 2 ) the use of compost or manure instead of conventional fertiliser, 3) the use of green cover, 4) the use of grass and clover and 5) rotation farming of cropland with grassland. We focus here on reduced tillage.

With reduced tillage, the farmer does not plough the soil. but tills it less intensely or deeply. This method has less impact on the soil structure and protects the soil surface. The circumstances are at least as important as the type of soil treatment here. For instance, soil that is too wet will always become more compact if it is worked, and even harvesting is detrimental to the soil structure in wet weather. Reduced tillage requires major alterations to farming practices. Not only do you need different machinery and techniques; it also involves a different way of sowing, tilling the land and harvesting.

Reduced tillage reduces erosion by 40 percent on average. If the technique were applied to all arable land in Flanders, only a quarter of the current erosion would occur. In combination with green cover, this decrease would be as much as 60 percent.

The technique has hardly any impact on the fertility of the soil. It does not increase the nutrients, but redistributes them in the soil. For instance, phosphorus becomes more available, making plants start growing faster.
On average, reduced tillage has only a small effect on food output. The same is also true of the other measures examined: the use of compost or manure instead of nitrogen fertiliser, the cultivation of green cover, crop rotation of cropland with grassland and the cultivation of grass and clover.

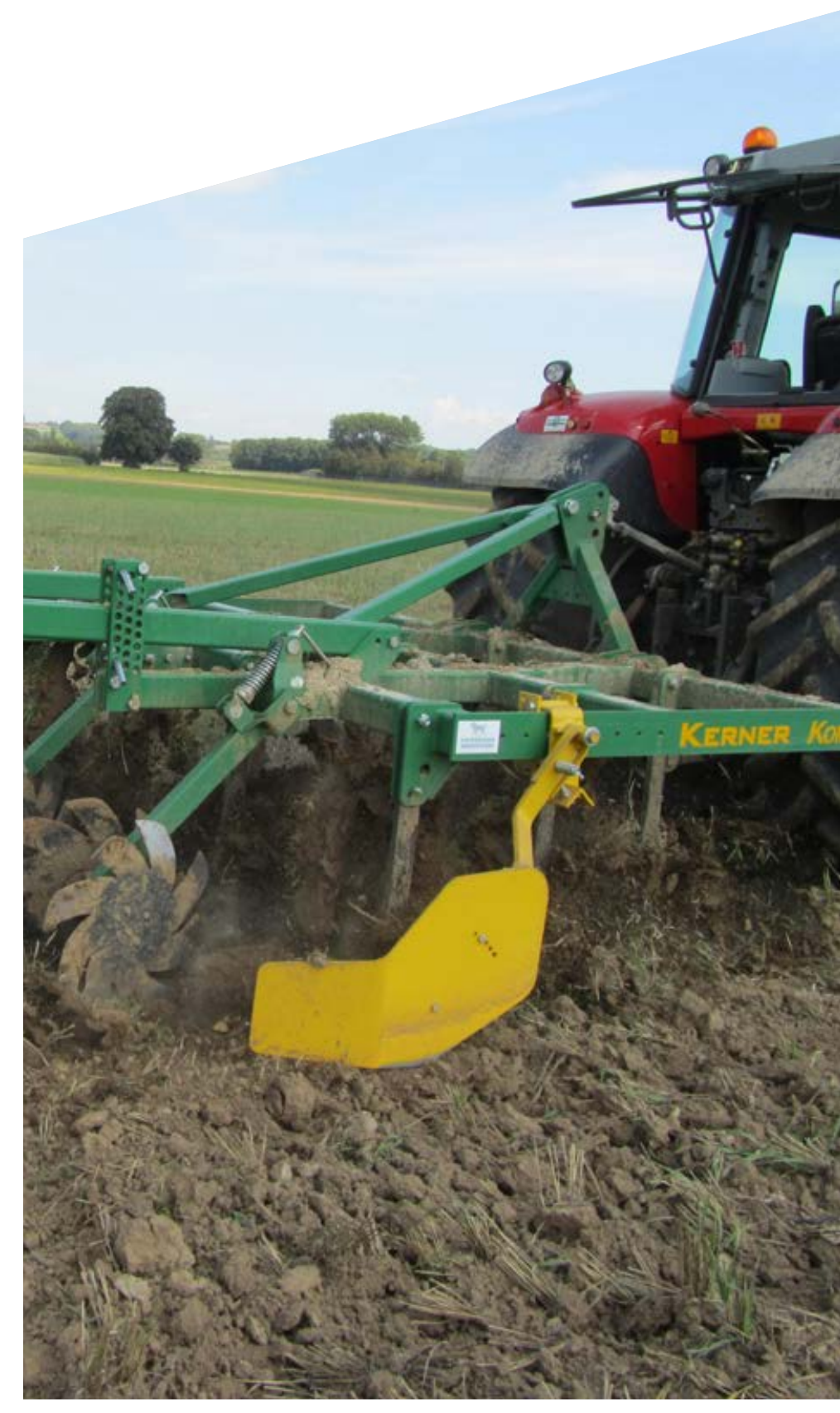




\section{Conclusions and recommendations}

Various measures in agriculture may affect ecosystem services. The table below shows whether a measure has a positive effect, a negative effect or no effect.

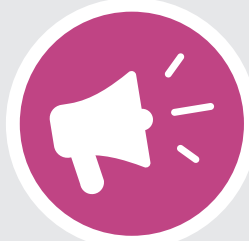

TABLE 2

Table summarising the effect of the measures discussed on the examined indicators for the selected ecosystem services.
- = negative effect

$0=$ no effect

$+=$ positive effect

$?=$ insufficient data

\begin{tabular}{|c|c|c|c|c|c|c|c|c|}
\hline \multirow[b]{3}{*}{ Measure } & \multicolumn{8}{|c|}{ Ecosystem service } \\
\hline & \multirow[t]{2}{*}{$\begin{array}{c}\text { Total } \\
\text { production }\end{array}$} & \multirow[t]{2}{*}{$\begin{array}{l}\text { Food } \\
\text { production }\end{array}$} & \multicolumn{3}{|c|}{ Conservation of soil fertility } & \multirow{2}{*}{ 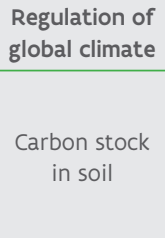 } & \multicolumn{2}{|c|}{ Water quality regulation } \\
\hline & & & $\mathrm{pH}$ & Nutrients & $\begin{array}{l}\text { Carbon } \\
\text { content }\end{array}$ & & $\begin{array}{l}\text { Nitrate } \\
\text { residues }\end{array}$ & $\begin{array}{l}\text { Reduction of } \\
\text { phosphorus } \\
\text { run-off } \\
\text { Reduction of } \\
\text { nitrogen run-off }\end{array}$ \\
\hline $\begin{array}{l}\text { Field edge } \\
\text { consisting of } \\
\text { grasses }\end{array}$ & & - & & & & + & & + \\
\hline $\begin{array}{l}\text { Field edge } \\
\text { consisting of tree } \\
\text { rows or hedges }\end{array}$ & & - & & & & + & $?$ & + \\
\hline Agroforestry & + & - & & & & + & & + \\
\hline Reduced tillage & & $\begin{array}{c}\text { - } \\
\text { (average } 1 \text { to } \\
3 \% \text {; limited } \\
\text { data for } \\
\text { vegetables) }\end{array}$ & 0 & redistribution & redistribution & & & \\
\hline Compost & & 0 tot $+^{a}$ & + & + & + & & 0 & \\
\hline Manure & & 0 tot $+^{a}$ & + & + & + & & $?$ & \\
\hline Green cover & & $?$ & $?$ & $?$ & $?$ & & & + \\
\hline $\begin{array}{l}\text { Cultivation of } \\
\text { grass and clover }\end{array}$ & & + & & & & & & 0 \\
\hline $\begin{array}{l}\text { Rotation of } \\
\text { cropland with } \\
\text { grassland }\end{array}$ & & 0 & & $+(N)$ & + & & & \\
\hline
\end{tabular}

a 0 for good soils and + for poorer soils

How can farmers' methods improve the provision of ecosystem services? This study offers the beginnings of an answer to this question. It is clear that there is great potential in Flemish farming to reinforce the ESS supply. To quantify that potential and convince the agricultural sector of the benefits of alternative methods, knowledge of this subject needs to be developed further. 


\section{Towards more sustainable food production: pioneers' stories}

Many members of the public and entrepreneurs are aware of the importance of their contribution to more sustainable land use, a healthier community and the restoration of biodiversity. They are developing new and innovative activities, methods, partnerships or organisational forms. In the future, some of these may become the new norm.

In Flanders, 45 percent of the land is used to produce food. Small changes in agriculture can therefore have a big effect. On the ground we see numerous examples of farmers helping to promote more sustainable land use and stimulate biodiversity. Their activities vary widely and are adapted to the landscape in which they operate, but they all show how farming can restore our ecosystems. In this report, we hear from four pioneers.

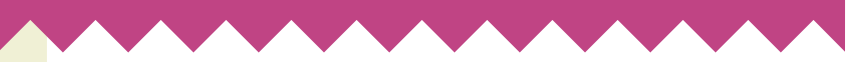

Ronny Aerts runs De Ploeg, a family dairy farm that produces and sells traditional dairy products.

\section{Intensive production with minimal footprint by closing chains and through local sales in the farm shop}

"After the agricultural and food crisis in the nineties I started to rethink our farming system. I wanted to make De Ploeg a farm that takes care of the planet and people, both locally and further afield.

The changes I introduced are inspired by the way people used to feed cows in the past. In modern farming operations, cows generally eat corn, supplemented with soy and grass. The importing of soy is very damaging to the climate and the environment. We therefore switched to a diet that consists mainly of dried grass and clover. The combination of grass and clover has a different protein composition and makes supplementation with soy unnecessary. The switch from corn to grass and clover also means that fertiliser is no longer needed, and this improves the soil structure.

At the same time, we use modern technologies: a new, openplan cowshed and optimal manure processing. The fermenting installation provides the energy needed to dry out the large quantity of clover. Little by little, we are closing our loops, and in this way making our ecological footprint much smaller. Because we no longer import soy, the impact elsewhere in the world is also addressed. And because we control the entire cycle ourselves, we can always guarantee our customers healthy products.

To keep it all profitable, we don't just focus on milk production. We have our own shop on the farm in which we offer a wide range of products such as cheese, butter, probiotic yoghurt and ice cream."

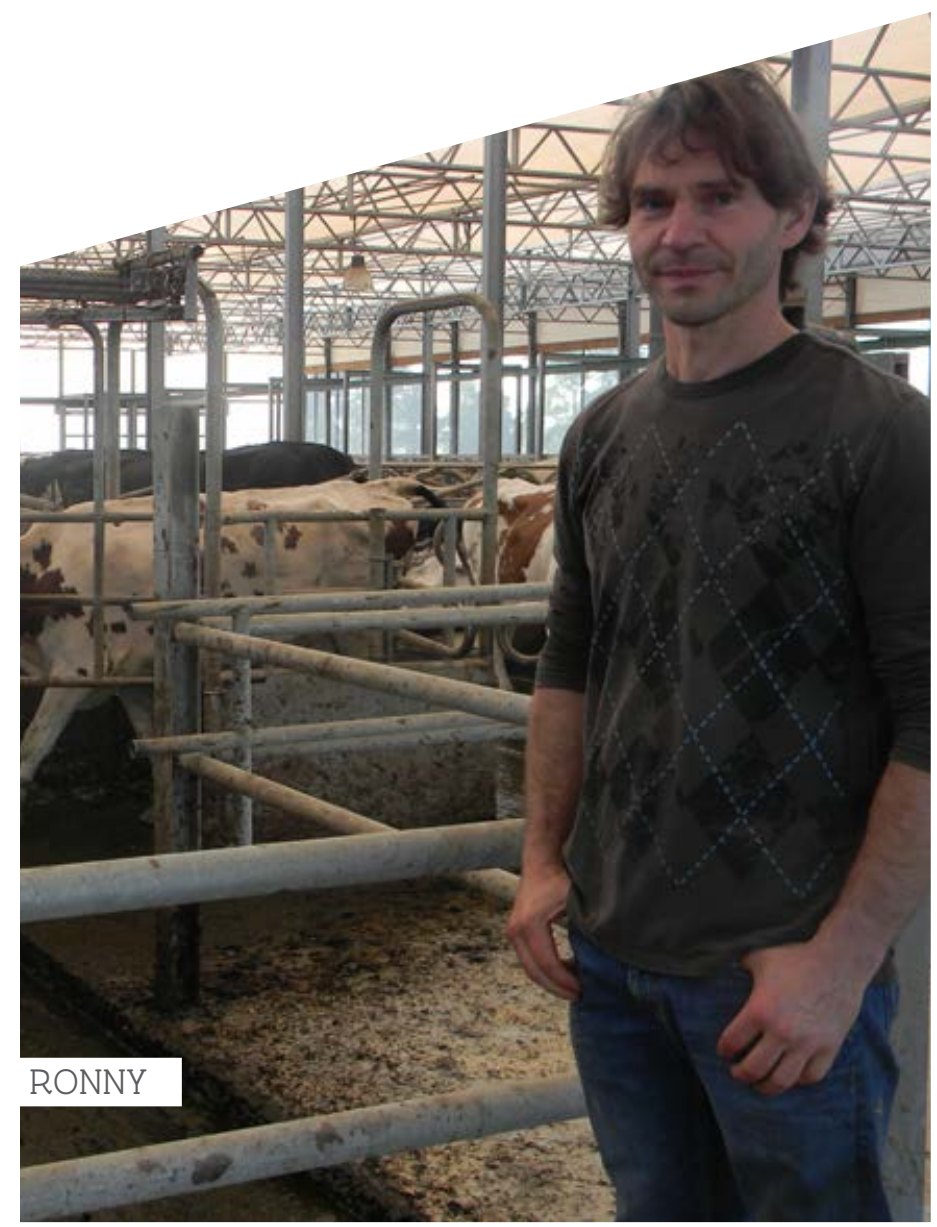


Tom Troonbeeckx started the first CSA farm in Flanders. He grows organic vegetables that his customers harvest themselves.

\section{Urban farming with production of organic vegetables, harvested by the consumer and with a fair income for the farmer}

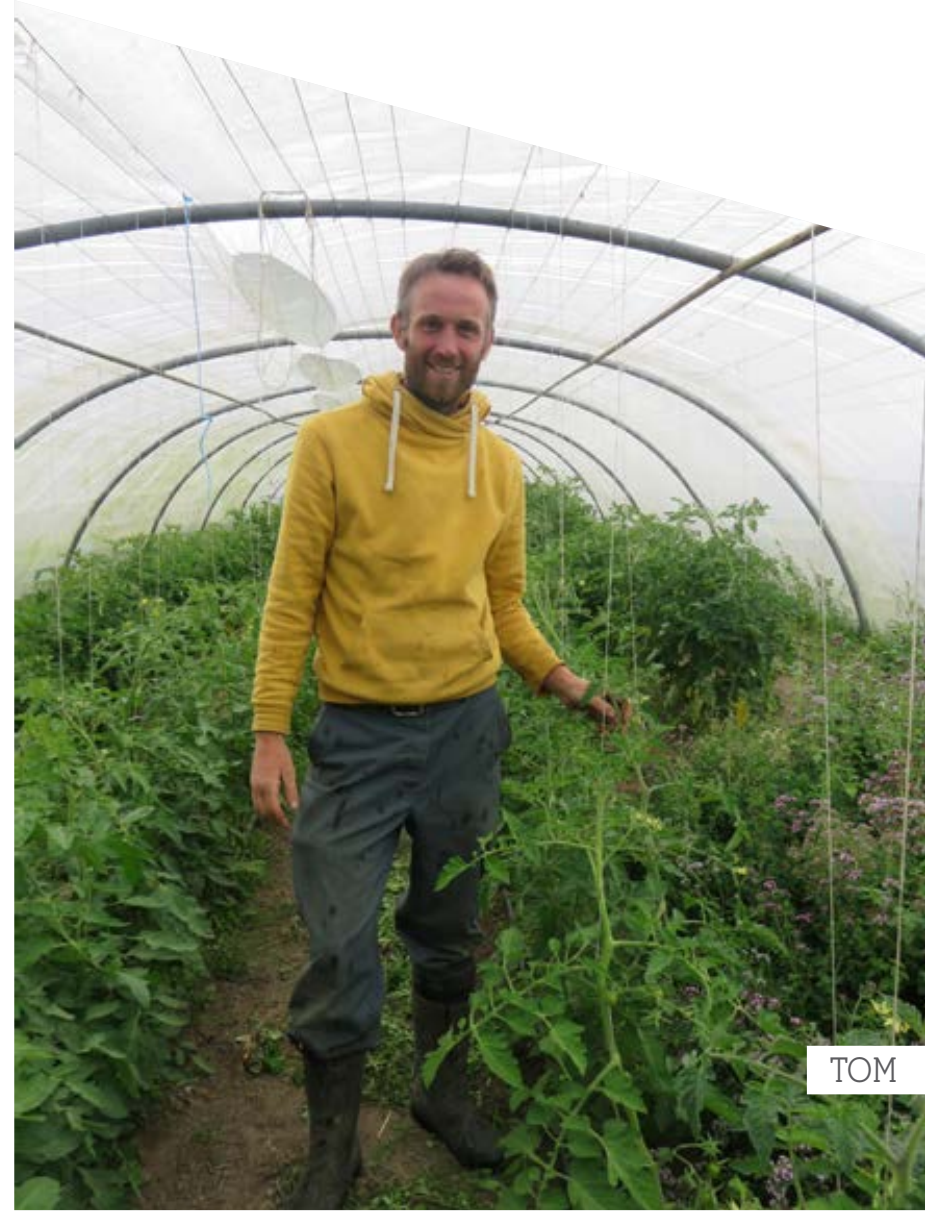

"During my training in the Netherlands I found out about Community Supported Agriculture, a form of cooperation between citizens and local farmers. I thought it made really good sense, because it combines sustainable farming methods with sustainable marketing. Ten years ago I therefore started out as a CSA farmer.

At Het Open Veld in Leuven, members pay their fee at the beginning of the season. This ensures that the farmer has the means to invest in the farm and pay him- or herself a decent wage. In return, the members are entitled to harvest beans, strawberries, tomatoes and other fresh vegetables themselves for a whole year.

There has been a long waiting list for years: our pickyour-own farm is a great success. It's located on the edge of Leuven. This is very important, because it means the members can easily reach us on foot or by bike. Because they pay in advance, they share in the risk of crop failure. And they also benefit if there are unexpectedly high yields.

The future of Het Open Veld is assured, but the challenge now is to develop the basic idea further. We want to ensure that everyone is respected in the chain: the farmer, the consumer, policy-makers and our ecosystem. The goal is to pass on the farmland to future generations in a better condition than we received it in." 


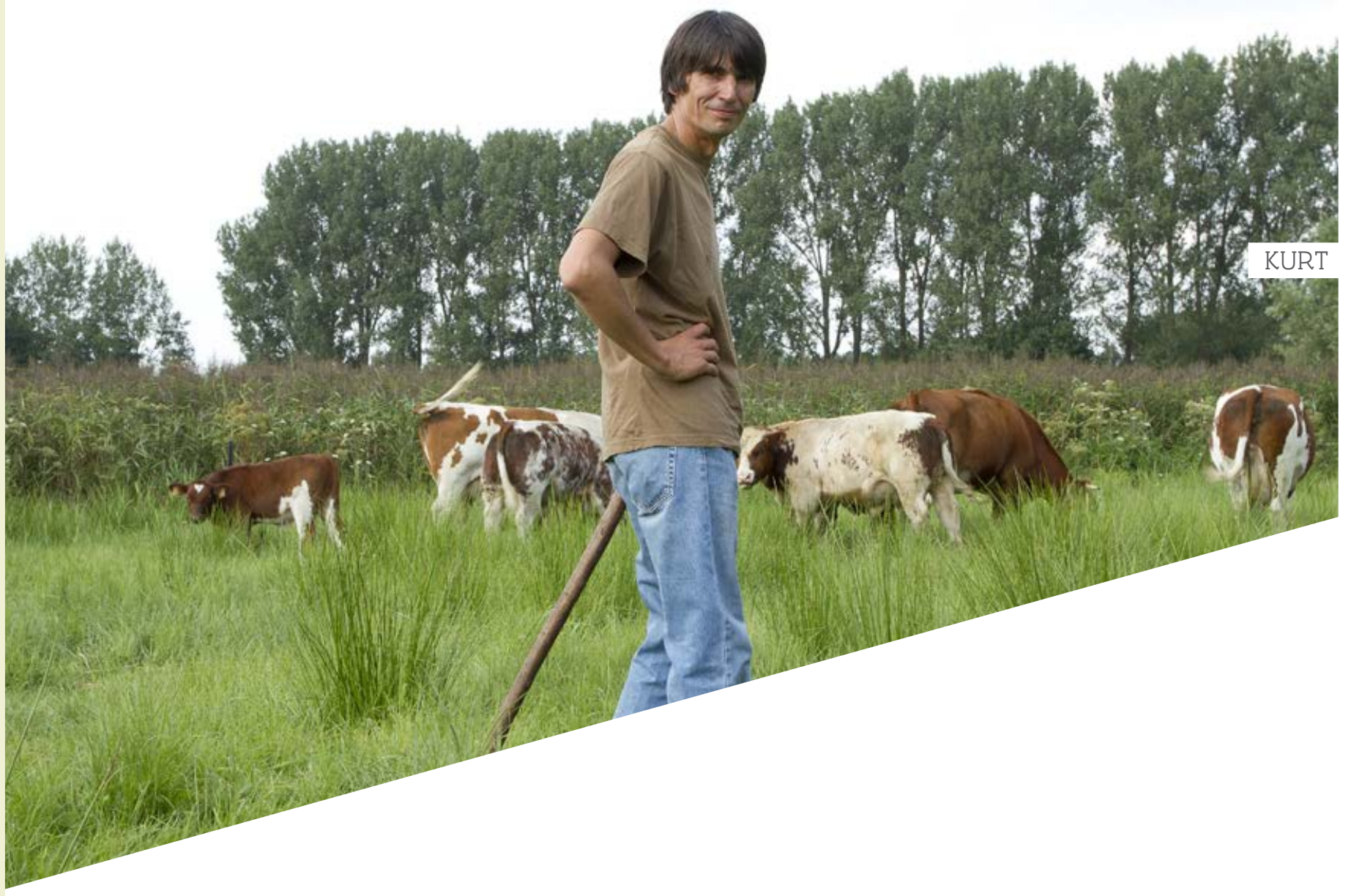

Kurt Sannen runs a cattle farm on the edge of a Natura 2000 site. He combines sustainable farming with nature management.

\section{Organic meat production goes hand in hand with grazing management in Natura 2000 area}

"Nature conservation and agriculture often see each other as rivals, and that doesn't work. I consider it my mission to work out how they can reinforce each other. On my nature farm, Het Bolhuis, the production of organic meat goes hand in hand with the management of 85 hectares of nature reserve owned by Natuurpunt.
Het Bolhuis is an organic farm with sixty cattle and just under a hundred sheep. The breeds that I rear are well suited to grazing on poor grasslands. Of the 100 hectares of my farm, only about 5 hectares are now farmed conventionally. The rest is a Natura 2000 area. Thanks to my cows I am able to achieve nature conservation goals inexpensively on this land.

I don't believe in a landscape with segregated functions, but in combining various functions. Agriculture plays an important role in this multifunctional or 'multi-layered' landscape, simply because it occupies to much space. We should hold farmers responsible for a host of landscape functions, but also pay them for those functions. If they manage nature innovatively on the farm and receive an allowance for doing so, they will see nature as an opportunity rather than a threat." 


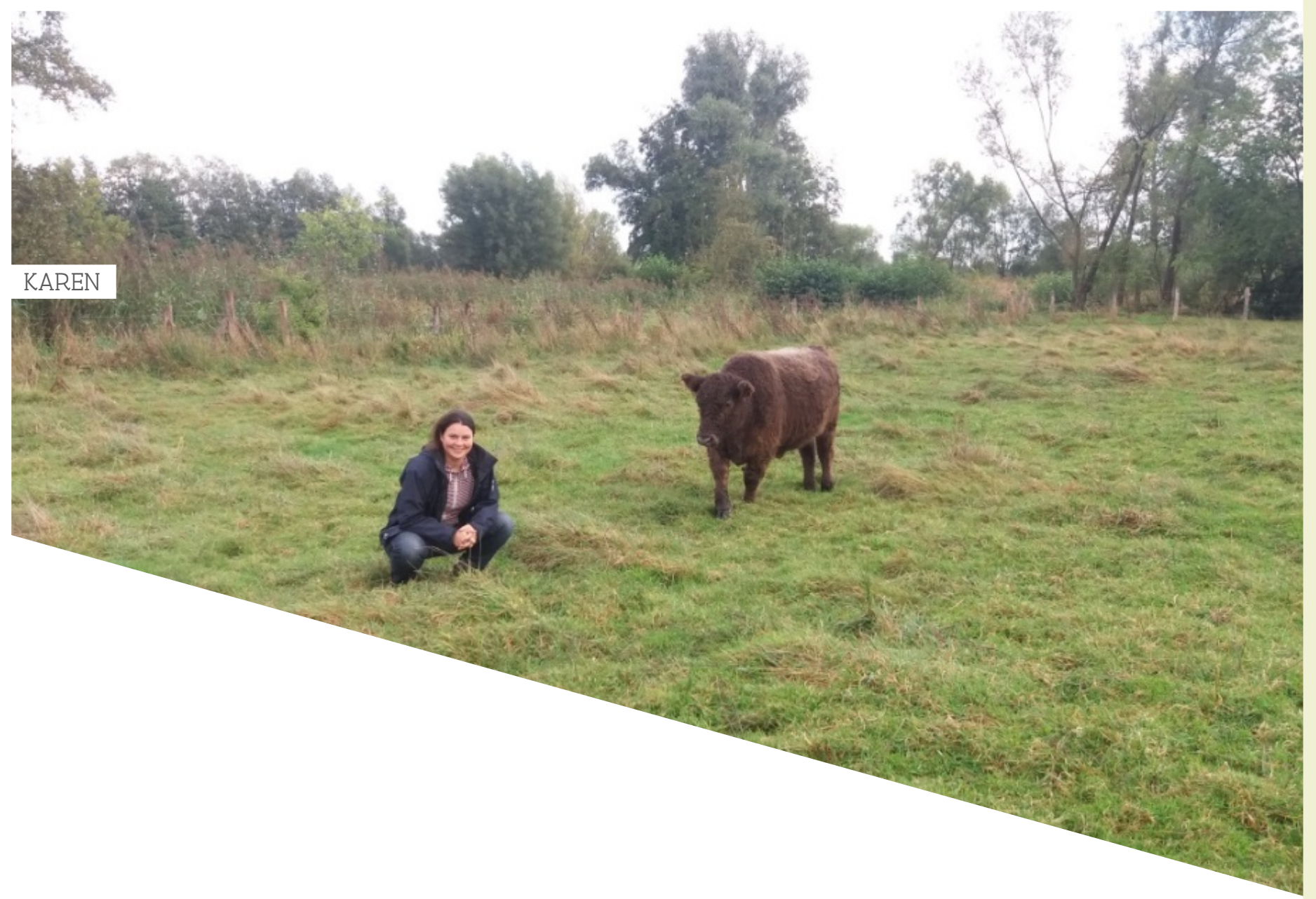

Karen Helsen manages Natuurpunt's livestock, with nature conservation being supplemented by the sale of nature friendly beef.

\section{Achieving nature conservation goals through grazing management and nature friendly meat production}

"I coordinate a herd of grazers which is used for the management of our natural areas. We prefer to work with local farmers in these areas. This is good for both the farmer and the nature reserve. However, some soils are too poor or too wet, and so of no interest to farmers.
To carry on being able to manage these lands, we have started keeping our own herd. The herd consists of about 1,000 cows, 250 horses and 200 sheep. Together they graze on 2,500 hectares of our nature reserve land. Most breeds of cattle with which we work are self-reliant: they go through the winter on their own. We look after animals on areas of land which are too small or too wet in the winter on one of our four farms.

The main reason we do all this is to achieve biodiversity targets. Grazing gives rise to variation in the structure of the nature reserve, and the open character of the land is maintained. The animals are also an attraction for walkers. What's more, we slaughter some of the cattle to sell as nature friendly meat. That way, we recover part of the cost and we keep the herd young. But the sale of meat is a sideline. The focus is on increasing the biodiversity levels in our areas." 


\subsection{IN THE REGIONAL LANDSCAPE RIVIERENLAND}

Vision-building about spatial development currently takes little account of nature's ability to provide ecosystem services. Can the ESS approach help to devise a sustainable vision for areas in a participatory manner? Flanders REA-P conducted an exercise to find out for the Regional Landscape Rivierenland.

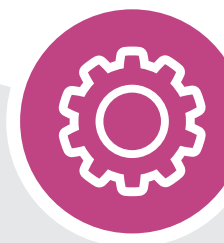

How did we proceed?

- We analysed the demand for ecosystem services in the Regional Landscape Rivierenland. First we undertook a social valuation of what people find important in the landscape. We did this with an online survey of the general public and interviews with thirteen key players.

- We then studied the supply of ecosystem services using maps and located bundles of ecosystem services.

- We analysed the instruments available to a Regional Landscape to apply the ESS approach.

\subsubsection{Focus on the Regional Landscape Rivierenland}

A Regional Landscape is a region with its own character which is of great value for nature and as a landscape. It is also a partnership between government agencies and groups aimed at preserving and strengthening the landscape. To approach the landscape as a whole, a Regional Landscape focuses mainly on cooperation, consultation and expertise. The provinces are responsible for approving, subsidising and following up with the Regional Landscapes.

Is the ESS approach a useful framework for developing a sustainable regional vision? We investigated this by looking at the Regional Landscape Rivierenland. We chose a Regional Landscape for the following reasons:

- Bridging organisations ssuch as Regional Landscapes are crucial for an ecosystem service-oriented policy. They exchange local and scientific knowledge and bridge the gap between the government and other stakeholders. They connect the different policy domains (e.g. heritage and nature) and levels of government (e.g. provinces and municipalities).

- Both the geographical scale of a Regional Landscape and the policy level (supra-local) are ideal for working with the ESS approach.

- Regional Landscapes place great emphasis on cooperation and consultation in their functioning. They are thus familiar with a participatory approach 
The Regional Landscape Rivierenland is centrally located in Flanders along the Antwerp-Brussels axis. It groups together the municipalities along the Rivers Rupel, the Grote and Kleine Nete, the Dijle and the Zenne. With nearly 334,000 inhabitants and an average population density of 780 inhabitants per square kilometre, it is among the most densely populated regions of Flanders. Its central location means that the Regional Landscape Rivierenland faces challenges also found at the level of Flanders as a whole, such as climate change, urbanisation and sustainable agriculture.

\subsubsection{The valuation of Rivierenland by users}

What do people consider important in the landscape in their region? To find out, we asked about the preferences, values and interests that people ascribe to nature and the landscape in Rivierenland.

\section{Key players value cultural and regulatory services highly} We interviewed thirteen key players: people who know the area well and have an understanding of the main issues and problems in the region. How important do they consider the ecosystem services and biodiversity characteristics of Rivierenland, and why? From their answers, we distilled a top five of the most important services. These were the most striking findings:

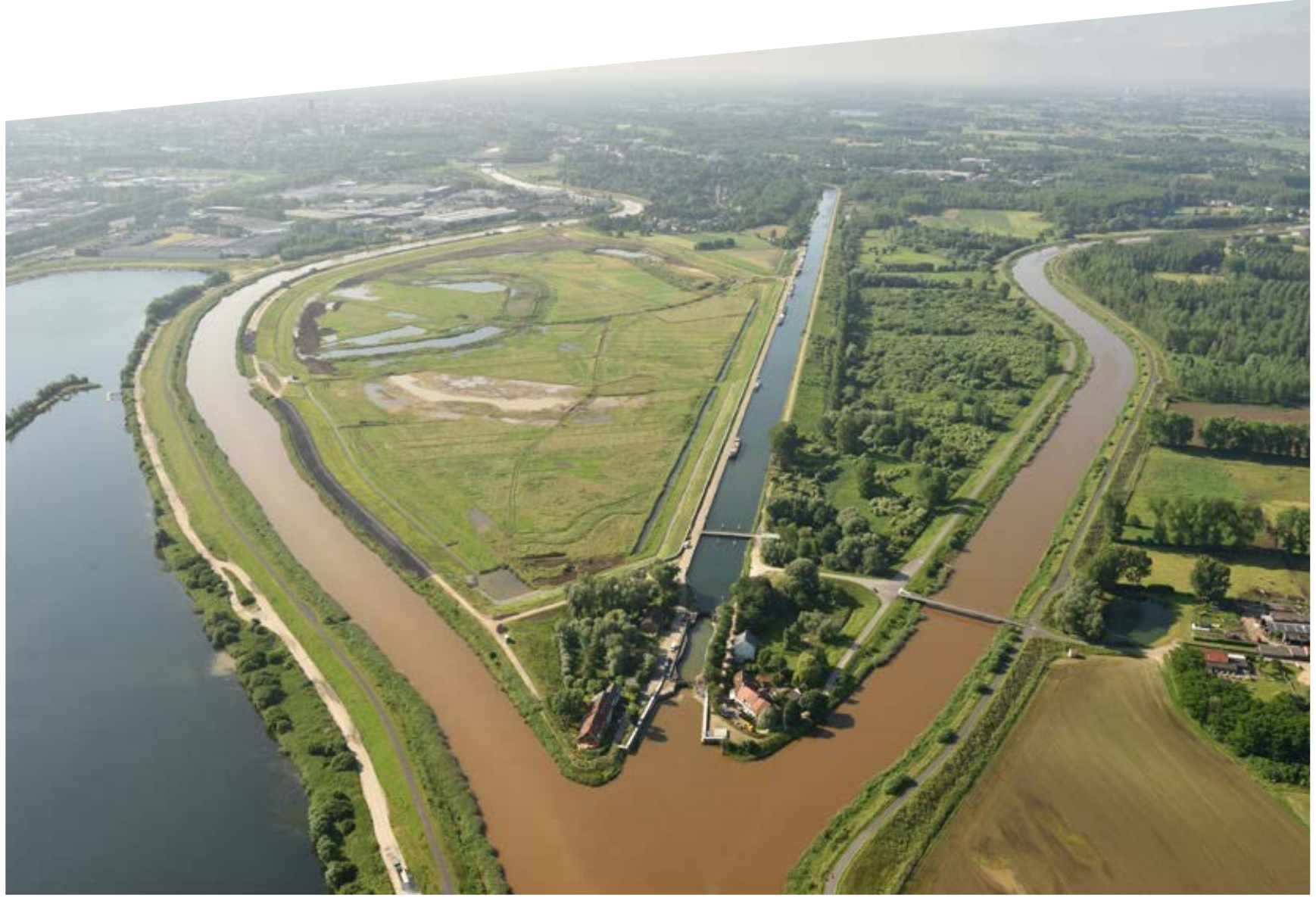




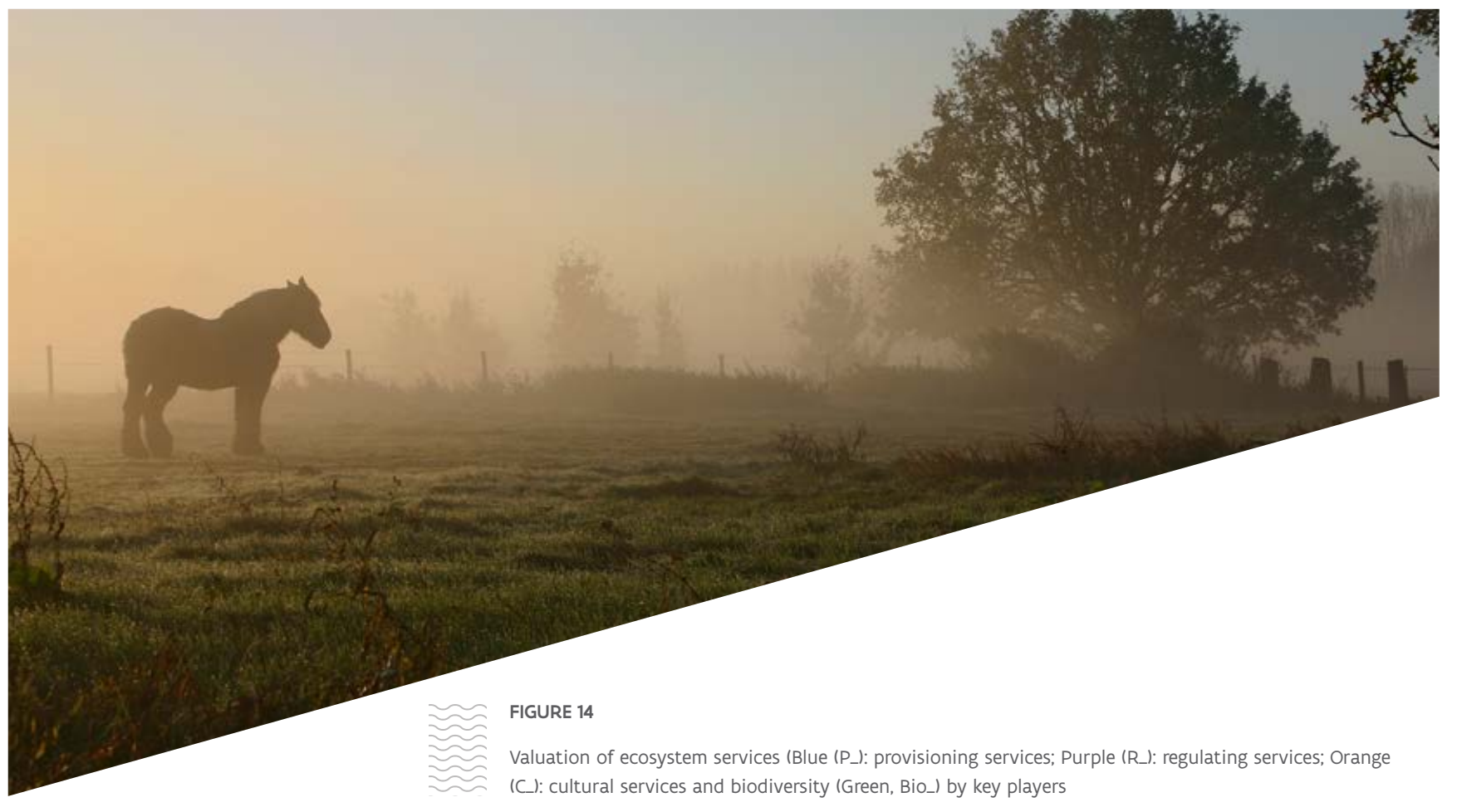

C_soft recreation

C_pleasant living and working environment

R_flood protection

C therapeutic effect

C_regional identity

C_education

P_agriculture_cropland and horticulture

Bio_diversity

R_air purification

R_pollination

R_natural pest control

Bio_rarity

$\mathrm{R}$ carbon storage

P_agriculture_livestock farming

R conservation of soil fertility

$\mathrm{R}$ _urban heat regulation

R_water purification

C outdoor non-motorised sports

C_nature study

P_timber production

R_noise regulation

C_source of technology research

Bio_unspoiled nature

P_groundwater supply

P_agriculture_glasshouse cultivation

P_energy crops

C hunting and recreational fishing

P_wild game_production

$\mathrm{R}$ erosion risk regulation

C_outdoor motorised sports

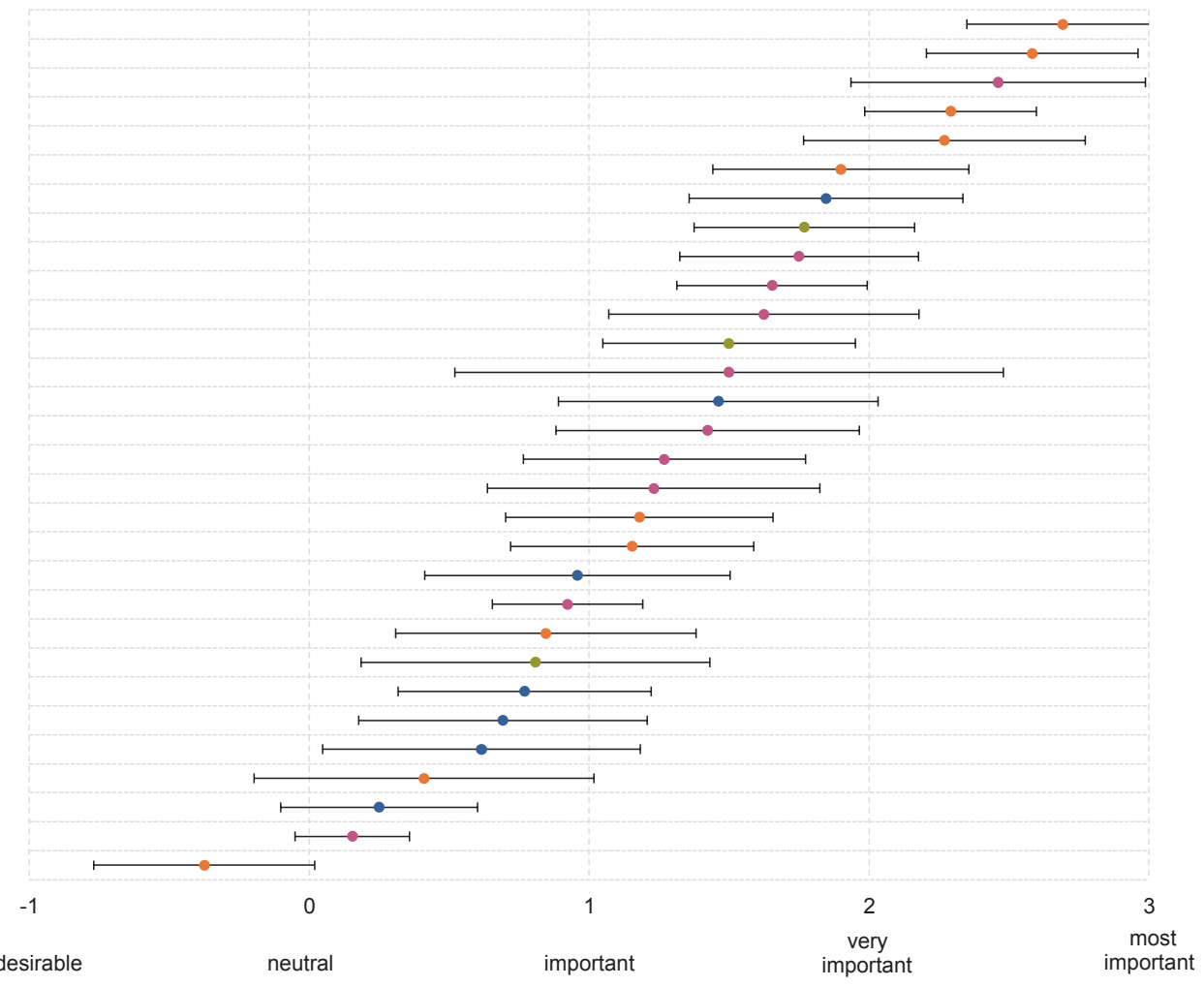


- Cultural services score very highly: heading up the top five we find four cultural services: 'soft recreation', 'pleasant living and working environment', 'therapeutic effect' and 'regional identity'.

- Most regulating ecosystem services appear in the group of important or very important services. 'Flood protection' is actually in the top five, with the multifunctionality of floodplains cited as one of the main arguments. Other regulating services, such as 'air purification' and 'noise regulation', are highly valued for their positive impact on the quality of the environment.

- For biodiversity, the different aspects we included in the survey were given different scores. 'Unspoiled nature' scores significantly lower than 'diversity' and 'rarity'. One reason given for this is that unspoiled nature is no longer possible in this region, and should therefore not be pursued. 'Diversity' is given a high score, firstly because of the fundamental value of species diversity for life on earth, and secondly because of the value of a varied, diverse landscape. According to the key players, rare species are important because protecting their habitats also protects other functions, and because their 'emblematic value', which is often considerable, can attract more support for nature conservation from the general public.

- 'Hunting' and 'greenhouse cultivation' are identified as being less important along with a number of other provisioning services, while 'outdoor motorised sports' are described by most interviewees as undesirable. The reasons they cite for this are the potential conflict with other land uses and the disruption of peace and quiet.

\section{Air purification important to the public}

We also organised an online survey of the general public. 376 people completed the questionnaire, including 280 who live in the Regional Landscape Rivierenland. Due to the small sample and the short duration of the survey we were unable to draw any definite conclusions about what aspects of nature are important to people who live in the region. However, the survey did provide an exploratory picture of people's preferences and their attitude towards nature.

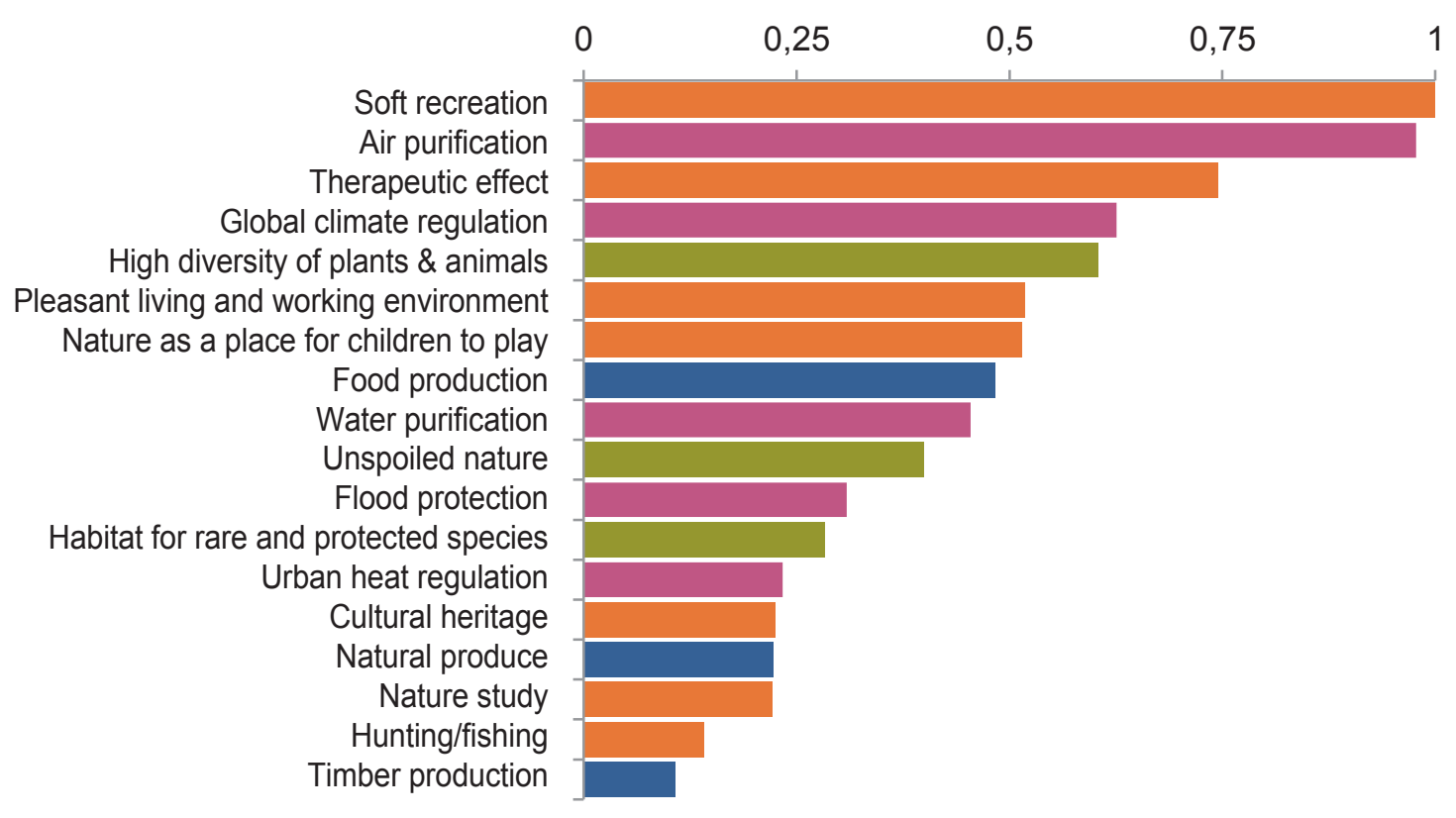

\section{FIGURE 15}

Valuation of ecosystem services (provisioning: blue; regulating: purple; cultural: orange) and biodiversity (green) by members of the public 
Some striking results:

- The cultural services 'soft recreation' and 'therapeutic effect' are ranked most highly. This was also the case in the interviews with the key players.

- By contrast, 'flood protection' is rated significantly lower than by the key figures.

- Among the biodiversity services, 'diversity of species' scores highly. By contrast with the key players, the general public value 'unspoiled nature' more highly than 'rare species'.

- 'Air purification' comes second in the online survey, whereas the key players only rank it in ninth place.

- At the bottom of the ranking we find 'timber production' and 'hunting'.

\section{Naming ESSs helps}

The survey and interviews provide a similar picture of the importance that people attach to nature in their region. One of the drawbacks of the online survey is that we have little insight into the reasoning of the respondents. As a result, we do not always know what they have in mind: are they assessing the ecosystem service itself or the benefits associated with it (e.g. air purification by nature as opposed to clean air)? The complexity of a concept such as biodiversity also makes it hard to determine exactly what people find important. Even so, identifying the functions of nature is helpful in getting people thinking about its importance, and thus increasing support for nature and nature conservation.

\subsubsection{The supply of ecosystem services in the Rivierenland}

Where are provisioning, regulating and cultural services found in Rivierenland? To answer this question, we first consider the spatial distribution of each ecosystem service separately. We then look at whether there are any common patterns and where services occur in bundles. We combine these findings with the information from the interviews with the key figures: what functions do they think can be combined well in the

Participatory planning with ecosystem services for the Green Valley special nature conservation project

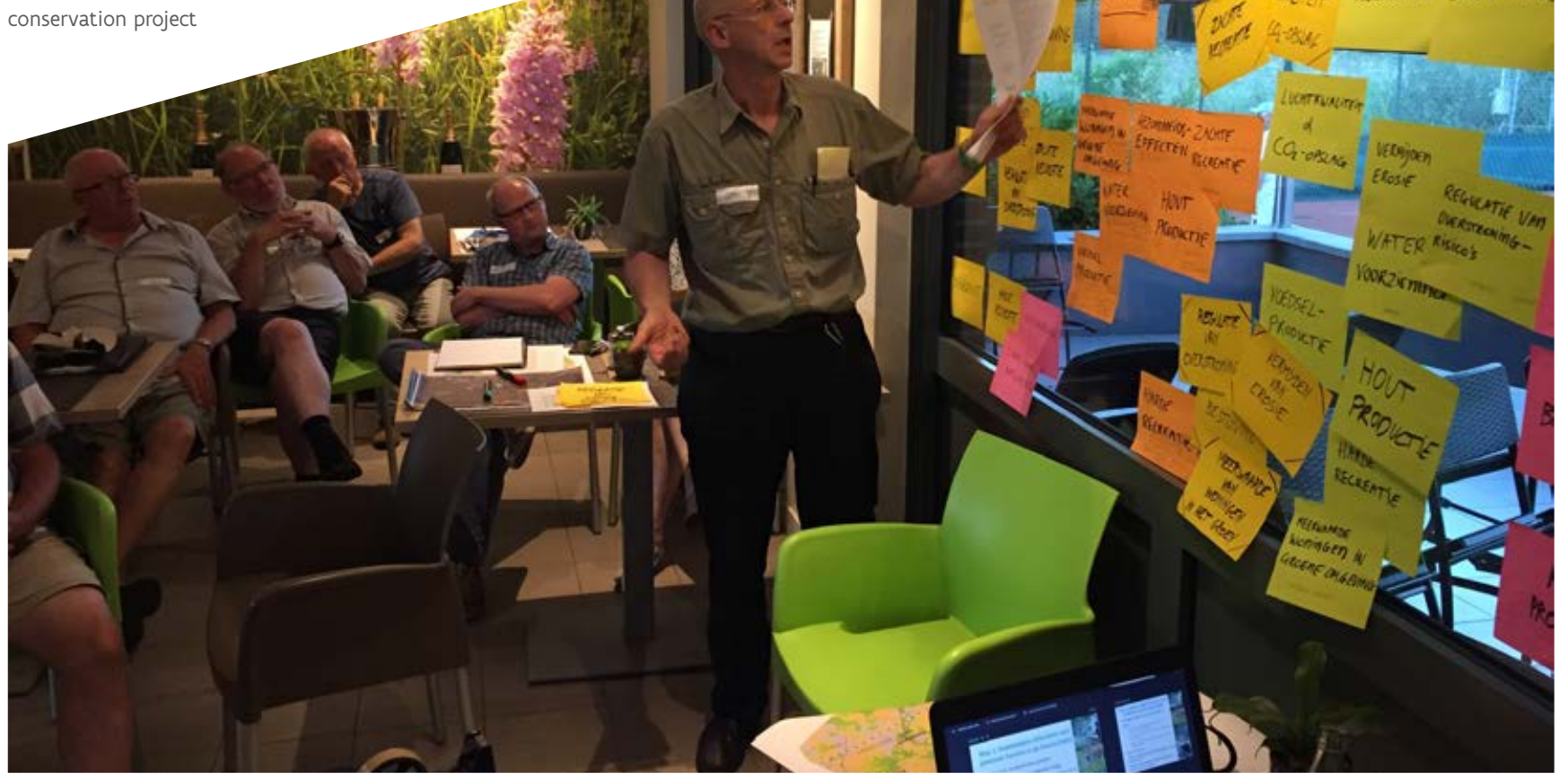




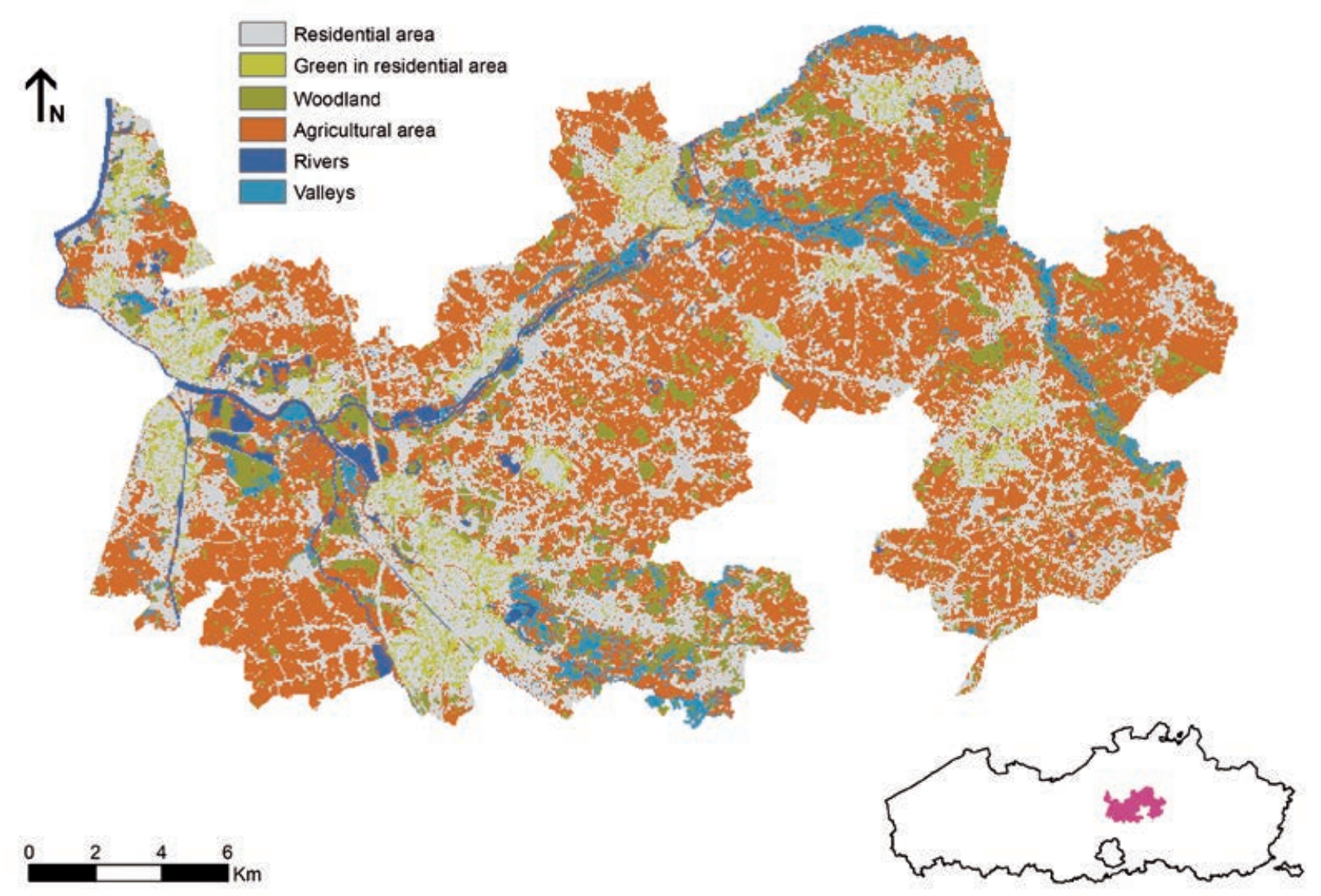

\section{FIGURE 16}

Bundles of ecosystem services in the Regional Landscape Rivierenland.

countryside? That gives us an idea of the opportunities for organising and managing the landscape multifunctionally. This is important because in a densely populated region like Rivierenland open space is under pressure and different sectors are laying different claims to the land. Finally, we link the valuation of ecosystem services to the supply: how we can ensure a better match between the natural strengths of the landscape and local needs?

\section{Bundles of ecosystem services}

What services an ecosystem can provide depends not only on the type of land use, but on the properties of the soil, the topography and other physical variables. Areas with the same physical characteristics thus often show a similar pattern with regard to the provision of ecosystem services. What is more, ecosystem services are usually delivered together.
Where in Rivierenland are such bundles of ecosystem services located, and what services are provided together? To get an understanding of this, we combined the ESS maps in a bundle analysis.

The bundle analysis groups together the areas in which the supply of ecosystem services is similar. Using ESS bundles may encourage cooperation between different sectors and stakeholders, because different goals are achieved within the same bundle. It may also increase the probability of the landscape being managed successfully, because multiple functions have to be taken into account and the different management strategies have to be geared to one another. As a result, policy-makers can develop targeted management measures focusing on multifunctionality within the bundles. 
In Rivierenland, we find six ESS bundles:

1) residential areas, 2) agricultural areas, 3) green spaces in residential areas, 4) woodland, 5) rivers and 6) valleys.

What can we learn from these bundles?

\section{- In terms of size, the built-up and agricultural areas} are by far the most significant. Built-up areas provide few ecosystem services. The agriculture bundle is important for food production, conservation of soil fertility, energy production from grass cuttings and replenishment of aquifers.

- The four other bundles represent a smaller area, but are still important for the delivery of specific ecosystem

services. Thus, the green spaces around residential areas (parks, gardens, road verges etc.) are relatively small, but the cells in this bundle are important for air purification, urban heat regulation, water retention and carbon storage. The water-rich cells provide recreation and water purification services. Along the rivers we find areas that are essential for flood protection. Forests are important for recreation, air purification, maintenance of soil fertility, timber production, pollination and services that ensure the regulation of global climate (carbon storage in soil and wood).
- These smaller bundles, which often overlap with nature reserves, are hotspots of multifunctionality. By protecting and reinforcing their multifunctional character, we can optimise the supply of socially important ecosystem services.

\section{Interactions between ecosystem services}

The bundle analysis proves that ecosystem services are delivered in bundles. However, services can also exclude or impede each other. Conversely, services that do not seem to go together at first sight can be mutually reinforcing with appropriate management. To gain a better understanding of the possibilities for combining ecosystem services in the landscape, we asked the key players which services do or do not go together in their opinion. These are their main conclusions:

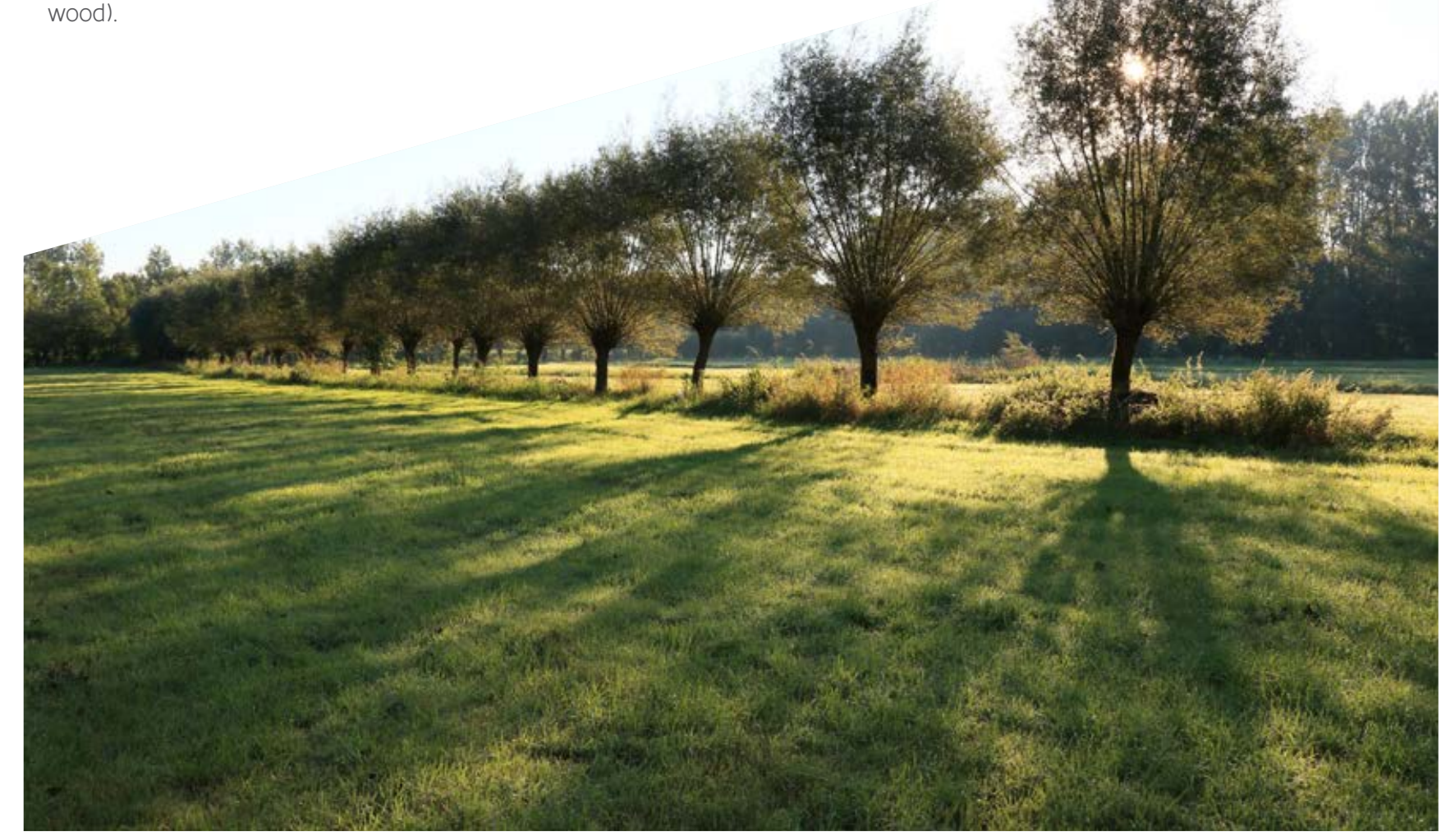




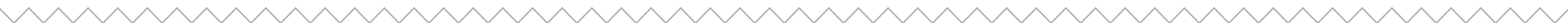

- The interviewees believe that the use of provisioning and recreational cultural ecosystem services often has a negative impact on biodiversity ('rarity', 'unspoiled nature', 'diversity').

- '(Motorised) recreation' and 'hunting' also have a negative impact on other cultural services, such as 'therapeutic effect' (peace and quiet), 'a pleasant living and working environment', 'nature study' or 'soft recreation'.

- 'Land-based agriculture and horticulture' can bring about many positive interactions with ecosystem services. However, the key players make a distinction between conventional intensive farming practices and more sustainable management practices, which make more use of ecosystem services. Agriculture is thought to be difficult to reconcile with 'rarity' and 'unspoiled nature', but the combination of agriculture and nature in the broad sense creates win-win situations in the view of the key figures.

- Intensive livestock farming has a negative impact on biodiversity, partly due to overfertilisation. Even so, most interviewees regard 'livestock farming' as important or very important in the Regional Landscape. This is because cattle keep the landscape open, and cows in the field also have a landscape value.

- Biodiversity and cultural ecosystem services might also have negative effects on agriculture and horticulture. Some key figures mention the risk of diseases and pests and the difficulty of managing weeds and thistles. Farming activities can also be disturbed by recreationseekers. In addition, trends such as the 'horsification' of the countryside are taking affordable land away from agriculture.

- The interaction between 'flood protection' and other ecosystem services and biodiversity is usually seen as positive. For agriculture and horticulture, flood protection can be negative, not least because of the loss of farmland. However, certain farming activities are still possible in floodplains.

- Opinions on 'hunting' are divided. Disturbance of the peace and quiet and conflicts with recreation-seekers are negative impacts, but ecological management of hunting land may also be good for biodiversity. If proper agreements are made, hunting and recreation can co-exist.

\subsubsection{Matching supply and demand}

The landscape of Rivierenland is multifunctional, as is clear from the bundles of ecosystem services. Most landscapes deliver multiple services simultaneously, but not every landscape can or should deliver each service to the same extent. Depending on land use and local demand, the emphasis will often be on one or a few services. For instance the focus in a floodplain will be on the flood protection function, while such an area may also be important for water purification, recreation, pollination, biodiversity and even agriculture. In a multifunctional landscape we can combine these functions and goals. Some services compete with each other, but even these trade-offs can be converted into synergies. With minor interventions, appropriate management and clear agreements we can reconcile the differing objectives of stakeholders within the bundles. In this way, we can create more win-win situations in the landscape.

Figure 17 summarises the relationship between supply and demand for ecosystem services and biodiversity. It also shows measures that a Regional Landscape can introduce to enhance the supply of services. We explain some of these measures below.

- Along with the urban bundle, the agriculture bundle covers the largest area of the Regional Landscape. A small improvement in such an area can therefore have a significant effect on the overall supply of ecosystem services and biodiversity in the region. In the agricultural area, for example, small landscape features or field margins can be implemented(1). These minor interventions are good for biodiversity, deliver supporting and regulating functions, can also be turned to economic benefit (e.g. the production of biomass energy from the management of hedgerows) and provide an attractive landscape for recreation - also important in the context of rural tourism. This in turn can generate extra income for farmers. 


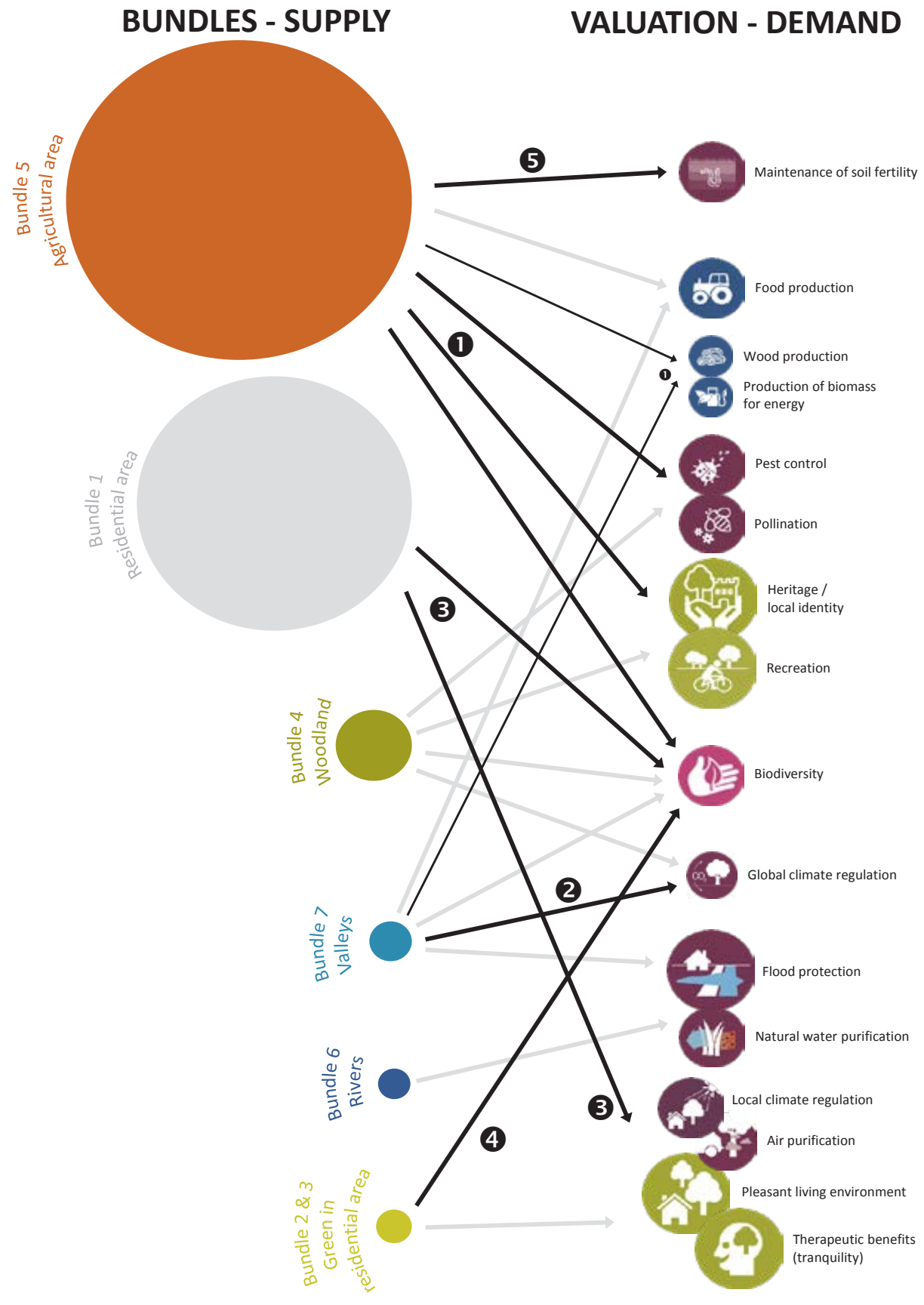

MEASURES

- Landscape management (hedgerows, pollard trees, pools, field margins, ...)

3 Green roofs, green facades, ...

(5) Protection of soil biodiversity

(2) Valley rewetting

4 Ecological management of gardens \& parks

Relationship between the supply of ecosystem services (left), the valuation of services (right) and possible measures to reinforce the supply (middle) in the Regional Landscape Rivierenland. 


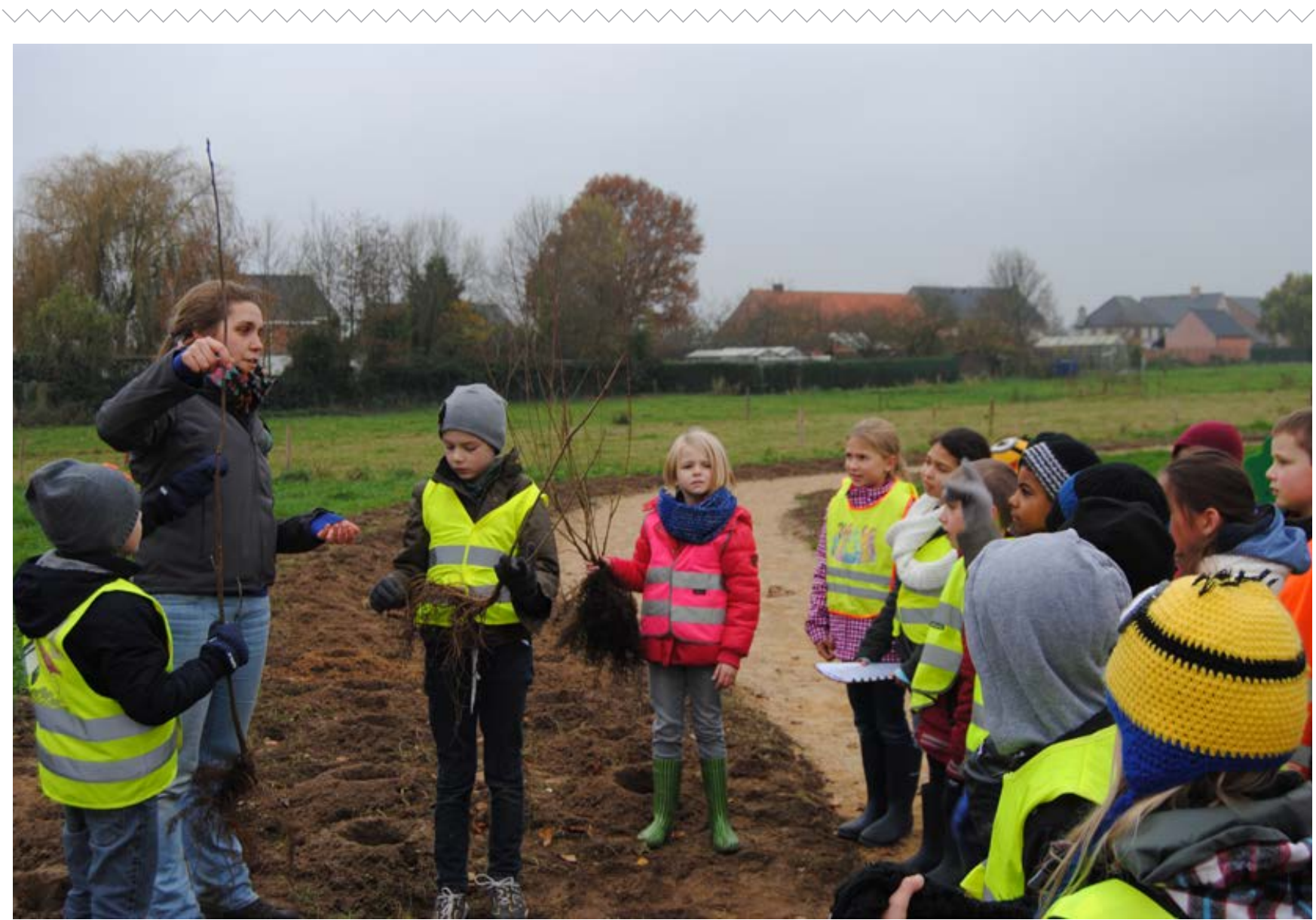

Planting a green play area with pupils from a primary school in Duffel.

- In urban areas too, there is room for interventions that benefit biodiversity and the provision of ecosystem services, such as ecological management of public parks and green areas (4). Citizens can play a special role through information campaigns and pilot projects in the design and management of green space. Appropriate management of private gardens and the creation of green roofs and walls offer opportunities for biodiversity and can reinforce ecosystem services in residential centres such as rainwater infiltration, carbon storage and urban heat regulation (3).

- Rivers and their valleys are a fundamental aspect of the landscape in the region. They determine its structure and are important for food production, recreation, flood protection, water purification and biodiversity. The pollard trees that are typical of wetlands have a special scenic and ecological value. The branches from pollarded trees may also be used as fuel wood or wood chips (1).
- The key players attach great importance to carbon storage, due to its positive effect on the climate. Forests are hotspots for the storage of carbon both above and below ground. Valleys can also be important for the storage of carbon in the soil. Areas with a high water table store especially large quantities of carbon. Rewetting of grasslands is therefore a potential management practice for CO2 sequestration (2)

- Carbon in the soil is also essential for soil fertility. A carbon-rich soil with plenty of soil life contains many nutrients, increases the soil's resilience and helps with natural pest control. Projects focusing on education and awareness-raising about soil fertility can convince farmers and garden owners to handle their soil more sustainably (5). 


\subsubsection{The Regional Landscape gets started} with ecosystem services

\section{Available tools}

An ecosystem service-oriented policy aims for sustainable management of ecosystems and ecosystem services. Such a policy recognises diversity, as there are multiple ecosystem services that may have different values. If a municipality, province or other governmental body wishes to implement such a policy, it must use a mix of policy instruments that can handle this diversity. Although a Regional Landscape cannot outline an ecosystem service-oriented policy itself, it can contribute to one. It can use a wide range of policy tools to do so.

We have compiled a list of social, economic and legal instruments and combinations of them that can be used by a Regional Landscape in order to get started. The list consists of various types of instruments. Regional Landscapes have a facilitating role and most of the instruments they use reflect this. Examples include the 'landschapsloketten', where people who wish to help maintain or improve the landscape can seek advice, or the 'landschapskranten' - newspapers distributed by Regional Landscapes to inform the public about actions to green the landscape. They can add to these by working with partners who have access to other tools. This is particularly easy for Regional Landscapes in view of their role as an intermediary between different parties. Tools that contribute to their bridging role between the government and local stakeholders and between different sectors are therefore extremely important.
The Regional Landscapes use the transfer of knowledge between the government and the people to increase support for nature and nature management. They are also in an ideal position to promote cultural ecosystem services such as recreation and education. Although of great value, these services are often overlooked because they do not belong to any one sector-. Advising, process management and landscape conservation are all tasks of a Regional Landscape that contribute to the promotion of cultural ecosystem services. Although sometimes less visible, they are part of the basic activities of the organisation. Despite this, this essential function is often undervalued.

\section{How do users view the ecosystem services approach?}

A survey of Regional Landscape coordinators shows that they do use the ESS approach in their activities, but that the focus is mainly on individual ecosystem services. For example, the Regional Landscapes may work on the provision of recreation facilities, set up a pollination project or organise campaigns relating to firewood. Yet projects in which they use ecosystem services to develop a vision are relatively rare.

However, the Regional Landscapes are aware of the many opportunities provided by the ESS approach to communicate about the landscape and nature, and are convinced that the approach can play a role in regional vision development and landscape design projects. They indicate that the main barriers to the inclusion of ecosystem services in their work are lack of knowledge and experience with the concept and the lack of suitable guidelines and tools. To help spread the ESS approach, more practical examples are therefore needed that show that the concept leads to better results. 


\section{Conclusions and recommendations}

1. Use the bridging function of the Regional Landscapes. A Regional Landscape plays a bridging or mediating role, and as such is of pivotal importance for policies making use of ecosystem services. At supra-local scale, it brings together various levels of government and sectors. Regional Landscapes help circulate local and scientific knowledge.

2. Work together. In order to define a policy vision that is widely supported, it makes sense to find out about the various stakeholders and their interests. Their demands and needs should be taken into account. An analysis of stakeholders, key players and local experts can be helpful here. An ecosystem service-oriented regional vision is developed participatively, by involving stakeholders and sectors at every step of the process. The natural strengths of the landscape and the needs of local users are the best starting-point here.

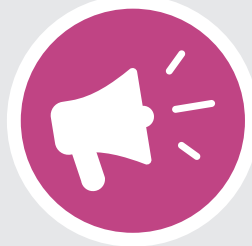

3. Make ecosystem services visible. The interviews with the coordinators of the Regional Landscapes show that the provisioning and cultural ecosystem services are well known, but the regulating services are far less so. In order to make these less apparent benefits of the landscape visible too, it is a good idea to map and value ecosystem services.

4. Communicate. Unknown is unloved: nature is all too often seen as an expense rather than as a source of benefits for society. We must therefore work to achieve broad support for nature and open space. Ecosystem services can help to build this support. This can be done with demonstration projects, by telling the stories of pioneers or by working with ambassadors.

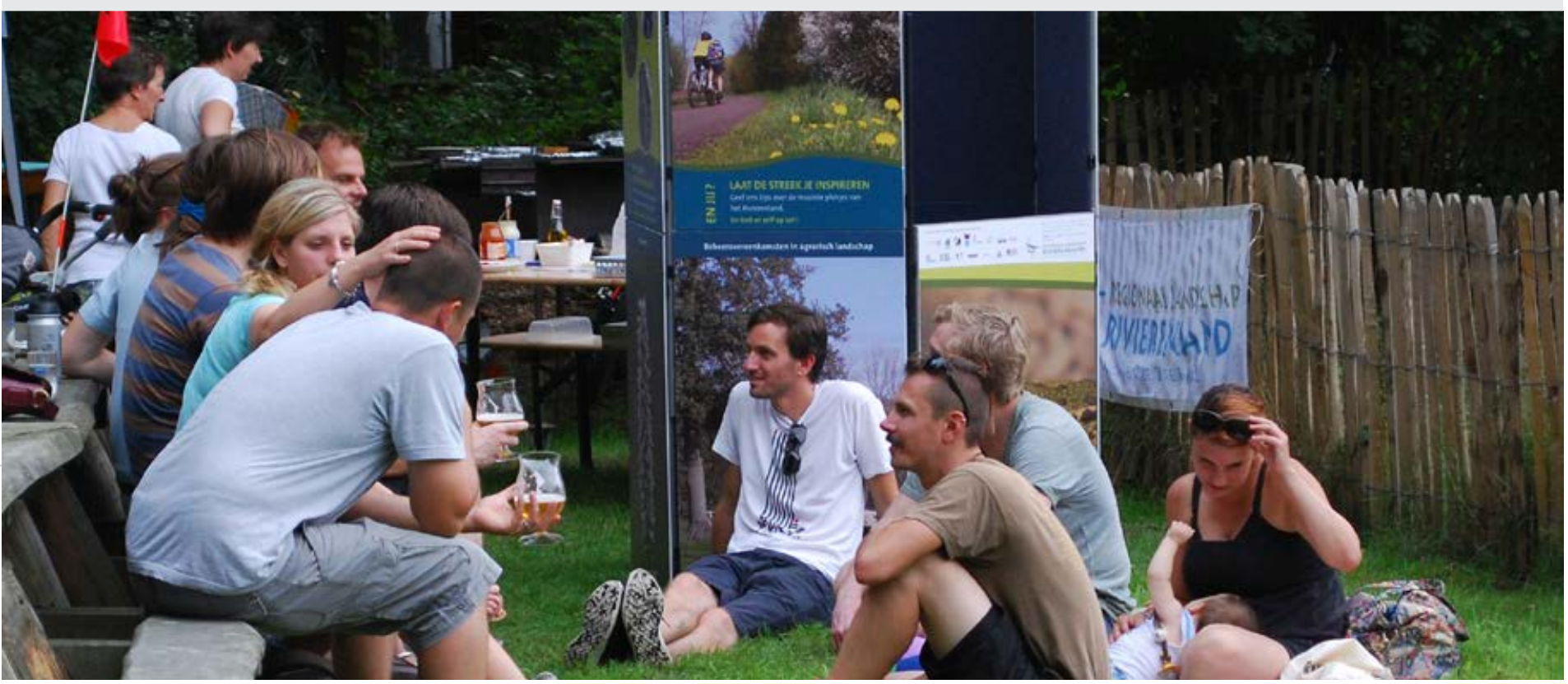

Presentation of the running of the Regional Landscape Rivierenland and the work of its partners during the Broekbos Festival in Blaasveldbroek 


\subsection{IN THE BUILT ENVIRONMENT}

We tend not to regard the built environment as an area of great natural resources. Yet here too, it is important to focus on reinforcing ecosystem services. Flanders REA-P focuses on the gardens in the Regional Landscape Rivierenland as providers of ecosystem services. We use an exercise to examine whether the ecosystem services concept plays a role in the decision to develop new residential expansion areas. We also study a case from the city of Antwerp, which has gained experience of communicating about ecosystem services in the city.

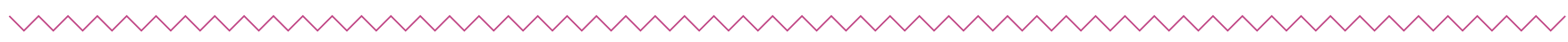

\subsubsection{Gardens: green stepping stones in}

\section{the landscape}

\section{Gardens in Flanders}

As much as 124,000 hectares or 9 percent of the Flemish region consists of gardens (see Figure 18). Approximately half of this garden area consists of grass and plants and a fifth of trees. 30 percent is under hard surfacing. We call the set of individual gardens in a particular region the garden complex.

\section{Gardens as providers of ecosystem services}

For many people in Flanders, their garden is an oasis right next to their home where they find peace and relaxation in contact with nature. But gardens also have a social function. The garden complex functions as a green network that extends from the city out across the countryside. It forms a link between nature areas and provides a habitat for many animal and plant species.

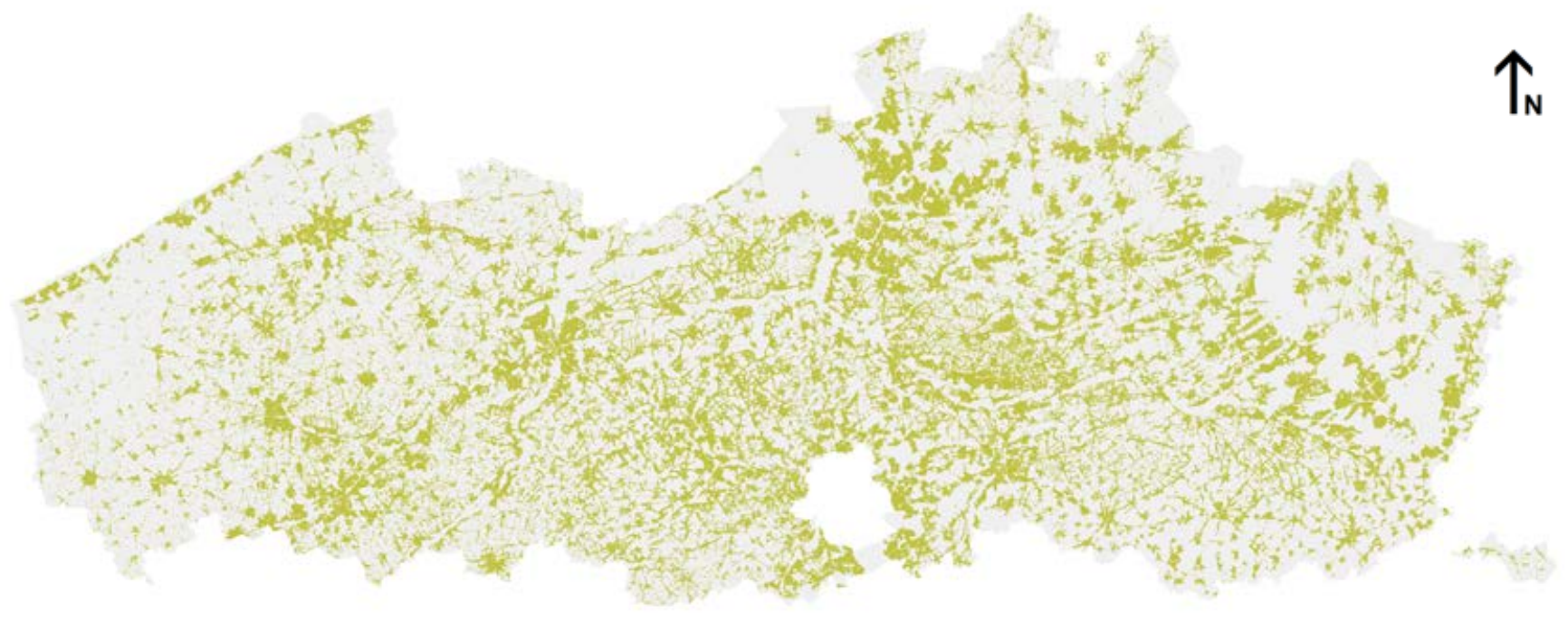


The garden complex can provide numerous ecosystem services. Examples of these services are rainwater infiltration, cooling, pollination, food production, relaxing greenery and social space. Because rainwater in the garden can seep into the soil, the peak flows that occur during very heavy rainfall are limited. This reduces the risk of flooding. In the city, gardens with large numbers of shrubs and trees also help reduce heat stress because of their cooling effect. Moreover, gardens help curb climate change by storing $\mathrm{CO} 2$ in trees, shrubs and soil. Finally gardens are good for biodiversity: they provide food and nesting places for numerous creatures. Flower beds attract pollinating insects, thus promoting the production of fruit.

\section{Ecological management of gardens}

People organise their gardens according to their own views, tastes and standards. The way we manage our gardens determines the extent to which they can contribute to the delivery of biodiversity and ecosystem services. By making the design and management of gardens more sustainable, we can optimise their supply of ecosystem services. For example, the storage of carbon in the soil may be increased by mowing the lawn without taking away the cuttings (mulch mowing). More natural management of this kind gives indigenous wild plants more opportunities, which in turn has a positive effect on biodiversity.

\section{Gardens in Rivierenland}

Much of the Regional Landscape Rivierenland is highly urbanised. However, this urbanised area is not completely built over. It also includes green spaces such as parks and private gardens. About 12 percent of the area of Rivierenland's municipalities consists of private gardens. This is more than the Flemish average, due to the relatively high level of urbanisation of the region.
For example, the government lacks a framework or set of tools to conduct a garden policy. Fear of interfering too much in the private sphere also makes it a challenge for the government to launch garden initiatives. For citizens, the dominant ideal of the well-maintained garden, individualism and lack of knowledge are particularly important factors. By making information about sustainable garden management accessible and educating people, Regional Landscapes can make a difference. They can show how things can be done differently by setting up pilot projects in which they involve different stakeholders, such as garden owners, local authorities, designers and garden centres.

\section{Why do people care so much about their gardens?}

The main reason why many Flemish people have a garden is because they want one. To gain an insight into the importance of gardens for owners in the Regional Landscape Rivierenland and the way they use their gardens, we asked about these matters in the online survey. The answers showed that the cultural services provided by a garden as a view of greenery and in terms of relaxation and closeness to nature score especially highly. The respondents also consider it important to grow vegetables in their gardens, mainly for health reasons. Gardens can thus also play a role in our food supply.

How can this multitude of individual private patches of greenery, the garden complex, enhance the delivery of ecosystem services in the region? Regional Landscapes can play an important role here. They can help both the government and members of the public to break down barriers. 


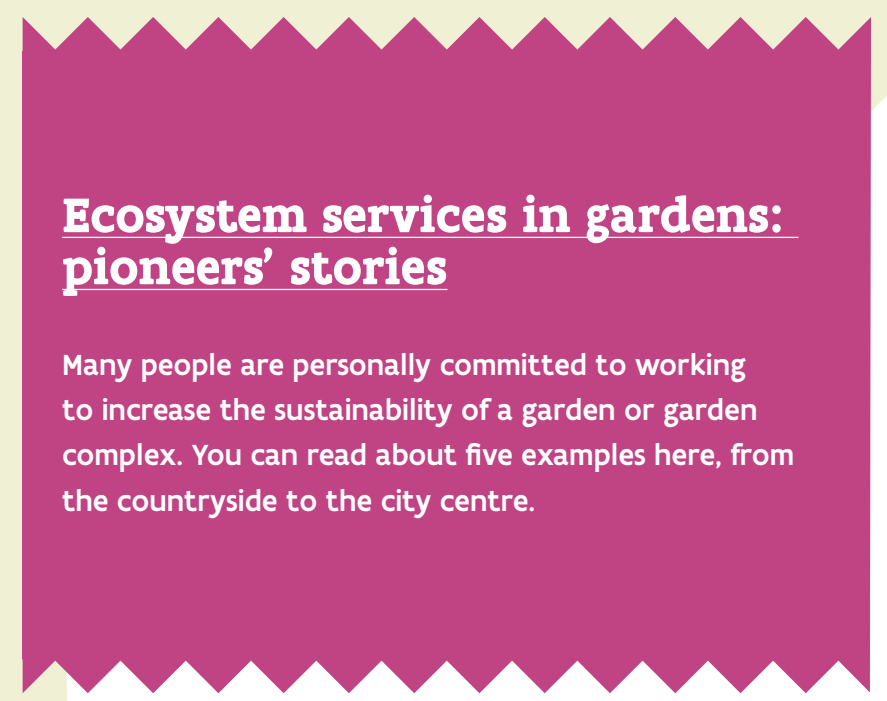

Valerie Dewaelheyns conducted research into the contribution to the community that gardeners can make.

\section{The great strength of garden complexes is the diversity of gardeners and garden designs}

\begin{abstract}
“We still don't know enough about the situation of our gardens. Yet gardens are very important in our daily lives, and they have great strategic potential. We can create something of great value with gardens, not just for the environment but for society too.
\end{abstract}

The diversity of garden designs and gardeners is an asset that we must use. In this way, different ecosystem services can be provided in different locations. In addition, gardens can play an important role in changing people's outlook. If they experience climate change and biodiversity loss in their own garden, they will take action faster.

I want to put the strategic role of gardens on the agenda, but also to engage in research and debate with others. This is the only way to get down to work in a properly substantiated way. The strategy must be based on knowledge. It should be a combination of regulations and awareness-raising. Regulations are needed to address urgent

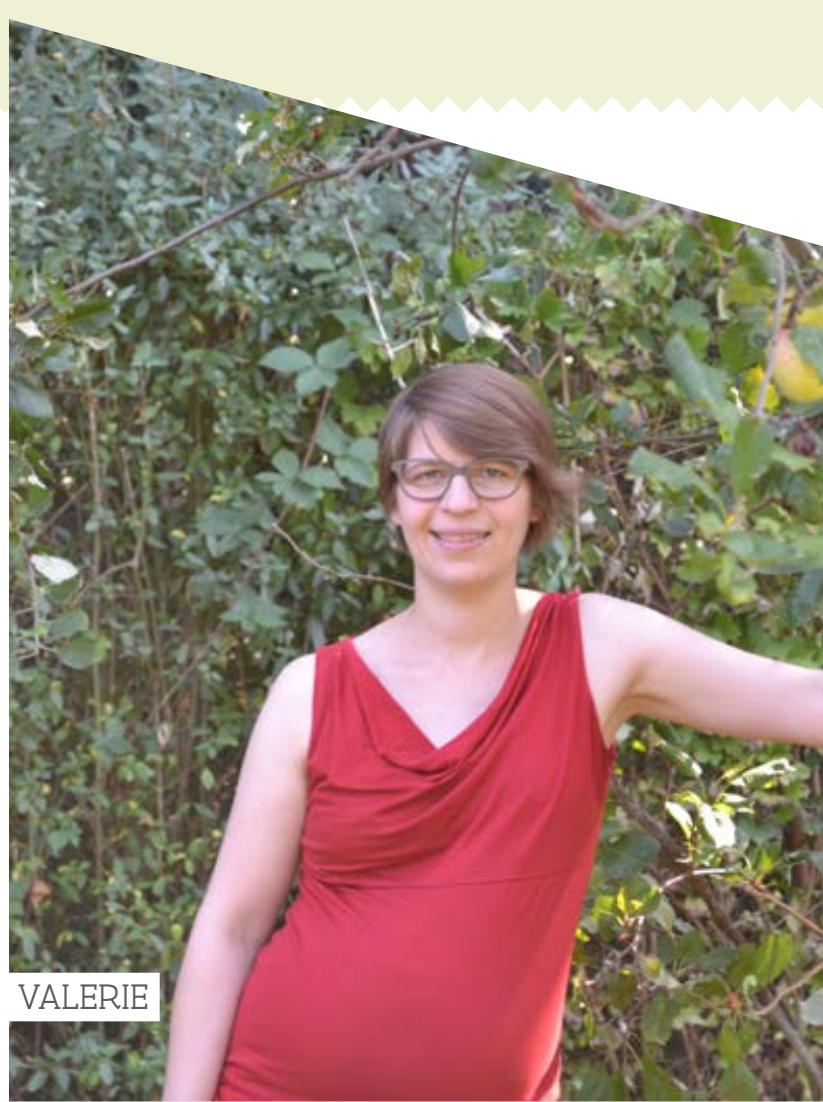

environmental problems, but awareness remains the basis. Individual gardening advice, district charters and model projects are needed to demonstrate all the things a garden can do for people and society."

Frank Van de Meutter manages a large country garden in Tessenderlo which is designed to be as insect-friendly and natural as possible.

\section{In our garden I try to apply the diverse, small-scale cultural landscape that used to be typical of our countryside}

\footnotetext{
"My garden is adjacent to a nature reserve. For me, the two areas are complementary. The garden reinforces nature and creates a smooth transition to the built-up area. As a result, the nature reserve becomes slightly bigger and is better protected. And we take advantage of the proximity of all that greenery.
} 
"The land where we garden has great biodiversity: part of it is scrubland, and another part is vigorous pioneer woodland. We have left the woodland undisturbed. We take the natural conditions as our starting-point in every respect. This creates a bit of a chaotic impression, but we support the stability of the ecosystem by doing so.

The garden is now run by volunteers. We have a rota system that ensures that someone is there on two or three days a week to keep the shed open and show people round and give them explanations if they are interested. But we need to become more professional if we want to consolidate the transition to a sustainable society. I therefore have a few policy recommendations:

- Create a network of sustainable urban agriculture. This brings farming closer to people and food closer to consumers.

- Support sustainable citizens' initiatives, so that people are (partly) paid for their involvement and more professionalism is possible.

- Define a good long-term plan for agro-ecological farming, the provision of green spaces and social cohesion."
Ine Timmerman is a creative therapist at the Sint-JanBaptist psychiatric centre in Zelzate. She aims to encourage a love of nature in her clients through garden therapy.

\section{My dream is to involve the neighbourhood in this garden and thus connect our clients even more closely with society}

"At the Sint-Jan-Baptist psychiatric centre in Zelzate, people with various psychological and social problems are taken care of and supported. In the Ligarsa day centre where I work, there are people who have been confined to care, but are in the final stages before they re-integrate into society. The therapies there closely reflect this.

Recently, we have been able to use a patch of land nearby As a result, we can offer 'garden work' as a therapy. The uniqueness of living beings, including plants, is that they do something of their own accord: germinate, grow, bear fruit, wither, die back, germinate again, and so on. They work with people, but sometimes they can be resistant too. This makes it easy to identify with them as living beings or to project feelings onto them.
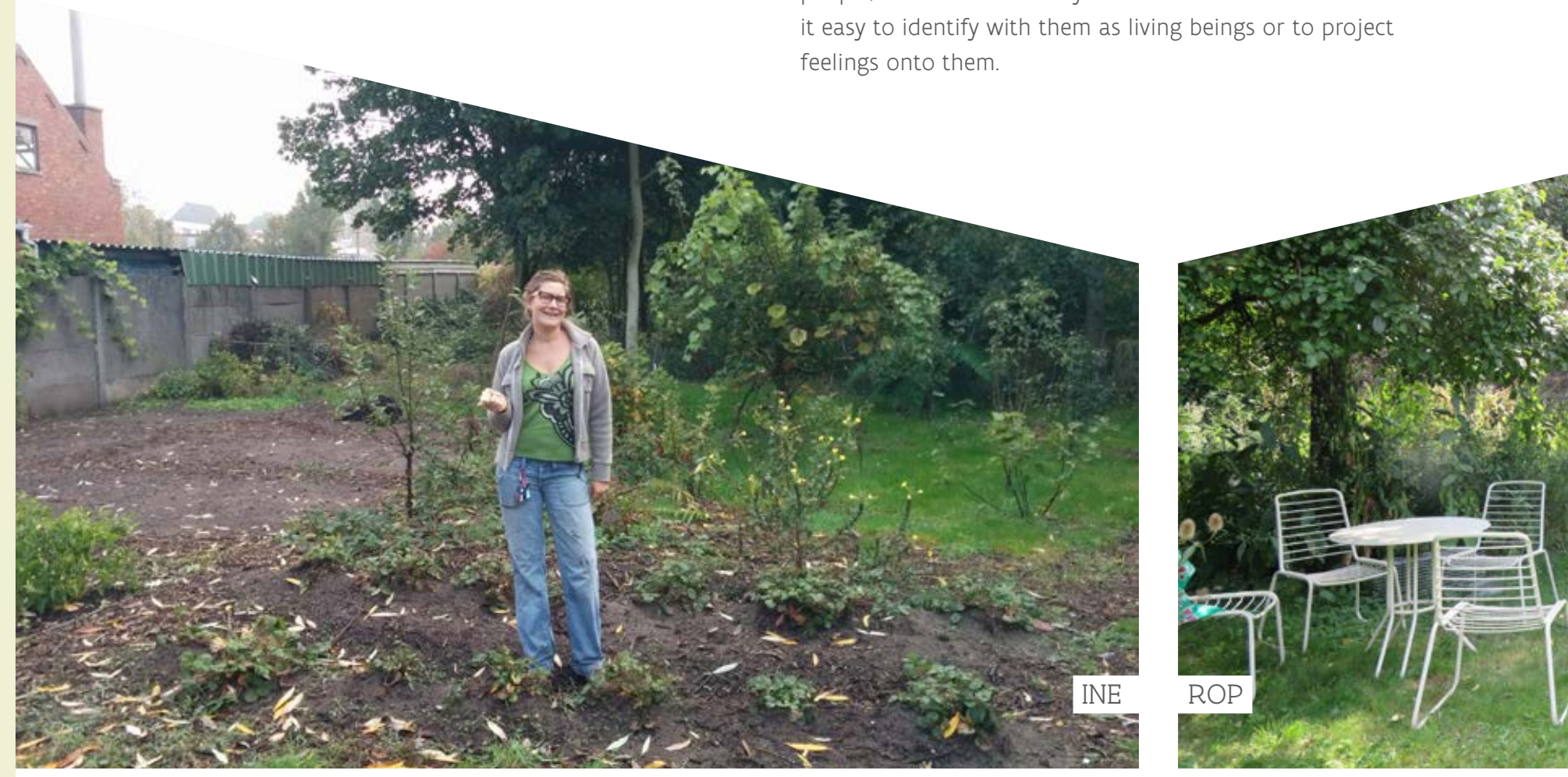
Garden therapy is about working outside and in contact with nature. We use no sprays and no electrical appliances. Mowing, weeding, pruning... it's all done purely with manpower. We also offer cooking therapy, for which we try to use as much of our own produce as possible.

The contact with nature has a positive effect on the wellbeing of our clients. Through gardening, they learn to care for something and cultivate empathy. They have watered the crop throughout the summer and protected it from pests and diseases. Here in the garden our clients can truly be themselves.

A lot of new homes are being built just opposite. My dream is that people from the neighbourhood will be able to work with us in this garden and get back in touch with nature. Especially for people who don't have a garden, it's important for their emotional well-being. It will also enable my clients to get to know the locals. A win-win situation, in other words."

\section{Rop Bosmans has a semi-wild garden in Ghent. It's a} paradise for birds, insects and spiders.

\section{With a few simple measures you can achieve this diversity in many urban gardens}

"In my garden I strive for a balance between personal use and a place where nature can take its course. I call it a semiwild urban garden. Wild because nature is left unchecked in some places, but semi-wild because I also put my own stamp on it.

I wanted as many plants as possible and the greatest possible variety of biotopes. I don't use chemicals and I leave a lot of dead branches and stems, only clearing them away after the winter is over. I have also created a lot of physical diversity with trees, rough corners, a pond, a wall covered with ivy, and so on

This ecological approach is paying off. I have done some research into spider biodiversity in Ghent. What do I find? In my garden alone, I have already found forty species. spiders are very important to humans. They control all kinds of insect pests. This shows that you can achieve a lot of biodiversity in a small, enclosed garden.

My garden is not far as the crow flies from the BourgoyenOssemeersen nature reserve. But I am convinced that with a few simple management measures you can achieve this diversity in many other urban gardens. To do so, you mainly need to focus on raising awareness. People don't know any better: they think that a garden should have a closelycropped lawn and a few cypresses. You have to teach them to manage their garden with more of a natural focus. This is why I regularly invite people to visit the garden. From the street, you can't imagine that such beautiful areas of greenery lie hidden behind the façades." 
3.4.2 Ecosystem services in residential expansion areas

The population in Flanders is growing. By 2030, 250,000 new homes are expected to be needed. As a result, remaining open spaces are coming even more under pressure. It will therefore be quite a challenge to protect open spaces and the ecosystem services they provide while coping with future social changes at the same time. The Spatial Policy Plan for Flanders White Paper advocates a robust open space which is able to provide ecosystem services. To achieve this, Flanders is seeking to achieve a 'halt to concrete' in 2040, reducing the occupation of additional space to zero. With this in mind, all levels of government are supposed to carry out an evaluation and to activate well-situated land and neutralise poorly situated land. On behalf of the Spatial Planning, Housing Policy and Heritage Agency, we have developed an assessment framework based on ecosystem services. Governments can use this tool when considering whether or not to give the go-ahead for building on undeveloped and unreleased residential expansion areas (WUGs).

\section{Residential expansion areas}

Since the seventies, Flanders has been divided into regional plans reflecting a designated use for each area. Each area is designated as residential land, nature land, industrial land and so on. Residential expansion areas are zones in the residential area which can be used for the residential function if needed.

The atlas of residential expansion areas indicates for each such area in Flanders whether or not it can be developed for housing or whether further investigation is needed. Each of these areas has been given a unique number. In July 2015 , Flanders had 2,408 residential expansion areas. This shows that 41 percent of the total area of residential expansion areas is still undeveloped and has not yet been released for development. It is on these areas that we focus.

\section{The assessment framework}

We created an assessment framework with which we would like to offer government bodies a new perspective. This framework can be used by means of a visual display application.

For each undeveloped and unreleased residential expansion area and for each Flemish municipality and province, we have determined the current land use. We have also quantified the average provision of sixteen ecosystem services (including food production, wood production, production of biomass for energy, green space for outdoor activities, pollination, regulation of erosion risk, conservation of soil fertility, regulation of global climate, regulation of noise pollution, air quality regulation, urban heat regulation (UHI), water production, water retention and flood protection). We have developed a visual display application that allows the results for the residential expansion area in which you are interested to be displayed quickly and easily in comprehensible charts with a single click.

For current land use, the graph shows the percentage of common land use classes in the residential expansion area itself, but also in the municipality and the province where the area is situated (see Figure 19). A separate graph also shows the percentage loss of each land use class with respect to the land use in the municipality, if the residential expansion area is developed for housing (see Figure 20). Web diagrams display the average provision of the sixteen examined ecosystem services in the residential expansion area compared to the average provision in all residential expansion areas within the municipality (see Figure 21), the province and Flanders and compared to the average provision for each examined service in the municipality, the province and Flanders as a whole. In this way the different residential expansion areas can be compared with each other, but you can also compare a residential expansion area with its immediate surroundings. The axes of the web diagram are rescaled between 0 and 1 . A value of 0 means that the service is not provided, a value of 0.5 means that the service is delivered at the average level, and a value of 1 means an optimal delivery of the service. 
The assessment framework was tested in the municipality of Nijlen. The information provided by the instrument during the test was found to confirm the knowledge that was available locally. In the case of Nijlen the information would have had no impact on decisions concerning changed land designations. However, more details about the strengths of the area emerged. This information may be useful when designing the re-designated areas.

\section{Example of the functioning of the visual display application with a residential expansion area in Mechelen}

The application is discussed in detail with reference to one residential expansion area in Mechelen (WUG 12025_06). Three land uses are found in this area: forest, grassland and urban undeveloped land (see Figure 19).

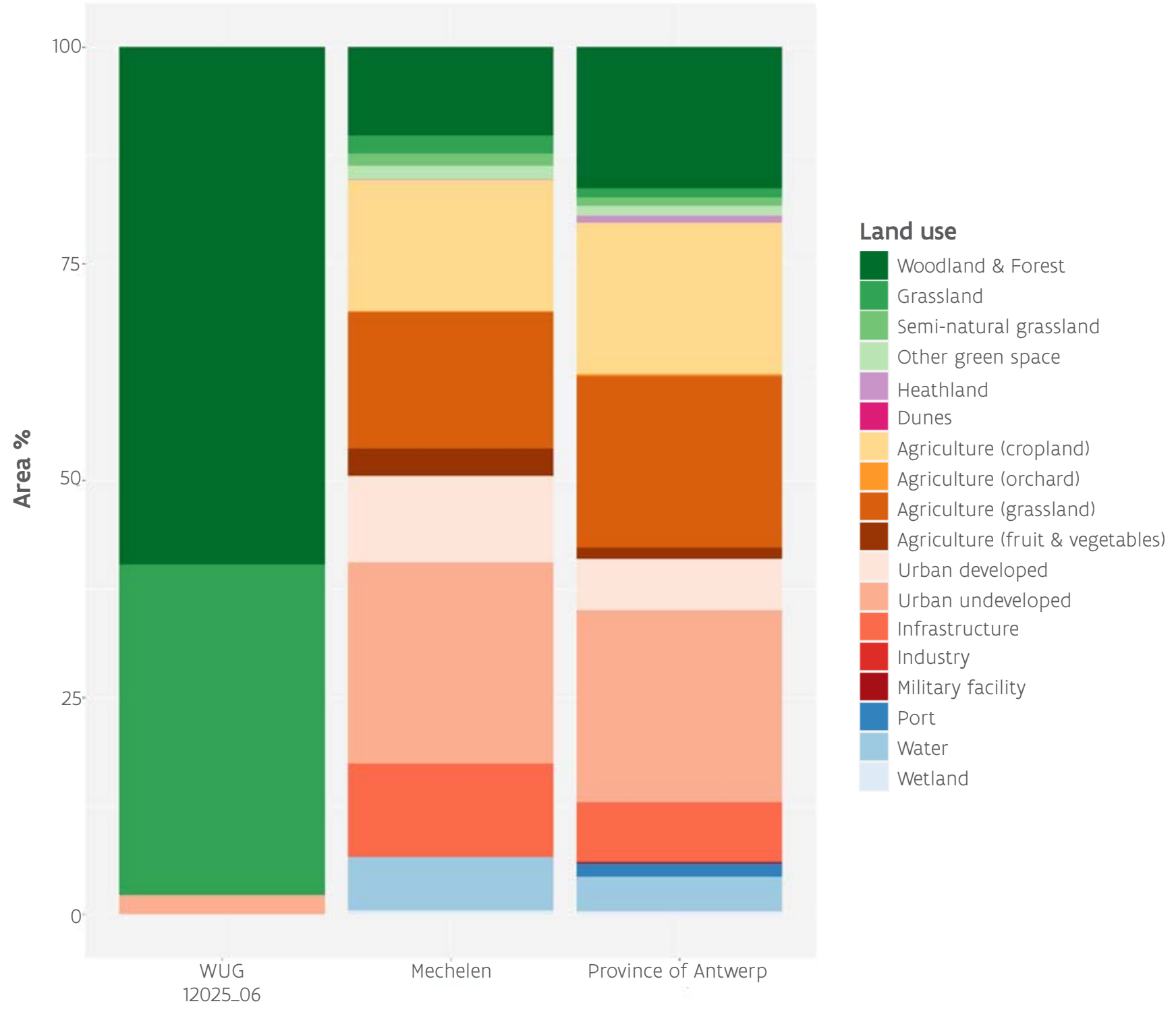

FIGURE 19

Percentage of common land use classes in residential expansion area number 12025_06 in the municipality of Mechelen and province of Antwerp 


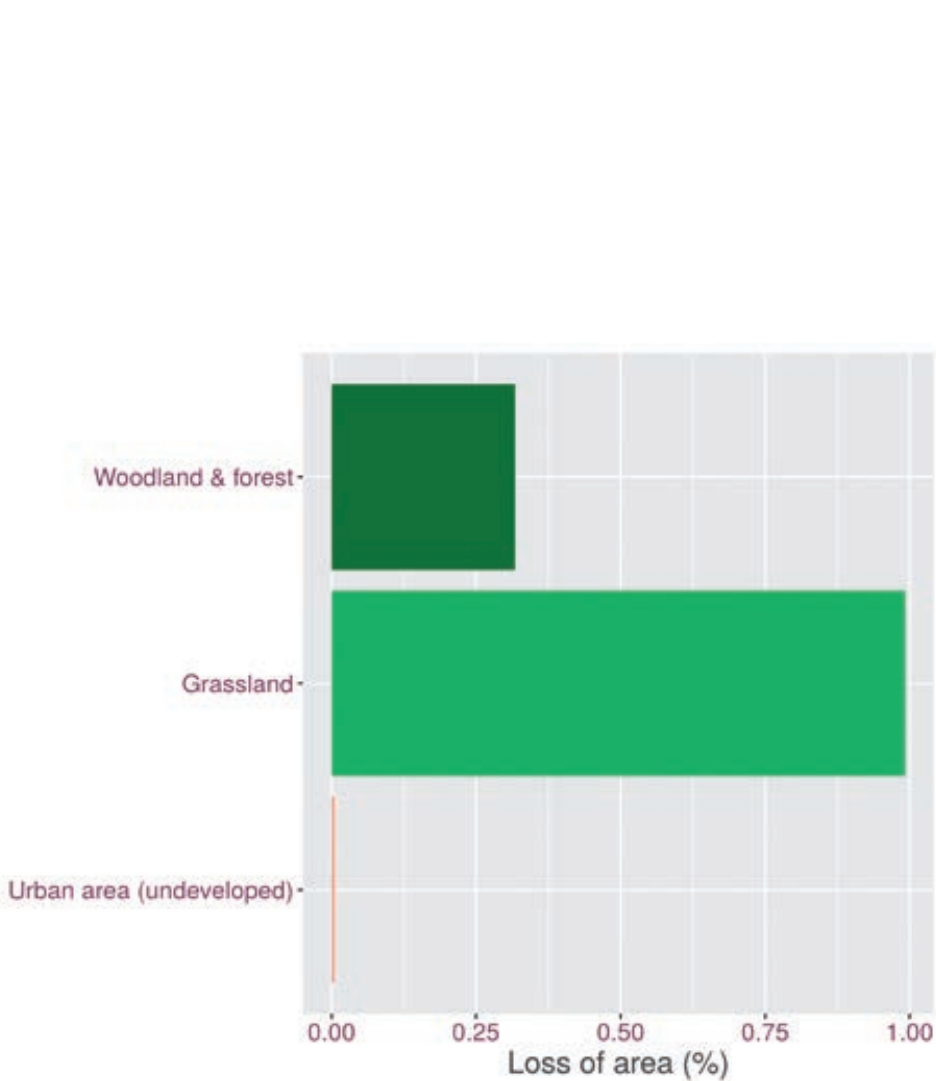

\section{FIGURE 20}

Percentage loss of area within the municipality per land use class if the residential expansion area is developed

Figure 20 shows the percentage loss of area within the municipality for each land use class, if the residential expansion area is developed for housing. The percentages are low. This means that none of the land uses in the residential expansion area is unique within the municipality as a whole.

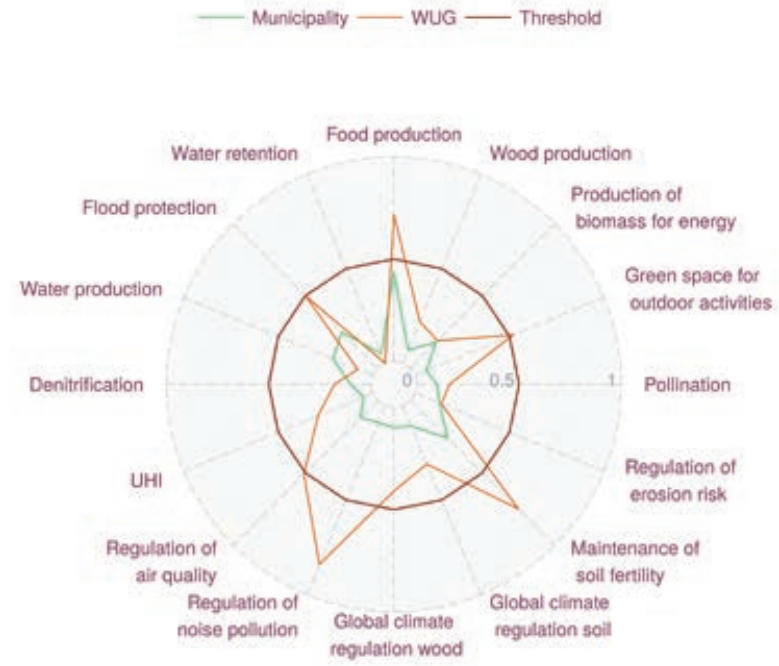

\section{Landuse}

Woodland \& forest

Grassland

Urban area (undeveloped)

\section{FIGURE 21}

The average provision of each ecosystem service in the residential expansion area (orange line) relative to the average provision of each ecosystem service in the municipality (green line). The red line indicates a value of 0.5

Figure 21 shows the average provision of each examined ecosystem service in the residential expansion area compared to that in the municipality of Mechelen itself. It shows that the area is relevant to the provision of a number of ecosystem services. For instance, 'green space for outdoor activities' scores above average, clearly indicating that there is little or no green space in the vicinity of the residential expansion area. 


\section{Ecosystem services in the city}

Iris Gommers, Sustainable City project leader in the City of Antwerp, outlines how green infrastructure can be put into practice in an urban setting, stressing the importance of communication.

"As Sustainable City coordinator I work every day, along with my colleagues, on a sustainable Antwerp. To do this, we have joined forces with many partners. But it is not always easy to convey the story in an inspiring way. We have therefore developed various tools.

For instance, together with VITO (the Flemish Institute for Technological Research) and Ghent University we have developed the Antwerp Green Tool. This is a platform with maps, examples and calculators that help planners and designers to calculate the effect of new greenery on the environment. What, for example, is the impact on air quality, heat stress, water management, noise perception, biodiversity and carbon capture? Clear and technical language is used in the Green Tool, combined with lots of maps and inspiring photos from Antwerp and other cities.

Antwerp locals can visit the EcoHuis to get a taste and feel for all the things that green and sustainable housing, living, building and renovation in the city mean. In support we have recently started a blog: www.plantwerpen.be, where real Antwerpers tell their story. We use their experiences as the basis for explaining the general principles, arrangements and functions. All the stories of private gardens, roofs and terraces, nature play areas, local food and shared gardens are persuading more and more residents to get involved.
The Facebook page of the EcoHuis also gives people inspiration and reinforces the connection between the 'green Antwerp' product and local people, as is clear from the many questions and responses that come in via that channel. There is also a strong focus on film and animation. As a result, everyone can pick up information or gain inspiration.

In addition, urban policy is becoming greener. The city has incorporated rules into its building code that ensure more greenery, such as a requirement to construct a green roof on new buildings. Antwerp is also experimenting actively with the functional use of greenery in several new urban developments. For instance Nieuw Zuid will be the first rain-neutral area in Flanders.

Together we can ensure that the reduction of hard surfacing and the greening continue. It's in the interests of us all."

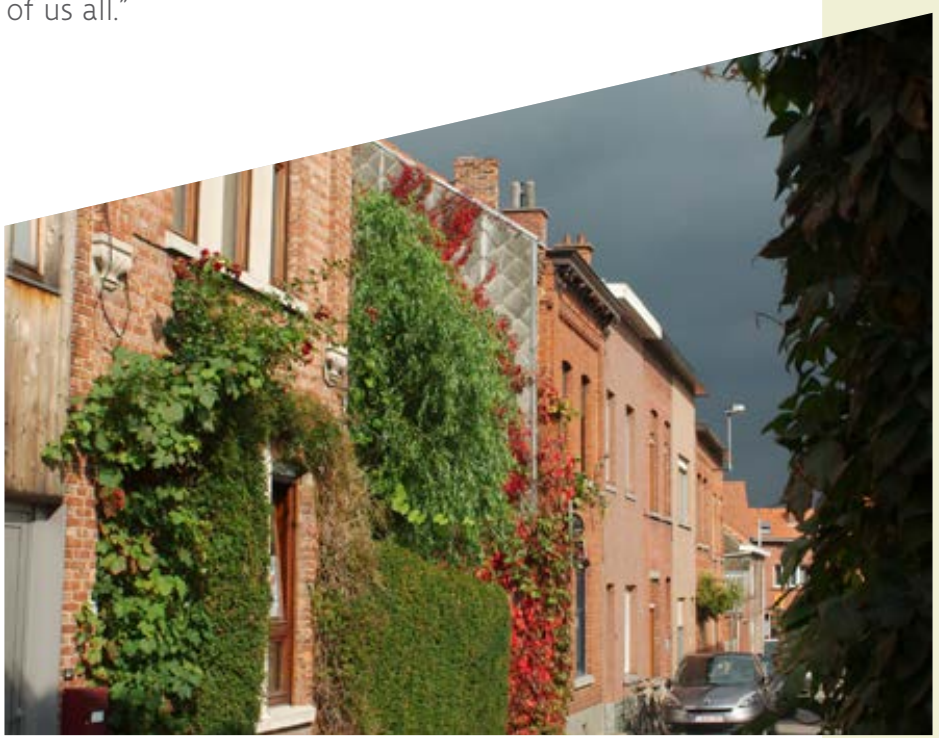





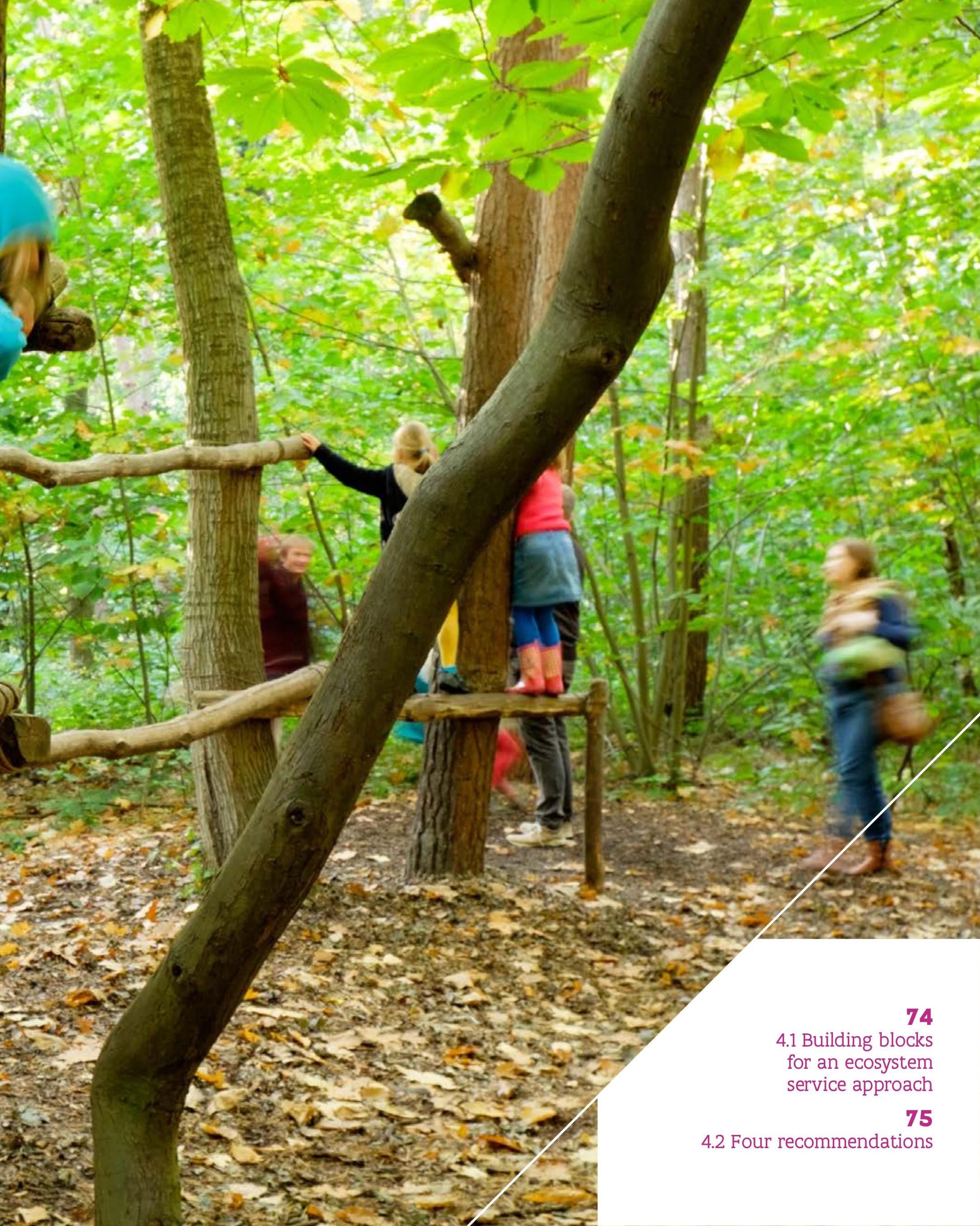




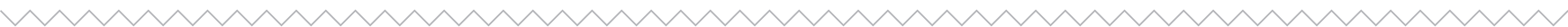

\subsection{Four recommendations}

On the basis of FlandersREA-P, we can formulate the following four recommendations.

\section{A broad policy approach for all landscapes from green to grey brings benefits for both biodiversity and society.}

Biodiversity is declining rapidly. There is a growing realisation that the social benefits of nature will be further impaired as a result. In order to address both problems simultaneously, Europe offers a strategy: the development of 'green infrastructure'.

Measures are needed across the entire gradient from green to grey landscapes. Investment in green infrastructure will lead to the greatest biodiversity and social benefits if work is done simultaneously on three strategies:

- conserving and restoring scarce nature in (semi-)natural landscapes;

- seeking a balance between social goals and nature conservation in mixed landscapes with a wide variety of natural elements;

- reducing people's ecological impact in intensively used landscapes.

Green infrastructure is a quality label. For the three strategies we therefore formulate core objectives and core qualities relating to biodiversity and ecosystem services across policy domains and sectors. In the definition of these goals we build on the existing sustainability agendas from various policy domains. A green infrastructure strategy requires innovation, in terms of goals, tools and institutions. A smart way to design and manage landscapes to make sustainable and multifunctional use possible requires new forms of organisation and market mechanisms.

The green infrastructure strategy needs to become a crucible for innovative developments in both open and built-up space, and it must also become possible to incorporate green infrastructure initiatives into current planning processes and projects.

\section{The valuation of ecosystem services and their relevance for ecosystems, well-being and prosperity helps inform policy-makers better and underpin sustainable policy choices}

Ecosystem services are often not addressed when policy options or economic or other decisions are considered, unless an increase or decrease in them has direct, clearly visible economic or social consequences. As a result, they are often undervalued in such circumstances and their availability tends to systematically decline in the long term. When land use changes are being considered, ecosystem services should be a systematic point for the attention of all public and private stakeholders.

Ecosystem services are often valued with reference to an economic discourse, which expresses the consequences of ecosystem change in monetary exchange values. In reality, increases or decreases in ecosystem services, both locally and on a global scale, are relevant to a much broader set of values and motives, including human survival and health, social justice and the preservation of non-human organisms and systems. Economic exchange values are based on the assumption that what is valued can be replaced by something else of equal or greater monetary value. These values offer no information on how best to deal with irreversible ecological processes, or with the loss of unique or irreplaceable sociocultural or ecological values. Integrated valuation therefore also attempts to make these values more apparent in a transparent decision-making framework. This makes it easier for policy-makers to make more informed and grounded choices between different alternatives.

Integrated valuation makes it possible to compare alternative scenarios or policy options on the basis of a number of ecological, social and economic values. Such values usually take various ethical motives as their starting-point. They may relate to characteristics of ecosystems (such as areas and populations), to ecosystem services (such as air purification, food production and climate) or to other services of socioecological systems (such as housing and mobility) and their impact on prosperity and well-being. 
As well as a knowledge of these aspects, integrated valuation above all requires an institutional framework that allows a relevant and substantiated selection of values to be made. This relates to what should or could be (or not be) valued, who may (or may not) determine that value, how it is expressed and where it can be used. Bridging organisations can help to bring together stakeholders from various economic, social and policy sectors to discuss these issues.

\section{Bridging organisations such as Regional Landscapes are essential for getting started with ecosystem services on the ground}

Working with ecosystem services requires an interdisciplinary and cross-sectoral approach. If ESS-oriented policies are to be conducted, organisations that bridge the gap between different policy levels, between different sectors and between politicians and citizens are an important instrument. They also ensure that local and scientific knowledge is exchanged and a sustainable network is developed. A Regional Landscape is such an organisation. Regional Landscapes connect the various stakeholders operating in the open space. Being locally embedded, they are well aware of the local situation and are in the best position to pick up on local values and interests. Furthermore, a Regional Landscape is located at the right geographical scale to work on multifunctional landscapes. The use of ESS knowledge and the available computational tools often requires some expertise, which is not always present locally or among the stakeholders. Again, bridging organisations can play a role, ensuring that the available knowledge and tools can be applied locally.

Successful organisations of this type thus encourage participation, bring the various parties together regularly, interpret, coordinate and mediate. However, they need to be recognised and given sufficient resources for this essential role, which is often less visible.

\section{Working with nature pays off, both for humans and for biodiversity}

It is clear from a variety of projects and narratives that working with nature pays off. Yet we are usually unaware of this. All too often we see nature as an obstacle to our prosperity. To reverse this perception, we need to show people what nature can do for us if we work with it. Flanders REA-P gives the initial impetus for doing so by including the stories of ten pioneers - garden-owners, farmers and a Sustainable City project leader. The report also looks at nine promising measures in agriculture. Of course, there are plenty of other pioneer stories that could be told for other ecosystems (such as forest, play areas and industrial land), ecosystem services (such as pollination) and measures (such as increasing the proportion of dead wood in forests).

To communicate widely about the pioneers' experiences and the benefits of nature, it is important for a clear ecosystem service language to be available. Powerful personal stories that people can identify with and that get through to them enrich the language. As successful communication is no easy task, we recommend active sharing of experiences with the use of a clear ESS language. Together we can make the ESS language more vivid and learn how to use it more effectively too.

The goal is to make working for nature everyone's business not just the government but the public, farmers, forest owners, gardeners, civil society organisations, schools and businesses too. 


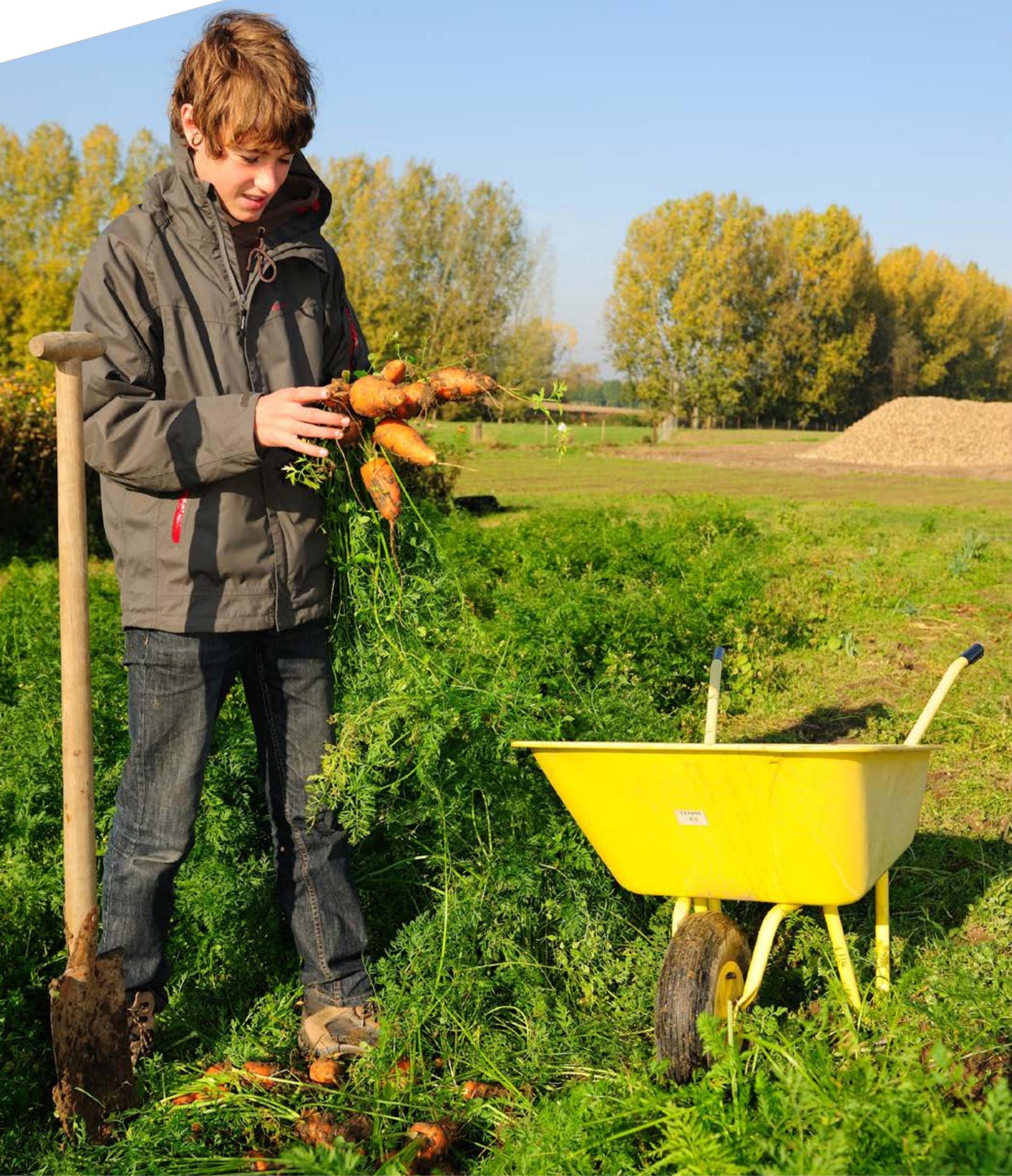




\section{Publication details}

Editorial team: Peter Van Gossum, Katrijn Alaerts, Lode De Beck, Heidi Demolder, Lieven De Smet, Helen Michels, Johan Peymen, Anik Schneiders, Maarten Stevens, Marijke Thoonen, Wouter Van Reeth, Inne Vught

80 pages

D/2017/3241/198

doi.org/10.21436/inbom.13117466

INBO.M.2016.13117466

ISBN 9789040303890

(C) 2016, Research Institute for Nature and Forest, Brussels Subject to acknowledgement, the reproduction of texts is encouraged.

Citation wording: Van Gossum, P., Alaerts, K., De Beck, L., Demolder, H., De Smet, L., Michels, H., Peymen, J.

Schneiders, A., Stevens, M., Thoonen, M., Van Reeth, W., Vught, I. (Eds.) (2016). Nature report - Getting started with ecosystem services. Synthesis report. Communications of the Research Institute for Nature and Forest, INBO.M. 2016.12342678, Brussels.

Distribution: Research Institute for Nature and Forest Design, copywriting and layout: Pantarein Publishing, Translation: Lu's Paragraph

Printing: Artoos

Photography: Vilda Photo, Francis Turkelboom (INBO),

Luc De Keersmaeker (INBO), Regional Landscape Rivierenland and Annelijn Steenbruggen (Bioforum), ILVO
Responsible publisher: Maurice Hoffmann, Research Institute for Nature and Forest, Kliniekstraat 25, 1070 Anderlecht

This Synthesis Report is based on a comprehensive Technical Report in Dutch, the various chapters of which can be consulted online at www.nara.be/technisch-rapport2016

The Technical Report was developed in collaboration with the Research institute for Agriculture, Fisheries and Food Research, the Department of Agriculture and Fisheries, the Agency for Nature and Forest, the Department for the Environment, Nature and Energy, the Flemish Land Agency, the Flemish Spatial Planning Department, the Heritage Agency, the Flemish Housing Agency, the Flemish Institute for Technological Research, the Agency for Innovation and Entrepreneurship, the Province of Antwerp. Regional Landscape Rivierenland, Leiedal Intermunicipal Association, the City of Antwerp, the City of Ghent, Valerie Dewaelheyns, the organisations involved in ESS language and the interviewees. 

